\title{
MORPHOLOGIE DES SERNFTALES
}

\author{
ERNSt Heibling
}

\section{VORWORT}

Die vorliegende Arbeit über das größte Nebental des Linthtales setzt sich zum Ziele, diese Landschaft vom morphologischen Standpunkte aus möglichst eindeutig darzustellen. Sie soll zugleich ein Beitrag an die geomorphologisch orientierte Hochgebirgsforschung bilden, wie sie seit einiger Zeit von der Geomorphologischen Gesellschaft der Schweiz beabsichtigt ist.

Der erste Teil der Arbeit umfaßt die Beschreibung der Einzelformen, die in ihrer Gesamtheit, aber auch in ihrer individuellen Ausbildung für das Untersuchungsgebiet außerordentlich charakteristisch sind. Zugleich soll dieser Teil der Arbeit die notwendige Ergänzung zur morphologischen Grundkarte des Sernftales bilden, deren Aufnahme die Hauptarbeit der Untersuchungen war.

Dem analytisch gefaßten ersten Teil steht ein zweiter Abschnitt nach, der als Synthese die genetischen Probleme erfaßt, wie sie aus der morphologischen Aufnahme hervorgehen. Da eine große Anzahl Erscheinungen eine genetische Deutung verlangen, und weil eine Fülle von Beobachtungen in dieser Form am besten zu einem Ganzen gefügt werden kann, sei dieser Versuch gewagt, auch wenn zur Stützung jeder Theorie über die Talgenese zahlreiche Korrelate fehlen.

Die Arbeit entstand in den Jahren 1944-1950, wobei die Feldaufnahmen in den Sommermonaten der Jahre 1944-48 durchgeführt wurden. Ich möchte nicht unterlassen, an dieser Stelle Herrn Prof. Dr. P. Vosseler für sein stetes Interesse und seine wertvollen Anregungen und Ratschläge meinen herzlichsten Dank auszusprechen.

Im Verlaufe meiner Arbeit kam ich auch in Verbindung mit der Geomorphologischen Gesellschaft der Schweiz, die meine Arbeit nicht unwesentlich beeinflußt hat. In diesem Zusammenhang danke ich vor allem Herrn PD. Dr. Ansahesm für seine anregenden Diskussionen, Hinweise und Exkursionen. - Mein Dank gebührt auch den verschiedenen Amtsstellen von Glarus, der Eidg. Landestopographie in Bern und dem Verlag, die meinen zahlreichen Wünschen bereitwillig entgegengekommen sind.

Der Verfasser

\section{Einleitung}

\section{DAS UNTERSUCHUNGSGEBIET}

\section{Das Sernftal}

Das Sernftal ist das größte Nebental des Linthtales. Von der Bevölkerung des Glarnerlandes wird es fast durchwegs als Kleintal bezeichnet, im Gegensatz zum Großtal, dem südlich Schwanden liegenden Abschnitt des Haupttales. Seine Fläche beträgt mit Einschluß der Seitentäler $210, j 3 \mathrm{~km}^{2} 36 *$.

Der Sernf entspringt als Wichlenbach einem kleinen Gletscherrest am Nordostfuß des Hausstockes in $2260 \mathrm{~m}$ Höhe. Er fließt zunächst nord-östlich bis Elm, um dann in einem auffällig regelmäßigen, halbkreisförmigen Bogen nach Westen umzubiegen, bis er bei Schwanden in $523 \mathrm{~m}$ Höhe in die Linth mündet. In seinem $22 \mathrm{~km}$ langen Lauf durchfließt der Fluß das Tal in drei deutlich voneinander verschiedenen Abschnitten.

1. Der oberste Teil, der sich über $9 \mathrm{~km}$ erstreckt und vom Talschluß bis nach Elm reicht, besitzt einen unregelmäßigen, gewellten Talboden, von dem aus die Abhänge im Norden eher sanft zur Freibergkette ansteigen, während sie im Süden steil zur Vorab-Segneskette hinaufführen.

2. Bei Elm beginnt der mittlere, $8 \mathrm{~km}$ lange Talabschnitt. Der Landschaftscharakter ändert sich frappant: die Talsohle wird breit und flach und der ungestüme Lauf des Sernfs geht in ein ruhigeres Fließen über. Der durchschnittlich $400 \mathrm{~m}$ breite Talboden wird beidseitig von steilen Abhängen begleitet, über denen sich stark gewellte 'Terrassen ausdehnen, die gegen die Berggipfel ansteigen. Von beiden Seiten haben sich zahllose kleinere und größere Bachschuttkegel in den Tal-

\footnotetext{
* Die hochgestellten Ziffern verweisen auf die Nummern im Literaturverzeichnis am Schluß.
} 
boden hinausgelegt; unter ihnen sind diejenigen des Krauchbaches und Berglibaches bei Matt und des Mühlebaches bei Engi die größten.

3. Bei Engi-Vorderdorf verläßt der Sernf das eigentliche Tal, um in eine enge, $V$-förmige Mündungsschlucht einzubiegen, welche auf $5 \mathrm{~km}$ ein Gefälle von $250 \mathrm{~m}$ aufweist. Die Talwände dieser Waldschlucht fallen mit gleichförmiger Böschung von den höchsten Erhebungen bis zum Sernf hinunter. Einzig beim Weiler Wart weicht die nördliche " $\Gamma$ alwand etwas zurück, sodaß hier auch für flacheres Gelände Raum geschafft werden konnte.

\section{Die linksseitigen Nebentäler}

Von Westen erhält der Sernf die Zuflüsse einer ganzen Reihe kleiner Nebentälchen von der Gestalt großer Trichter, die sich nach oben muldenartig erweitern. Im obersten 'Talteil münden in steilen, schluchtartigen Rinnen die Tälchen von Erbsalp, Bischofalp und Embächlialp. Zwischen Elm und Engi sind die Tälchen der Kühbodenalp, Geißtalalp, Berglialp und Lauelialp zu nennen.

\section{Die rechtsseitigen Nebentäler}

Bedeutend länger und größer sind die rechtsseitigen Zuflüsse des Sernfs. Noch im Talhintergrund, bei Wallenbrugg, mündet das in mächtigen Stufen vom Panixerpaß niedersteigende Jätztal. Bei Elm vereinigt sich das Sernftal mit dem Ramintal, welches am Foopaß seinen Anfang nimmt. Vom Spitzmeilen her erstreckt sich das Krauchtal über eine Länge von $12 \mathrm{~km}$, bis es bei Matt ins Sernftal mündet. Beinahe ebenso groß ist die Ausdehnung des Mühlebachtales, das sich bei Engi als letztes großes Seitental anschließt. Die Runsen, die talauswärts noch zum Sernf hinuntersteigen, können nicht mehr als Talbildungen betrachtet werden, da die Bäche nur mäßig eingetieft haben.

\section{Die Gebirgsumrahmung}

Das ganze Sernftal liegt im östlichen Teil der Glarneralpen. Seine Wasserscheiden fallen nicht nur mit den Gemeindegrenzen der drei Ortschaften Elm, Matt und Engi zusammen, sondern sie verlaufen auch auf orographisch günstigen Kammlinien. Die das Tal umrahmenden Gebirge können gut in vier Hauptgruppen gegliedert werden.

\section{Orographische Gliederung}

\begin{tabular}{|c|c|c|c|c|c|}
\hline Gruppe & Länge & Höchste Erheb & bungen & Grateinsenkung & gen \\
\hline$\overline{\text { Kärpfgruppe }}$ & ca $10 \mathrm{~km}$ & $\begin{array}{l}\text { Gr. Kärpf } \\
\text { Bleistöcke } \\
\text { Karrenstock }\end{array}$ & $\begin{array}{l}2794,2 \mathrm{~m} \\
2447 \mathrm{~m} \\
2421 \mathrm{~m}\end{array}$ & $\begin{array}{l}\text { Richetlipaß } \\
\text { Wildmaad } \\
\text { Berglimatt }\end{array}$ & $\begin{array}{l}2260 \mathrm{~m} \\
2290 \mathrm{~m} \\
2154 \mathrm{~m}\end{array}$ \\
\hline Hausstockgruppe & ca. $6 \mathrm{~km}$ & $\begin{array}{l}\text { Hausstock } \\
\text { Rinkenkopf }\end{array}$ & $\begin{array}{l}31.58,1 \mathrm{~m} \\
2626,4 \mathrm{~m}\end{array}$ & Panixerpaß & $2404 \mathrm{~m}$ \\
\hline Segnesgruppe & ca. $14 \mathrm{~km}$ & $\begin{array}{l}\text { Vorab } \\
\text { Doppelgipfel } \\
\text { Piz Segnes } \\
\text { Saurenstock }\end{array}$ & $\begin{array}{l}3028,0 \mathrm{~m} \\
3018,0 \mathrm{~m} \\
3099,7 \mathrm{~m} \\
3055,8 \mathrm{~m}\end{array}$ & $\begin{array}{l}\text { Sether Furca } \\
\text { Segnespaß } \\
\text { Foopa } B\end{array}$ & $\begin{array}{l}2593 \mathrm{~m} \\
2627 \mathrm{~m} \\
2223 \mathrm{~m}\end{array}$ \\
\hline Spitzmeilen & ca. $18 \mathrm{~km}$ & $\begin{array}{l}\text { Foostock } \\
\text { Spitzmeilen } \\
\text { Magerrain } \\
\text { Rottor }\end{array}$ & $\begin{array}{l}2610,7 \mathrm{~m} \\
2502,1 \mathrm{~m} \\
2524,1 \mathrm{~m} \\
2496,2 \mathrm{~m}\end{array}$ & $\begin{array}{l}\text { Risetenpaß } \\
\text { Schönbühlpaß } \\
\text { Widersteiner- } \\
\text { furggel }\end{array}$ & $\begin{array}{l}2187 \mathrm{~m} \\
2206 \mathrm{~m} \\
2006 \mathrm{~m}\end{array}$ \\
\hline
\end{tabular}

a) Die Kärpfgruppe trennt das Einzugsgebiet des Sernfs von dem der Linth. Trotzdem sie tektonisch mit der Hausstockgruppe in Zusammenhang steht, ist ihre Abgliederung wegen ihrer Geschlossenheit gerechtfertigt. Der brüchige, stellenweise auch sehr scharfe Grat bildet vom Richetli- 
$\mathrm{paß}$ bis zum Großen Kärpf eine auffallende Einheit. Weiter nördlich aber geht er in eine Art Hochfläche über, der kleinere und größere Gipfel in Form von Felstürmen aufgesetzt sind. Im mittleren Teil dieser Hochfläche liegt zwvischen den Bleitstöcken und dem Berglihorn das Wildmaad, eine wellige Felsfläche mit zahlreichen eingetieften Seelein.

Die Nebengräte der Kärpfkette sind insofern von Bedeutung, als sie die Trennung der zum Sernf absteigenden Nebentälchen bewirken. Erbserstock, Tierbodenhorn, Taufstein, Schabell, Schafgrindspitz und Nägelistock bilden die auffälligsten Ausläufer dieser Art.

Während auf der Nordseite des Kärpfs noch ein unbedeutender Gletscherrest vorhanden ist, zeigt die Südseite gegen das Sernftal keine Eisbildung mehr, es sei denn, man wolle den Firnfleck zwischen Groß- und Kleinkärpf dazurechnen.

b) Südlich dem Richetli-Karpaß schließt die Hausstockgruppe an, deren höchste Erhebung, der doppelgipflige Hausstock, den imposanten Talabschluß des Sernftales bildet. Mit den Ausläufern gegen Westen zusammen wird diese Gruppe vielfach auch als Muttseegruppe bezeichnet $\left({ }^{3}\right)$, worin dann allerdings Bifertenstock und Selbsanftmassiv eingeschlossen sind. Der starke Unterschied im tektonischen Bau rechtfertigt aber eine Trennung dieser beiden Gruppen.

Während im Sernftal die Vergletscherung auf einen kleinen Rest am Nordostfuß beschränkt ist, erstreckt sie sich auf der Südseite des Berges als Meergletscher noch bis in die Nähe des Panixerpaßes.

c) Die Segneskette, welche das Sernftal gegen das Rheintal begrenzt, ist außerordentlich stark gegliedert. Als gewaltiger Klotz beherrscht der Vorab mit dem Glarner- und dem um wenige Meter höheren Bündnergipfel den westlichen Teil. Vom $\mathrm{Tal}$ aus gesehen erscheinen allerdings die vorgelagerten $Z$ wölfihörner $(2744,3 \mathrm{~m})$, die „Glarner Dolomiten“, höher. Sie bilden jedoch nur den Eckpfeiler eines Grates, der sich vom Bündnerbergfirn (Vorabgletscher) aus über das Mittaghorn nach Elm hinunterzieht. Während der Vorab gegen Norden in einer riesigen Steilwand abfällt, leitet im Nordwesten eine mehrstöckige Taltreppe über das Martinsmaad in die Tiefe. Gegen Osten verschärft sich die Vorabhochfläche ganz plötzlich zum bekannten Grat der Tschingelhörner (Mannen), die mit dem Felsenfenster des Martinsloches das Wahrzeichen von Elm bilden. Nordöstlich des Segnespaßes folgt die dem Vorab ähnliche Sardona mit dem Piz Segnes und dem Saurenstock, eine vom Saurengletscher bedeckte Hochfläche. Ein scharf gezackter Felsgrat leitet über die Scheibenstöcke zur Bifurkation des Foopaßes hinunter. Als weiterer Ausläufer gegen das Sernftal verdient auch das Mörderhorn Erwähnung, dessen Kammlinie die Tschingelalp von der Alp Falzüber trennt.

Leider vermag der Siegfriedatlas den komplizierten orographischen Verhältnissen in diesem Gebiet nur zum Teil gerecht zu werden.*

d) Die Spitzmeilengruppe, die das Sernftal im Osten und Norden begrenzt, weist die größte Länge auf. Dessen ungeachtet erreicht sie nirgends die große Auffälligkeit der schon genannten Bergzüge. Ihre Kammlinie folgt einer mittleren Höhe von $2300-2400 \mathrm{~m}$. Risetenhörner, Faulen, Spitzmeilen, Magerrain (auch Magereu) und Rottor bilden als Stöcke die markantesten Erhebungen. Jegliche Vergletscherung ist in diesem Gebiet verschwunden, und in heißen Sommern vermag sich nicht einmal Alt- und Lawinenschnee zu erhalten.

Die Gratausläufer gegen das Sernftal hin sind nur kurz und steil. Einzig dem Gipsgrat erwächst besondere Bedeutung. Er zieht sich als gestreckte Linie vom Weißmeilen bis zur Bützi und führt dann als gewundene Kammlinie zum Gulderstock $(2520,0 \mathrm{~m})$ hinüber, wobei er die Wasserscheide zwischen Mühlebachtal und Krauchtal bildet. Von ähnlichem Aufbau ist der Gufelstock $(1436,1 \mathrm{~m})$, von dem aus sich der Guntelkamm bis zur nördlichen Talwand der Mündungsschlucht zieht.

\section{DIE GEOLOGISCHEN VERHÄLTNISSE}

\section{Übersicht}

Die klare Gliederung der Glarneralpen macht sich nicht nur in der Topographie geltend, sondern sie tritt auch bei der Betrachtung der geologischen Verhältnisse klar zutage. Das Sernftal liegt mit seinem oberen 'Teil in einer breiten Flyschzone, die sich vom Weißtannental zum Klausenpaß hinüberzieht. Sie trennt das über $3000 \mathrm{~m}$ hohe autochthone Gebirge von dem sich nordwärts ausdehnenden Überschiebungsgebirge. Von der Segneskette aus senkt sich die Basis des Deckengebirges bis zum Linthtal um $2000 \mathrm{~m}$ und schafft so zum flyschreichen, breiten oberen Sernftal einen vom Verrucano geformten, engen unteren Abschnitt. Zwischen dem überschobenen Kalkgebirge und seiner Wurzelzone besteht kein direkter Zu-

* Die Auswertungen für die Neue Landeskarte lassen vermuten, daß im kommenden Kartenwerk eine ausgezeichnete Darstellung vorhanden sein wird. 
sammenhang mehr, da sowohl der Richetlipaß im Westen, als auch der Foopaß Im Osten bis auf den Flysch erniedrigt sind.

\section{Tektonik}

$\mathrm{Da}$ das Aarmassiv ostwärts zur Tiefe sinkt, fallen auch die Faltenachsen seines Sedimentmantels in dieser Richtung. Die Falten selbst kommen damit unter die mächtigen Flyschmassen zu liegen, welche zwischen Autochthon und Deckengebirge eingeschaltet sind. Nur im westlichen Teil des Sernftales, in der Gegend des Panixerpasses, wo der Flysch ausklingt, dringt eine einzelne parautochthone Falte an die Oberfläche. Diese, die Tscheppfalte, bildet mit ihrem verkehrt liegenden Schenkel die Malmwände des Vorab, während der senkrecht stehende Normalschenkel Kalkhorn und Rinkenkopf aufbaut.

Als breite Zone von beträchtlicher Längenausdehnung lehnt sich im Norden der Flysch an. Seine tektonische Stellung ist außerordentlich kompliziert, da es sich einerseits um tertiäre helvetische Bildungen handelt, anderseits aber auch ultrahelvetische Serien vorkommen, die zwischen Autochthon und Deckengebirge eingewickelt sind. Es erübrigt sich, an dieser Stelle näher auf die komplizierten Verhältnisse einzugehen. Eine ausführliche Darstellung aller Hypothesen über die Tektonik des Flyschs ist im Monumentalwerk «Geologie der Glarneralpen » von J. OBERHOLZER enthalten ${ }^{29}$.

Über dem autochthonen Gebirge und dem Flysch liegen die helvetischen Dekken. Im Gebiet des Sernftales treten aber nur Glarnerdecke und Mürtschendecke mit großer Mächtigkeit in Erscheinung. Die Überschiebungsfläche wird vom Lochseitenkalk gebildet, der nach oben glatt begrenzt, nach unten aber gewellt und eingefaltet ist. Die Glarnerdecke zeigt ihre mächtigste Entwicklung in der Schildgruppe; sie ist deshalb vorwiegend am Aufbau des unteren Sernftales beteiligt. Im Kärpfgebiet klingt sie vollständig aus. Die gewaltigen Verrucanomassen dieses Gebirgsstockes gehören schon zur darüberliegenden Mürtschendecke, deren Teile die höchsten Erhebungen der Gebirgsumrahmung im Sernftal bilden. Zur auflagernden Axendecke kann im Sernftal einzig der Gipfel des am Panixerpaß gelegenen Rotstocks gerechnet werden.

Es sei hier kurz daran erinnert, daß der komplizierte Zusammenhang der verschiedenen Decken und Deckenreste, sowie die 'Tatsache, daß in diesem Gebiet die jüngsten Gesteine an der Basis, die älteren aber obenauf liegen, seinerzeit zur Theorie der «Glarner Doppeltialte geführt haben ${ }^{15}$.

\section{Die Gesteine}

Vom Quellgebiet bis zur Mündung durchmißt das Sernftal verschiedene tektonische Einheiten. Die an ihrem Aufbau beteiligten Gesteine stehen mit der Morphologie oft in so engem Zusammenhang, daß sie einer besonderen Erwähnung bedürfen.

'Parautochthon. Die parautochthone Tscheppfalte baut sich in der Vorabkette hauptsächlich aus Malm auf, der hier eine Mächtigkeit von mehreren hundert Metern hat. Er bildet die obersten Stufen des Jätztales und des Martinsmaads. Die Schichten der jüngeren Kreide sind nur wenig mächtig vorhanden und für die Ausbildung der morphologischen Formen nicht von besonderer Bedeutung.

Helvetikum. Sowohl Glarner- als auch Mürtschendecke sind über den Lochseitenkalk hinweggeschoben. Dieser bildet im ganzen Sernftal eine auffällig klare Trennungslinie und Härtezone, die bei der morphologischen Untersuchung mancherorts verwirrend in Erscheinung tritt. Die Mürtschendecke besteht aus einer mächtigen Verrucanomasse, in der sehr oft Ergußgesteine auftreten. Diese basischen und z. T. sauren Eruptiva liegen stellenweise wiederholt übereinander und haben besonders in der Kärpfgruppe weitgehend die Formung bestimmt, obwohl vielfach nur die obersten Teile der Berge daraus aufgebaut sind. Der Formenschatz ist im Verrucano nicht gleichmäßig gut erhalten, da dieses Gestein einerseits durch seine Sprödigkeit eine rasche Verwitterung begünstigt, 


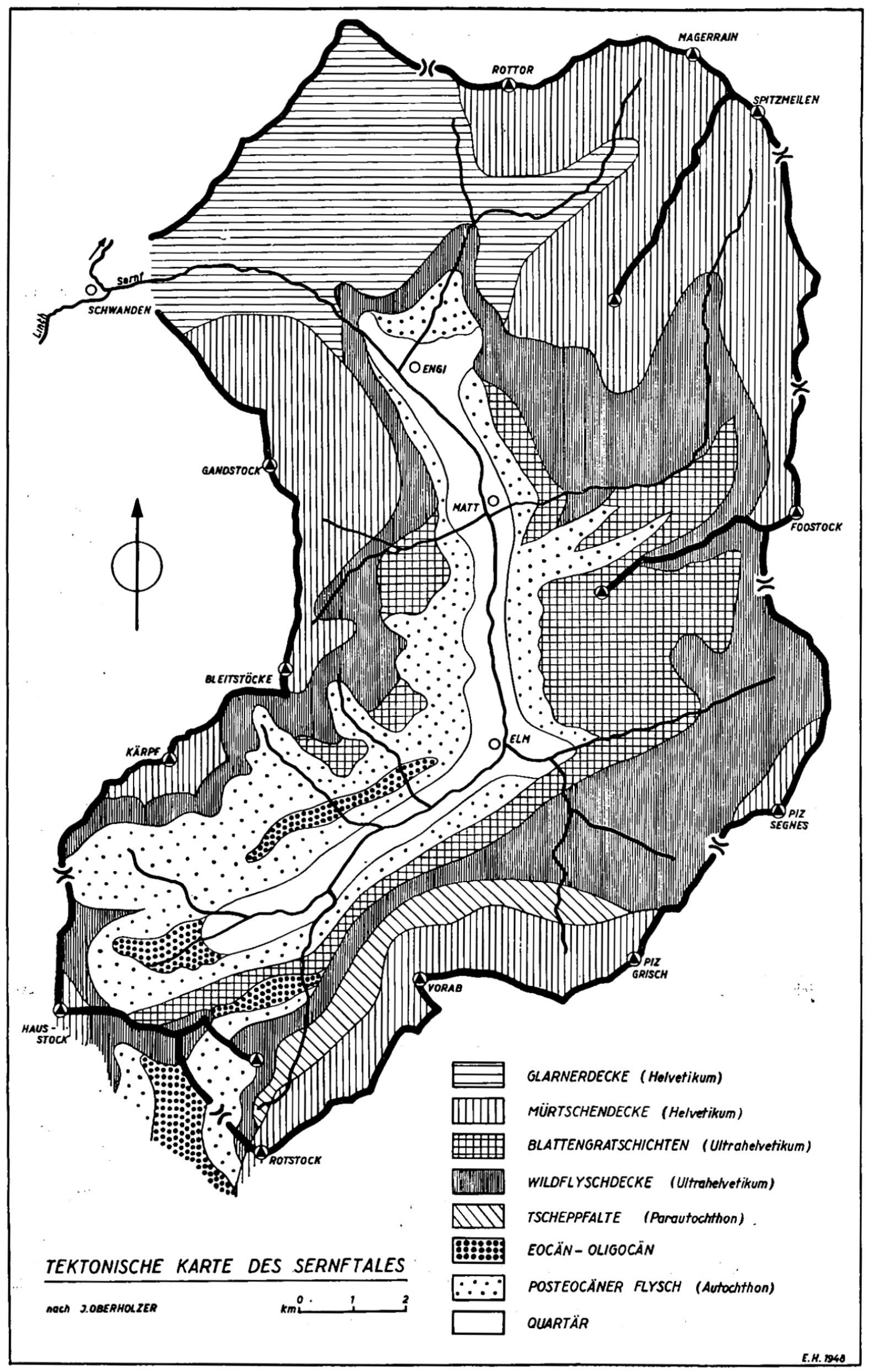


anderseits aber bei glatter Oberfläche eine stark konservierende Kraft entfaltet. Dadurch entsteht im Verrucanogebiet ein besonders starker Unterschied zwischen ehemals eisfreien und glazial bedingten Formen. Da auch die Glarnerdecke aus Verrucano aufgebaut ist, findet man in ihrem Verbreitungsgebiet ganz ähnliche Erscheinungen. Am besten sind die Formen im Rötidolomit der Trias der Mürtschendecke erhalten geblieben; doch beschränkt sich dieses Gestein auf die Spitzmeilenkette und den Gipsgrat, sowie auf einige kleine Gipfel am Panixerpaß.

Ultrahelvetikum. Die ultrahelvetische Schubmasse der Wildflyschdecke und der Blattengratschichten besteht vorwiegend aus Nummulitenschichten, Globigerinenmergel (Stadschiefer, Flyschschiefer), Taveyannazsandstein und Dachschiefern. Sie treten meist in der obigen Reihenfolge auf. Mit Ausnahme der Nummulitenkalkbänke, die immer als Härtekanten hervorstechen, sind alle anderen Schichten derart weich, daß sie der Erosion nur venig Widerstand entgegenzusetzen vermögen. Demgemäß ist der Erhaltungszustand der Einzelformen selten gut.

Posteocäner Flysch. Dem autochthonen helvetischen Flysch kommt ungefähr die gleiche Bedeutung zu wie dem Wildflysch. Die Sandsteine und Dachschiefer dieser Gruppe besitzen nur im Taveyannazsandstein eine härtere Schicht, die denn auch im Talschluß öfters als Härtezone hervortritt.

Wenn auch im Einzelfalle die Kleinformen vielfach von der Gesteinsbeschaffenheit abhängig sind, so besteht für die Großformen anderseits ein weit größerer Zusammenhang mit dem tektonischen Bau. Immer wieder aber kann erkannt werden, daß sich das Relief diesen Einflüßen doch zu entziehen vermochte.

\section{DIE UNTERSUCHUNGSMETHODE}

O. Maull bezeichnet die Geomorphologie als die «Lehre von der Formung und dem Formenschatz der festen Erdoberfäche » 25, A. PENCK definiert sie als die «Lehre von der Erscheinung, dem Vorkommen und der Entstehung der Oberflächenform ${ }^{30}$. Aus diesen Definitionen, die - wenn auch abgewandelt - in der Fachliteratur immer wieder auftreten, geht hervor, daß zur Erlangung morphologischer Erkenntnisse eingehende Beobachtungen notwendig sind. Nicht umsonst haben schon die ersten Morphologen, wie Davis, Richthofen, u. a. ihre Ërgebnisse aus Feldbeobachtungen geschöpft und stets wieder darauf hingewiesen, daß nur dieser Weg zu klaren Resultaten führt 10, ${ }^{31}$. Wo später andere Wege beschritten wurden, hat die Geomorphologie ihren Selbstzweck, Arbeitshypothese zu sein, verloren und wurde nur noch als Mittel zum $Z$ weck betrachtet.

Auch in der vorliegenden Arbeit bilden Beobachtungen und Detailuntersuchungen die Grundlage der morphologischen Deutung. Wenn auch im Rahmen dieser Arbeit nicht die ganze Problematik geomorphologischer Untersuchungen behandelt werden kann, so sollen doch drei Punkte näher erörtert werden, die allgemeine Bedeutung haben und immer wieder Schwierigkeiten verursachen können: die Karte, die Feldaufnahme und die Darstellung.

\section{Die Kartengrundlage}

Die Karte kann mit Bestimmtheit als das wichtigste Darstellungsmittel in der Geomorphologie bezeichnet werden. Sie dient der Eintragung des morphologischen Tatsachenschatzes und stellt deshalb gewisse Anforderungen in bezug auf den Maßstab und die Zeichnung. Besondere Bedeutung besitzt der Maßstab, wenn die Untersuchungen, wie im vorliegenden Fall, im alpinen Gelände durchgeführt werden. Je kleiner die Maßstäbe gewählt werden, umso schwieriger gestaltet sich die Eintragung. Wenn auch in Einzelfällen ein Maßstab von 1:25000 genügen kann, so darf doch erfahrungsgemä $\beta$ behauptet werden, daß normalerweise nicht mit Maßstäben unter 1:10000 gearbeitet werden sollte ${ }^{7}$.

Mit der Feldkartierung begann ich im Sommer 1944. Leider stand mir damals keine günstige Kartengrundlage zur Verfügung, sodaß ich gezwungen war, meine Eintragungen auf vergrößerte Siegfried-Blätter (1:25 000) zu machen. Sehr bald zeigte sich aber, daß diese Karte des kleinen Maßstabes wegen nicht gut brauchbar war. Es war beinahe ausgeschlossen, beobachtete Formen auf dieser Karte genau zu lokalisieren. Auch konnten keine brauchbaren Querprofile gewonnen werden, da durch die Vergrößerung auch die schon vorhandenen Fehler entsprechend vergrößert waren.

Von 1945 an standen mir die photogrammetrischen Übersichtspläne 1:10 000 der Eidg. Vermessungsdirektion in Bern zur Verfügung. Diese Karten, die als reine Kurvenkarten keine Felszeichnung aufweisen, waren für die morphologische Aufnahme besonders geeignet, da die Äquidistanz nur $10 \mathrm{~m}$ beträgt, was sich speziell bei der Erstellung von Querprofilen günstig auswirkte. Eine gewisse Schwierigkeit bereitete dagegen das Fehlen jeglicher Nomenklatur. 
Wenn einerseits für die Feldkartierung ein Maßstab von 1:10000 gefordert werden darf, so wird sich andererseits für die Auswertungen sehr of ein kleinerer Maßstab besser eignen, da solche Karten eine größere Übersicht gewährleisten. Doch darf auch hier der Maßstab nicht zu klein gewählt werden, denn durch die notwendige Generalisierung beim Übertragen auf eine kleinere Karte können unter Umständen viele Kleinformen verloren gehen, die für die Deutung der Talgeschichte ausschlaggebend sind und nicht weggelassen werden dürfen. Für ein Gebiet von der Größe des Sernftales dürfte der Maßstab 1:50 000 die äußerste Grenze darstellen.

Die vorliegende Karte besitzt als Grundlage die Artilleriekarte $I: 25000$ (vergrößerte Landeskarte). Die Ortsbezeichnungen und Eigennamen im Text entstammen jedoch noch der Siegfriedkarte.

\section{Die Feldaufnahme}

Die Art des Vorgehens bei Geländeaufnahmen scheint mir derart individuell zu sein, daß dafür wohl nur schwerlich allgemein gültige Richtlinien aufgestellt werden können. Aber die Lösung dieser Frage hängt so sehr mit der Arbeit selbst zusammen, daß ich trotzdem einige Überlegungen anbringen will, obgleich ich mich fast nur auf persönliche Erfahrungen stützen kann.

Die Feldaufnahmen erfolgten erst nach einem gründlichen Studium der Topographie und der geologischen Verhältnisse und wurden in den Sommern 1944-48 durchgeführt. Die Begehung des Gebietes erfolgte stets im Hochsommer, da zu anderen Jahreszeiten für morphologische Studien allzuviel Gelände noch Schneebedeckung aufweist. Auch bieten die Monate Juli und August im Sernftal die relativ größte Sicherheit für gutes Wetter, was für Feldbeobachtungen beinahe unbedingt notwendig ist.

Mit der Feldkartierung begann ich im obersten Talteil, um dann allmählich talausiärts vorzudringen. Erfahrungsgemäß liegen die Verhältnisse im Talschluß einfacher als beim Talausgang, wo eine große Häufung von wirkenden Kräften sich spürbar macht.

Die Begehung des Geländes erfolgte mehrmals, da es nicht immer möglich war, sämtliche Formen an Ort und Stelle einzutragen. Sehr oft erscheint eine Form von einem andern Standort aus in vollkommen anderer Art; auch habe ich bemerkt, daß die Beleuchtung von großem Einfluß sein kann.

Da die kartographische Aufnahme eines kleinen Gebietes die großen Zusammenhänge nur selten erkennen läßt, habe ich als Ergänzung zur Karte ein Protokollbuch geführt, in das ich die wichtigsten Eindrücke eingetragen habe. Während einiger Zeit versuchte ich die Protokollierung von „Örtlichkeiten “, wie sie MERIAN ${ }^{26}$ durchgeführt hat. Bald zeigte sich aber, daß ein solches Vorgehen für ein Gebiet von der Größe des Sernftales viel zu viel Zeit beanspruchen würde.

Zur Auswertung der Feldaufnahmen dienten mir eigene Fotos aus dem Gelände. Weiterhin habe ich Fliegeraufnahmen der Eidg. Vermessungsdirektion verwendet, die sich besonders da eigneten, wo die Umrisse einer morphologischen Form vom Boden aus nicht genau bestimmt werden konnten. Auch zur Fixierung bestimmter Geländepunkte hat sich das Flugbild sehr gut bewährt.

\section{Darstellung und Légende}

Die Darstellung der Ergebnisse geschieht in der Form einer morphologischen Grundkarte, die vorwiegend analytischen Charakter aufweist, was eine detaillierte Feldkartierung voraussetzt. Was kartographisch nicht festgehalten werden konnte oder einer weiteren Erklärung bedarf, wurde dem Begleittext, der als Erläuterung zur Karte gedacht ist, beigefügt.

Aus der morphologischen Karte entstand die morphogenetische Karte, wobei auf induktivem Wege die Kenntnisse der morphologischen Verhältnisse zur Deutung der Genese verwendet wurden. Diese Karte verdeutlicht vor allem die großen Zusammenhänge und gibt Auskunft über die talgeschichtliche Entwicklung seit dem Jungtertiär.

Als Legende verwendete ich die Signaturen, die von der Geomorphologischen Gesellschaft der Schweiz für die morphologischen Spezialkarten der Alpen vorgeschlagen sind ${ }^{3}$. Die gut aufeinander abgestimmten Zeichen sind eng mit den natürlichen Formen verbunden und bewirken eine gute Leserlichkeit. - So sind im allgemeinen Akkumulationsformen flächenhaft dargestellt, während Kanten durch Linien gekennzeichnet werden. Für die erosiv-denudativen Formen sind verschiedene Eịnzelzeichen vorhanden. Die Legende eignet sich gut zu einer einfarbigen Darstellung.

Die morphologische Grundkarte des Sernftales weist zwei Farben auf. Die roten Signaturen umfassen säntliche Akkumulationsformen, ohne Rücksicht auf ihre Entstehung, während für alle Erosionsformen die schwarze Farbe gewählt wurde. Die rote Farbe für die flächenhafte Darstellung der Akkumulationen bewirkt, daß auch die topographische Grundlage noch leserlich bleibt.

Obwohl sich die morphologische Grundkarte auch zur Darstellung der Genese sehr gut eignen würde, habe ich mich zur Ausführung einer speziellen morphogenetischen Karte entschlossen, da für das Sernftal die Talgeschichte nur hypothetisch erfaßt werden kann. Eine Zusammenlegung der genauen morphologischen Aufnahme mit der noch nicht bis ins Letzte ergründeten Entwicklungsgeschichte würde jedenfalls den Wert der Karte nur beeinträchtigen.

Da für die vorliegende genetische Karte des Sernftales der morphologische Tatsachenschatz allein nicht genügt hätte, mußte ich auf deduktivem Wege durch Vergleiche mit dem Haupttal und dem Vorland weitere Anhaltspunkte finden, um auch das zeitliche Moment in der Talgeschichte erfassen zu können. 


\section{Die morphologischen Verhältnisse}

Die Formen der festen Erdoberfläche sind das Ergebnis eines Werdeganges, der sich so langsam vollzieht, daß sein Ablauf nur in den wenigsten Fällen direkt beobachtet werden kann. Der gegenwärtige Zustand einer Form ist das Resultat so vieler Vorgänge, daß eine reine Beschreibung allein die Bedeutung einer einzelnen Form für den genetischen Prozeß nicht wiederzugeben vermöchte. Es wird deshalb von vornherein notwendig sein, schon bei der morphologischen Untersuchung die Abhängigkeit der Formen in bezug auf ihre Entstehung kritisch zu beobachten. Diese individualgenetischen Betrachtungen stehen mit der Genese eines ganzen Gebietes nur in einem bedingten Zusammenhang. Sie sind jedoch absolut erforderlich, wenn sie, wie in vorliegendem Falle, als Erläuterungen zur morphologischen Karte gedacht sind. Würden Betrachtungen dieser Art einfach ausgeschlossen, so wären die Ergänzungen zur Karte rein morphographischer Natur. Es wäre dann nicht einmal möglich, eine Einteilung der Formen in verschiedene Gruppen vorzunehmen, da schon ein derartiges Vorgehen eine Klassifizierung nach Entstehungsarten bedingt.

Anderseits sind aber zahlreiche Formelemente in ihrer Anlage und Ausbildung von solch komplizierter Struktur, daß erst eine genetische Deutung des Gesamtgebietes ihre Entstehung im Einzelnen zu erklären vermag. Schlußfolgerungen in dieser Richtung anzustellen wäre aber innerhalb dieses ersten Teiles der Arbeit sicher verfrüht, da erst die genaue Kenntnis des gesamten Formenkomplexes Antworten auf solche Fragen geben kann.

\section{ABHÄNGIGKEIT DER FORMEN VOM TEKTONISCHEN BAU UND VOM GESTEIN}

$\mathrm{Da}$ die ehemalige, tektonisch bedingte Oberfläche längst abgetragen worden ist, stellen die heutigen Tal- und Gebirgsformen im Sernftal nur noch Ruinen des einstigen Reliets dar. Die Ursachen, welche einst das Relief in seinen großen Zügen bestimmt haben, sind heute wohl kaum mehr zu erkennen.

Wohl liegt die Vorab-Segnesgruppe in einer axialen Kulmination im Längsverlauf der Alpen, und das Quertal des Sernfs von Elm bis Schwanden würde gut in eine axiale Depression passen, wie sie nach STAUB ${ }^{34}$ um die Wende von Oligozän und Miozän im Primärrelief der Alpen hestanden haben soll. Doch hätte sich gerade diese Depression weit nach Süden erstreckt und das Gebiet des heutigen Hinterrheins eingeschlossen. Wenn nun aber das Sernftal sein Ende am Vorab findet, und die genannte Depression in ihrer Mitte von der tiefen Rheintalfurche gequert wird, so ist das sicher Beweis genug, daß man auf der Suche nach Zusammenhängen zwischen der tertiären Tektonik und den Großfornien des heutigen Reliefs fast gänzlich auf Vermutungen angewiesen ist.

Wenn sich nun einerseits auch das Relief vom Gebirgsbau unabhängig gemacht hat, so sind anderseits doch gewisse junge, epirogenetische Bewegungen nicht ohne Einfluß auf die Talgestaltung geblieben. Ihre Wirkungen erkennt man am besten an den zahlreichen 'Terrassen und Talstufen, die sich durch Hebung des Gebirgskörpers und dadurch bedingte Tieferlegung der Erosionsbasis gebildet haben. Der ganze Fragenkomplex dieses Problems darf jedoch an dieser Stelle übergangen werden, weil er im Zusammenhang mit der morphogenetischen Deutung der Talbodenreste ein eigenes Kapitel füllen wird.

Außerordentlich scharf erkennbar ist dagegen der Einfluß des geologischen Baues und vorwiegend der einzelnen Gesteinsarten auf die morphologischen Spezialformen. Besonders in Erscheinung tritt diese Tatsache bei den Erosionsformen. Diese sind in weichen Gesteinen oft großartig ausgebildet, während sie in härteren Gesteinszonen nur kleine Dimensionen erreichen können. Ich möchte aber gerade hier ausdrücklich bemerken, da $\beta$ die Widerstandsfähigkeit eines Gesteins im Verhältnis zu anderen Faktoren, wie der Erosion usw., nur als mitbedingender Umstand der Talgestaltung betrachtet werden darf. - Aber nicht nur die Erosionsformen, sondern auch die Akkumulationen erhalten durch die Gesteine einen bestimmten Charakter. So sind Aufschüttungsformen aus Verrucano meist grob- 
klotzig, während bei gleicher Entstehungsart solche aus Flyschgestein meist feinere Struktur aufweisen. Es werden sich bei der Behandlung der morphologischen Ein. zelformen in den folgenden Abschnitten immer wieder Gelegenheiten bieten, auf die Abhängigkeit der Formen vom Gestein hinzuweisen.

Am eindrücklichsten wird der Gesteinsunterschied dort, wo sich eine Form über mehrere Gesteinszonen erstreckt. Die auffällig klare Trennungslinie und Härtezone, die der Lochseitenkalk im ganzen Sernftal bildet, wurde schon im $\Lambda$ ibschnitt der Geologie (Seite 91) erwähnt. Auch die übrigen Gesteine machen hierin keine Ausnahme.

Von besonderem Einfluß ist auch die Lage der Gesteinsschichten auf das Landschaftsbild. So bilden die fast südlich einfallenden tertiären Schiefergesteine und die ultrahelvetischen Flyschbildungen mit ihren Schichtköpfen an den Nordabfällen des Vorab und des Blattengrates ausgedehnte Härteterrassen, während sie an den gegenüberliegenden Talhängen nicht besonders in Erscheinung zu treten vermögen. Auch die Rückläufigkeit verschiedener Erosionsterrassen kann immer wieder auf die Lagerung der Schichten zurückgeführt werden. Als markanteste Beispiele seien nur die Terrasse der Weißenberge im Haupttal und die Terrasse «Auf den Saumen 》 im Krauchtal erwähnt.

Eigenartigerweise macht sich der Einfluß der Gesteine in den Gipfelformen weit weniger bemerkbar als erwartet. Fast im ganzen Sernftal findet man die höchsten Erhebungen in der Form mächtiger Stöcke, wie sie auch in Kalkgebieten anzutreffen sind. Schon die Namen Kärpfstock, Karrenstock, Foostock, Gufelstock zeigen, daß es sich um gleichartige Formen handelt. Eine Ausnahme bilden einzig die Erhebungen in der Vorab-Segnesgruppe, wo die Gipfel die Form von wildgezackten Hörnern (Tschingelhörner, $Z$ wölfihörner) angenommen haben.

Man könnte leicht in Versuchung geraten, auch die Breite der Talsohle mit den Gesteinen in Zusammenhang zu bringen. Tatsächlich wechselt ja auch die Talbreite von Wichlen bis Schwanden sehr stark; und das breite, obere Sernftal steht in krassem Gegensatz zum engen unteren Abschnitt. Wir wir aber schon festgestellt haben, fließt der Sernf von Elm an in einem ausgesprochenen Quertal; es ist somit selbstverständlich, daß er sich in seinem unteren Lauf kein solch breites Tal zu schaffen vermochte wie in der weichen Flyschzone, die er in ihrer Längsrichtung durchfließt.

Zusammenfassend kann festgestellt werden, da $\beta$ die Gesteine auf die einzelnen Formen wie auf das gesamte Landschaftsbild einen großen Einflu $ß$ auszuüben vermochten. Dieser Einfluß ist jedoch nicht grundlegend, sondern meist mit anderen Gestaltungsfaktoren verknüpft und wird deshalo bei jeder einzelnen. Form von einem anderen Standpunkte aus berücksichtigt wcrden müssen.

\section{DIE EROSIONSFORMEN}

Es ist eine der Hauptaufgaben der geomorphologischen Forschung, die Arbeit der Gletscher und Flüsse während des Pleistozäns genetisch zu erfassen. Die Wechselwirkung von Eis und Wasser hat aber of derartig komplizierte Formen zu schaffen vermocht, da $\beta$ eine monogenetische Deutung einzelner Formen in vielen Fällen zum vorneherein unmöglich wird.

Meine Einteilung der Erosionsformen in eine glaziale und eine fluviale Hauptgruppe darf deshalb nicht als eine genetische Klassifizierung aufgefaßt werden. Das Hauptaugenmerk bei der Untersuchung richtete sich in dieser Beziehung weit weniger auf die Genese, als auf das Problem, ob eine spezielle Form in ihrer heutigen Anlage überhaupt hätte entstehen können, wenn nur eine einzelne Kraft gewirkt hätte. 
$\mathrm{Zu}$ den glazialen Formen habe ich demnach jene gerechnet, die durch die Arbeit des $\mathrm{W}$ assers allein nicht hätten entstehen können; zu den fluvialen jene, welche die Gletscher allein nicht erzeugen konnten.

Ich bin mir vollkommen bewußt, daß auf diese Weise das Problem der Einteilung nicht endgültig gelöst ist, und $\mathrm{da} \beta$ auch dieser Auffassung gewisse Mängel anhatten. $\mathrm{Zu}$ einer Einteilung des morphologischen Formenschatzes eines Gebietes aber eignet sich eine Klassifizierung nach diesen Gesichtspunkten ausgezeichnet. In $Z$ weifelsfällen müssen sowieso alle Faktoren der Gestaltung berücksichtigt werden, wenn die Deutung umfassend sein soll.

\section{Glazialerosion}

$\mathrm{Wie}$ in allen Alpengebieten treten auch in unserem Untersuchungsgebiet die glazialen Erosionsformen am deutlichsten in Erscheinung. Als Kare, Rundhöcker, Gletscherschliffe und kleine Riegel sind sie über das ganze Sernftal verteilt und zcugen für die im Diluvium wirksam gewesenen Kräfte. Die Vielzahl der Formen und ihre in sich differenzierte Ausgestaltung bedingen eine Einteilung in Gruppen, von denen jede für sich behandelt werden soll.

Da im Sernftal die Seen sozusagen rein glazialer Entstehung sind, werden sie ebenfalls unter die glazialen Erosionsformen engereiht.

\section{Die Kare}

Wie in allen ehemals vergletscherten Alpentälern, sind auch im Sernftal die Kare die charakteristischsten Formen der Glazialerosion. Wenn sie auch im allgemeinen zahlreiche gemeinsame Eigenschaften aufweisen, so sind sie in ihrer Ausbildung doch so differenziert, daß eine Einzelbesprechung unumgänglich ist.

\section{Hausstockgruppe}

Ein prachtvolles Kar ist der große Zirkus, mit dem das Sernftal am Hausstock endet. Die Karwand wird vom Hausstock, Mättlenstock und Leiterberg gebildet und umschließt eine Nische von genau $2 \mathrm{~km}$ Durchmesser. Der Karboden ist mäßig steil und beherbergt in seinem südlichen Teil noch einen kleinen Rest des Sernfgletschers, sodaß dieser Kar als noch aktiv bezeichnet werden darf. Die vom Eise freien Teile weisen zahlreiche Rundhöcker und Gletscherschliffe auf; der weitaus größte 'Teil des Karbodens ist aber von einer bis $40 \mathrm{~m}$ mächtigen Moränenschuttdecke bedeckt. In seiner ganzen Ausdehnung ist der Boden von zahlreichen breiten Rinnen zerschnitten, deren Anlage sehr alt sein muß3, da sie Moränenschutt und Gletscherschliffe enthalten. Von den mächtigen Karwänden her hat feiner Gehänge- und grober Bergsturzschutt die Sohle überflutet und ein unruhiges Relief geschaffen. Talauswärts wird der Boden durch eine mächtige Steilstufe abgeschnitten, deren oberer Rand beinahe genau mit der 1800 m-Isohypse übereinstimmt.

Alle übrigen im Sernftal auftretenden Kare sind inaktiv und zeigen keine Eisbedeckung mehr. Demgemäß ist es oft schwer zu entscheiden, ob es sich um echte Gletscherkare oder um Erosionsformen anderer Entstehung handelt.

Einen sehr schönen Karboden stellt die Felsfläche dar, welche mit mäßiger Neigung vom Hexenseeli am Panixerpaß nordwärts ansteigt und zahlreiche Rund: höcker aufweist. In Norden und Westen sind die Karwände der rückwärtsschreitenden Erosion zum Opfer gefallen, sodaß nur noch auf der Ostseite im Rinkenkopf und Kalkhorn ein Teil der Felsumrahmung erhalten geblieben ist. Dieser alte Karboden reicht dadurch bis auf die Kammlinie des Wichlenberges hinauf und wird von demjenigen des Meergletschers auf der Südseite des Hausstockes nur durch eine niedrige Felsstufe getrennt. Die nur schwach ausgebildete Stufe zum 
Hexenseeli wird von einem Riegel beherrscht, der vom Bach an mehreren Stellen durchbrochen wird.

Zwischen Hagelegg und Kalkhorn öffnet sich eine Nische gegen Jätzalp-Oberstafel, die einen karförmigen Grundriß aufweist. Südlich davon liegt zwischen Kalkhorn und Rinkenkopf eine zweite Mulde mit gleichem Charakter. Beide dürfen auf Grund der Moränenwälle an ihrem unteren Ende als Kare betrachtet werden, wenngleich kein eigentlicher Karboden vorhanden ist. Alle übrigen, auf Vergletscherung hinweisende Formen müßten unter der mächtigen Decke von Verwitterungsmaterial liegen, welche beide Nischen ausfüllt.

\section{Kärpfgruppe}

Auch vom Kärpf her öffnet sich eine ganze Anzahl Kare gegen das Sernftal. Das typischste und größte ist das $2 \mathrm{~km}$ breite und $1 \mathrm{~km}$ lange Becken von Wichlenmatt. Die Karwände sind fast in geschlossener Linie vorhanden; einzig am Richetlipa $ß$ hat die rückwärtige Erosion zwischen Leiterberg und Kalkstöckli eine Bresche zu schlagen vermocht. Der Karboden ist außerordentlich flach und wird talauswärts von einem Felsriegel begrenzt, der von zahlreichen Rundhöckern bedeckt ist. Dieser Riegel gab wohl auch Anlaß zur Bildung des ausgedehnten Geschiebebodens, der heute ein Felsbecken ausfüllt, das ehemals vielleicht von einem See erfüllt war. Diese geradezu klassische Karform ist eindeutig der harten Taveyannazsandsteinmasse zu verdanken, die vom Leiterberg zum Erbserstock hinüberzieht und eine stärkere Eintiefung verhindert hat. Die am Erbserstock auftretenden Rundhöcker zeigen überdies, daf. das Eis zeitweise die Mulde nicht quer, sondern längs zum Riegel verließ.

Der Gipfelaufbau des Kärpfs bildet einen Karling, der gegen das Sernftal (und übrigens auch gegen Norden) eine weit vorspringende Felsfäche besitzt. Dieser ausgedehnte Boden bildet über dem Wichlenmattkar, über der Erbsalp und über dem Talschlu $\beta$ der Bischofsalp eine mächtige Felsbastion, die dadurch bedingt ist, daß hier die harten Gesteine der Mürtschendecke auf den weichen Schichten des Flyschs aufliegen. So ist durch diesen Gesteinsunterschied eine Kartreppe entstanden, deren oberer Boden gleichzeitig drei Karen angehört, da die $Z$ wischenwände zu kaum wahrnehmbaren Rundungen erodiert sind.

Das Tal der. Bischofalp endet gegen den Schwarztschingel und die Bleitstöcke mit einer mächtigen Karwand, deren oberer Rand an eine ausgedehnte, rundhöckrige Hochfläche anstößt, welche mit der Felsfläche unterhalb des Kärpfgipfels identisch sein dürfte.

Auch die vom Wildmaad und dem Berglihorn zum Sernftal absteigenden Tälchen sind in ihrem oberen Teil karartig umgestaltet. Darauf deuten die in der Embächli-, Kühboden- und Geißtalalp liegenden Endmoränenbogen hin. Doch sind auch hier dic Karböden relativ kurz und steil, sodaß sie in keinem Falle durch markante Kanten begrenzt werden.

Dic schönste Ausbildung all dieser Kare besitzt dasjenige des Kühbodenalptälchens. Die Wildmaadseelein bilden beckenförmige Vertiefungen auf dem obersten Absatz, der wie beim Kärof wiederum drei Tälern gemeinsam ist; in der unteren Stufe stellt der Kühbodensee einen typischen Karsee dar. Daß das Kühbodenkar nicht wie die übrigen die Gestalt eines steilen Trichters annahm, ist mit Sicherheit auf die widerstandsfähigen Nummulitenkalkbänke zurückzuführen, die die Riegelbildung stark gefördert haben. Der unterirdische Abfluß des Sees hat die postglaziale Oberflächenerosion zum Stillstand gehracht, sodaß hier die Glazialformen sehr gut erhalten geblieben sind.

Kleine Kare, deren Rückwände nur noch in Fragmenten vorhanden sind, öffnen sich von der Berglimatt und dem Karrenstock gegen die Berglialp, sowie vom Gand- 


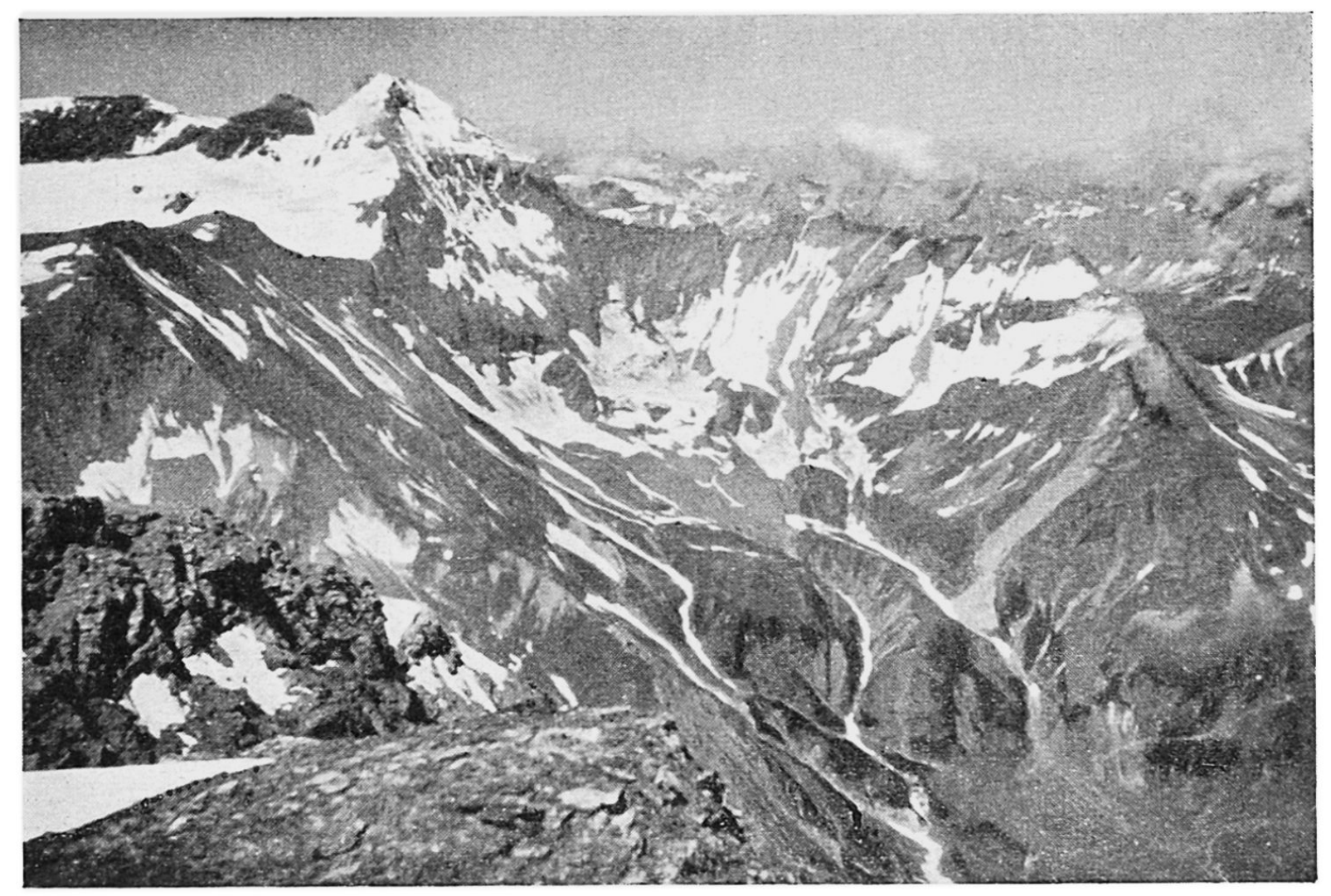

Blick vom Vorab in den Karzirkus von Hausstock-Leiterberg mit seinem von Wall- und Grundmoränen bedeckten, stark zerschnittenen Talboden. (Photo Helbling)

stock gegen die Lauelialp. Moränen und Rundhöcker sind auch hier stellenweise gut erhalten.

\section{Vorab-Segnesgruppe}

An der Westseite des Vorab sind in ca. $2800 \mathrm{~m}$ Höhe eine ganze Anzahl von Nischen eingelassen, die noch über das Ende der Diluvialzeit hinaus Hängegletscher beherbergt haben. Die zahlreichen Rundhöcker westlich der beiden Vorabgipfel lassen erkennen, daß diese Nischen vom Überlauf des Bündnerbergfirns gespeist wurden. Leider sind diese Kartrichter unzugänglich, sodaß über ihre Ausbildung nichts gesagt werden kann.

Die Nordseite des Vorab wird von einer mächtigen Wand begrenzt, die sich in drei Teilen vom Glarner Gipfel bis zu den Zwölfihörnern erstreckt. Der westliche Teil stellt die Karwand eines Hängegletschers dar, welcher wohl ebenfalls durch den Vorabgletscher gespeist wurde. Der östlich anschließende Teil bildet die südliche Begrenzung jenes Kars, welches sich zwischen Zwölfihorn und Vorab eingesenkt hat, und dessen Boden das Bocksmaad umfaßt. Die Rückwärtserosion in diesem Kar hat zur Isolierung der Zwölfihörner geführt, die einst wohl nur ein Erker im Vorabmassiv gewesen sind.

\section{Das Martinsmaad}

Die eigenartige Form und die verblüffend regelmäßige Ausgestaltung des Martinsmaads rechtfertigt eine eingehende Besprechung dieses Kars, welches sich als steile Treppe zwischen Mittaghorn und Ofen vom Vorab gegen Norden senkt. Diese Treppe wird durch fünf ausgeprägte Stufen gebildet, über die der Tschingelbach in mächtigen Wasserfällen zur Tiefe stürzt.

I. Wand $(2600-2430 \mathrm{~m})$. Die durchschnittlich $150-200 \mathrm{~m}$ hohe Kalkwand bildet den obersten Rand des Kars. In einem flachen, nach Süden ausholenden Bogen erstreckt sie sich vom Zwölfi- 
horn im Westen bis zum östlich gelegenen Ofen. An drei Stellen ist sie leicht eingebuchtet und läßt dort noch schwach erkennen, daß sie aus mehreren Einheiten zusammengesetzt ist. Vor wenigen Jahren sind diese Nischen noch von Eis erfüllt gewesen, welches mit dem Bündnerbergfirn zusammenhing, während heute nur noch im mittleren Wandteil ein kleiner Firnrest zurückgeblieben ist.

Boden I $(2400-2200 \mathrm{~m})$. Dieser Boden ist mit zwei kleinen Wallmoränen ausgezeichnet, enthält aber sonst nur Akkumulationen mechanischer Verwitterung.

2. Wand $(2200-2120 \mathrm{~m})$. Diese Wand verläuft in der gleichen Richtung wie die erste und enthält im mittleren Teil einen schwach vorspringenden Sporn. Die obere Kante wird von einem Nummulitenkalkband gekrönt, welches durch seine Widerstandskraft der Erosion hier Einhalt geboten hat.

Boden II $(2120-2000 \mathrm{~m})$ ist der eigentliche Karboden. Durch seine Härtezone im Wildflysch wird er in zwei Abschnitte geteilt. Der obere umfaßt die Nische, welche sich gegen den Ofen hinaufzieht, während der untere Teil sich an das vom Zwölfihorn kommende Kar anlehnt. Die Härtezone ist durch ein etwa $15 \mathrm{~m}$ hohes Wändchen gekennzeichnet, das vom rechten Zufluß des Tschingelbaches an seiner niedrigsten Stelle durchsägt wird. Der südliche 'Teil dieses ausgeprägten Bodens ist von Moränen- und Gehängeschutt vollständig überdeckt. Talauswärts steigt die Fläche um wenige Meter leicht an und bildet so einen kleinen Riegel mit grob geformten Rundhöckern, zwischen denen sich der Bach stellenweise außerordentlich tief eingeschnitten hat.

3. Wand $(2000-1830 \mathrm{~m})$. Dieser Steilabfall vor der Martinsmaadhütte zeigt trotz der fortgeschrittenen Verwitterung schöne Rundbuckel. Der Bach hat sich im oberen Wandteil metertief eingeschnitten und die Rundformen in seinem Bett zeigen, daß die Anlage nicht postglazial sein kann.

Boden III $(1800-1760 \mathrm{~m})$ ist ein kurzer und sehr flacher Absatz, welcher von beiden Seiten durch Gehängeschutt zugedeckt ist. Der Tschingelbach hat aber etwa $20 \mathrm{~m}$ tief bis zum Anstehenden erodiert.

4. Wand $(1750-1700 \mathrm{~m})$. Die Eckpfeiler dieser Wandstufe werden von Sardonaquarzit gebildet, der im Wildflysch eingeschlossen ist und durch seine Härte der Erosion entgegengetreten ist.

Boden IV $(1700-1650 \mathrm{~m})$. Diese Verebnung ist die flacheste aller Böden und wird talauswärts von einem Riegel abgeschlossen, an dem der Bach entlangfließt, ehe er an der niedrigsten Stelle das "Becken" verläßt. Über die alluvialen Aufschüttungen legen sich von beiden Seiten Schuttkegel. Die Tatsache, daß der Bach den Boden mit unmerklichem Gefälle durchfließt, und den Riegel im Anstehenden durchschneidet, läßt die Vermutung zu, daß unter dem Aufschüttungsmaterial ein Becken liegt, welches einst von einem Seelein erfüllt gewesen sein mag.

5. Wand $(1650-1550 \mathrm{~m})$. Die zur Tschinglenalp hinunterleitende Stufe ist stark zerschnitten und weist mehrere trockene Läufe des Tschingelbaches auf. Glaziale Spuren sind keine vorhanden.

Boden $V$ (Tschinglenalp) ist ein von mächtigen Grundmoränenmassen und vier prächtigen Wallmoränen bedeckter Boden von dreieckiger Form, der vom Segnes- und Tschingelbach im Westen schon stark eingetieft wurde.

Das Martinsmaad stellt somit ein ausgezeichnetes Treppenkar dar, welches außer zwei eigentlichen Karböden (Boden II und IV) noch weitere Stufen aufweist, die entweder auf die Widerstandsfähigkeit des Gesteins oder auf die fluviatile Erosion zurückzuführen sind.

$Z$ wischen Ofen und Mörderhorn liegt ein weiteres mächtiges Kar. Die Wand ist leider nicht mehr vollständig erhalten, da sie am Segnespaß und westlich P. 2742 ausgebrochen ist. Entsprechend den Karböden des Martinsmaads sind auch hier zwei Böden vorhanden, die aber nur kurz und relativ steil sind. Der obere, in ca. $200 \mathrm{~m}$ liegende Boden zeigt eine dünne Grundmoränendecke. Zum zweiten Boden hinunter zieht sich eine kleine Wallmoräne. Auch dieses Kar endet im moränenbedeckten Boden der Tschinglenalp.

Vom Plateau zwischen Piz Segnes und Piz Sardona öffnen sich eine ganze Anzahl von Karen gegen die Falzüberalp. Die $Z$ wischenwände sind fast allerorts abgetragen, soda $\beta$ man im Großen eher eine mächtige :Wandflucht vor sich zu haben glaubt. Die Einzeluntersuchung zeigt aber, daß sich nördlich des Mörderhorns eine Nische gegen Falzüber-Oberstafel hinunterzieht und dort, sowie auf dem Boden von Stäfeli, die Spuren des Eises in Form von Wallmoränen erhalten geblieben sind.

Zwischen Horn und Geißegg öffnet sich ein langgestrecktes Kar, welches von der Sardona heruntersteigt. Drei Wallmoränen begleiten den Bach und im Boden hinter P. 1952 liegt eine ausgedehnte Moränendecke. Die Form all dieser Kare 
wird stark durch die Schichtung des Gesteins bedingt, das hier fast genau südlich einfällt und von Westen nach Osten streicht.

\section{Spitzmeilengruppe}

Die Westabdachung der Spitzmeilen-Foostockkette zeigt nur wenige deutlich ausgeprägte Karformen. Zwei kleine Karnischen sind die Eintiefungen bei P. 2401 südlich des Foopasses sowie am Foostöckli selbst. Die nur wenig charakteristischen Karböden sind in beiden Fällen durch kleine Wallmoränen gekennzeichnet.

Ein typisches, von einer halbkreisförmigen Wand eingerahmtes Kar ist dagegen die Nische von Bützi auf der Westseite des Foostockes. Deutliche Rundhöckerformen sind in den Nummulitenkalkbänken in der Mitte des Karbodens erhalten geblieben. Auch die Eintiefung im Westen des Weißgandstöcklis besitzt eine karähnliche Form. Leider sind jedoch keine Spuren glazialer Erosion vorhanden.

Eine schön ausgeprägte Karform zeigt die Nische von Schönbühl zwischen Gipsgrat und Spitzmeilen. Der Boden ist sehr unregelmäßig geformt, besitzt aber prachtvolle Rundhöcker; zwischen Spitzmeilen und Rinderhörnern scheint die Karwand schon frühzeitig abgetragen worden zu sein, da die Rundbuckel den ganzen Übergang ins Schilstal bedecken.

Die lange Terrasse «auf den Kämmen» westlich des Gipsgrates ist mit ihren Rundhöckern, rundlichen Mulden und kleinen Seelein ein typischer alter Gletscherboden. Die Karwand wird durch die langgestreckte Dolomitwand des Gipsgrates gebildet.

Zwei kleine Kare öffnen sich auch auf der Südseite des Goggeien gegen die Mühlebachalp. Die östliche Nische ist in ihrem flachen Teil von einer dünnen Grundmoränendecke überzogen.

Zwischen Heustock und Ruchsiten steigt ein kleines Kar zur Lusermatt hinunter und südlich vom Rottor liegt eine Nische, die im unteren Teil zwei kleine Wallmoränen aufweist.

Das fast $2 \mathrm{~km}$ breite und ebenso lange, sanft nach Süden sich senkende Plateau von Fässisalp ist ein alter Gletscherboden, der Boden eines Kars, dessen Rückwand und Ostrand durch die eckig verwitterten 100-200 $\mathrm{m}$ hohen Verrucanohänge der Kette Heustock-Gufelstock gebildet werden. Von seinem Westrand ist im Schafläger noch ein Stück erhalten geblieben. Im gleichen Niveau mit dem mittleren Teil der Fässisalp liegt auf der Südostseite von Gufelstock und Guntelkamm der an geglätteten Rundhöckerformen reiche Karboden von Gufelialp-Oberstafel.

Ein deutliches Kar ist auch die Mulde am Südabhang des Gulderstocks, dem Ausläufer des Gipsgrates. Der Karboden zeigt in seinem vorderen Teile eine muldenförmige Vertiefung, während der darüber sich erhebende Außenrand der Terrasse rundhöckerig abgeschliffen ist. Auch die Trichter von Gulderblanken und Fuckenthal an der West- und Ostseite des Gulderstocks sind in ihren oberen Partien karartig umgestaltet.

\section{Rundhöcker und Gletscherschliffe}

Als untrügliches Zeichen der ehemaligen Vergletscherung fallen besonders die Rundhöcker und Gletscherschliffe auf. Da die beiden Formen eng miteinander verwandt sind, rechtfertigt sich eine gemeinsame Besprechung. - Im Sernftal finden sich diese Kleinformen der Glazialerosion überall dort, wo die diluviale Vergletscherung hinkam: in der Talsohle, an den Trogwänden und auf den Trogschultern.

In den Talsohlen sind infolge der Schuttbildungen und Moränendecken Rundhöcker und Gletscherschliffe gewöhnlich nicht zu sehen. Sie pflegen aber sofort aufzutreten, sowie sich die Sohle über diese Schuttmassen erhebt. An den Talwän- 
den können die Rundhöcker und Felsglättungen wegen der großen Steilheit und dadurch bedingten postglazialen Abwitterung ebenfalls nur selten beobachtet werden. Das erklärt, weshalb uns die Rundhöckerlandschaften auf den Trogschultern und in den Karen umso ausgedehnter erscheinen. Nicht selten erstrecken sie sich vom Trogrand bis zu den eckig verwitterten Gipfeln.

\section{Hausstockgruppe}

$\mathrm{Da}$ in der Hausstockgruppe außer der schuttbedeckten Talsohle nur wenige flache Gehängepartien vorhanden sind, finden sich entsprechend selten Rundhöcker in größerer Anzahl. Eine Ausnahme bildet der alte Karboden, der sich vom Wichlenberg zum Panixerpaß hinunterzieht und in seiner ganzen Ausdehnung von prächtigen Rundhöckern bedeckt ist. Die Felsrücken sind fast durchwegs von gleicher Größe, wenn der Taveyannazsandstein die Unterlage bildet; in Wildflysch dagegen sind die Rundungen oft nur schwach erkennbar. Ein Beweis, wie sehr die Art des Gesteins auf die Erosionskraft einzuwirken vermag.

Drei wundervoll ausgebildete Rundhöcker zieren den Riegel am Abfluß des Hexenseelis. Mit großer Wahrscheinlichkeit dürfen weitere unter den Trümmermassen in der Gurgel vermutet werden.

Weniger ausgeprägt, aber doch gut erkennbar sind die Rundformen auf der Höhe des Panixerpasses. Sie bedecken nicht nur den Boden an der tiefsten Stelle der Einsenkung, sondern auch die zum Rotstock ansteigende Terrasse.

Einzelne Rundhöcker treten immer wieder auf, wenn das Anstehende aus irgendeinem Grunde aufgeschlossen ist. Diese Stellen sind aus der Karte ersichtlich.

\section{Kärpfgruppe}

In der Kärpfgruppe sind die Rundhöcker fast durchwegs mit dem Auftreten des Verrucanos verknüpft. Das rührt wohl daher, daß dieses Gestein in einer Höhe auftritt, wo die Vegetationsdecke nicht mehr hinzureichen vermag. In unregelmäBiger Ausbildung treten Rundhöcker auf den Absätzein der vom Kärpf absteigenden Kartreppe auf; besser erhalten sind diejenigen auf der Verebnung in der Lücke zwischen Groß- und Kleinkärpf.

Auch auf der Terrasse zwischen Schwarztschingel und Bleitstöcke sind neben schwach gewellten Felspartien gut ausgebildete Rundhöcker vorhanden. Am eindrücklichsten aber erscheinen die Felsbuckel auf dem Wildmaad. Die durch kleine K.anten gestufte Hochfläche ist in ihrer ganzen Ausdehnung von Rundhöckern bedeckt, zwischen denen sich kleine, mit Wasser gefüllte Becken befinden. Die Längserstreckung all dieser Buckel weist deutlich gegen die Kühbodenalp. Auch am Gandstock und Karrenstock sind die Verebnungen von Rundhöckern bedeckt, doch treten diese nur spärlich und schwach ausgebildet auf.

Außer im Verrucano treten aber im Kärpfgebiet auch in anderen Gesteinen Rundformen auf. So ist beispielsweise die Terrasse unterhalb des Wichlenmattkarriegels von langen Felsrücken bedeckt, die typisch die glaziale Erosion erkennen lassen. In ihrer unmittelbaren Nachbarschaft finden sich an den Hängen gegen den Leiterberg hinauf rundgeschliffene Felspartien, deren Oberfläche deutliche Schliffspuren aufweisen.

\section{Vorab-Segnesgruppe}

Die Vorab-Segnesgruppe ist geradezu arm an Rundhöckern und Gletscherschliffen. Beide Formen treten hier nur vereinzelt auf und vermögen nie der Landschaft ein besonderes Gepräge zu verleihen. Glatt- und rundgeschliffen erscheinen die Stirnseiten der Schichten am Nordabhang des Vorab. Klassische Formen lassen sich aber nicht feststellen, wenngleich die gerundeten Felsköpfe deutlich genug für die Gletscherwirkung zeugen. 
$\checkmark$ ereinzelte Formen finden sich vorwiegend in den schon besprochenen Karnischen, wobei die Böden des Martinsmaads die besten Spuren aufweisen.

\section{Spitzmeilen-Foostockkette}

Ähnlich wie im Kärpfgebiet sind auch in dieser Berggruppe Rundhöcker in Gestalt konvexer Felsrundungen im Verrucano an reichlichsten erhalten geblieben. Eine typische Rundhöckerlandschaft ist der südostliche Teil von Fässisalp, die Terrasse am Südostfuße des Gufelstockes. Ebenfalls schöne Rundformen beobachtet man auf der Höhe der Widersteinerfurggel, und Gletscherschliffe findet man auf der Westseite im Widersteinerloch.

Die prächtigste Rundhöckerlandschaft des ganzen Sernftales ist die Terrasse « Auf den Kämmen » auf der Westseite des Gulderstockes, wo zwischen den rundgeschliffenen Felsrücken immer wieder kleine Becken ausgeschürft sind. Von gleichem Charakter sind die Felsbuckel an Schönbühlpaß und auf der Terrasse \%wischen Gipsgrat und Spitzmeilen.

Daß die Rundhöcker aber nicht an die Widerstandsfähigkeit des Gesteins gebunden sind, beweisen die welligen Hochfächen auf der Alp Camperdun oberhalb Elm, wo der Flysch die Unterlage bildet. Wieweit jedoch die Humusschicht an der Konservierung der Formen teilnimmt, kann nicht ohne weiteres ermittelt werden, da die Vegetationsdecke keine exakte Beobachtung zuläßt.

\section{Die Schliffgrenze}

Die obere Schliffgrenze ist im Sernftal nicht an ein bestimmtes Niveau gebunden gewesen; je nach der Lage der einstigen Lokalgletscher lag sie bald höher, bald tiefer am Gehänge. Wenn heute nur noch wenige Spuren gefunden werden, so liegt das an der starken Verwitterung, die in den spröden Gesteinen große Fortschritte gemacht hat.

An einigen wenigen Stellen im Kärpfgebiet und in der Spitzmeilenkette fällt aber doch der starke Gegensatz zwischen den eckig verwitterten Gräten und den runden Formen der darunterliegenden Terrassen deutlich in die Augen. Wenir auch dadurch keine eigentliche Trennlinie zwischen ehemais eisfreiem und eisbedecktem Boden entsteht, so kann doch daraus ungefähr die Höhe der Eisbedekkung geschätzt werden.

Im Kärpfgebiet erhebt sich über den Rundhöckerterrassen des Wildmaads eine Anzahl von kleinen Gipfeln, die keine Rundungen durch das Eis mehr aufweisen und somit wohl über dem Eisniveau (ca. $2400 \mathrm{~m}$ ) gelegen haben dürften. Die gleichen Erscheinungen beobachtet man auch am Weißmeilen und an den Risetenhörnern in der Spitzmeilenkette. Der Blattengrat, welcher das Krauchtal im Süden begleitet, zeigt auf seinem Nordabfall ein ähnliches Bild. Doch wird hier die Beob)achtung erschwert, weil nur sehr wenig vom Anstehenden aufgeschlossen ist.

In der Vorab-Segnesgruppe kann keine Schliffgrenze beobachtet werden, da das Eis sich von den höchsten Erhebungen bis ins Tal hinunter ausgebreitet hatte.

Am ehesten wäre die Schliffgrenze in Gebiet der Mündungsschlucht zu erwarten. Doch hatte die dichte Vegetationsdecke, die vom Talboden bis zu den Berggipfeln reicht, keinen Raum für Beobachtungen offen gelassen.

Das Höhersteigen dieser Pseudo-Schliffgrenze in Gebieten ehemaliger Lokalgletscher verursacht derart komplizierte Lageverhältnisse, daß auf Grund der wenigen Beobachtungsmöglichkeiten eine auch nur einigermaßen genaue Höhenbestimmung ausgeschlossen wird. Auf Grund der Moränenausdehnung darf mit Sicherheit angenommen werden, daß zur Zeit des Eishochstandes nur gerade dic höchsten Erhebungen eisfrei geblieben waren. 


\section{Die Seen}

Die im Sernftal auftretenden Seen liegen durchwegs im Gebiet der ersten Talanfänge, namentlich auf den Karböden und den breiten, welligen Hochflächen über dem oberen Rande der 'Taltröge. Sie haben meistens nur geringe Dimensionen. Da sie ihre Entstehung ausnahmslos der Gletscherwirkung verdanken, rechtfertigt sich ihre Einreihung unter die Glazialerosionsformen.

\section{Hexenseeli}

Das am Panixerpaßweg liegende Seelein ist eine kaum $1 \mathrm{~m}$ tiefe Wasseransammlung in einer langen, flachgestreckten Mulde, die durch Bachanschwemmungen langsam ausgefüllt wird. Am vorderen Ende verschwindet das Wasser in einer Spalte des anstehenden Seewerkalkes. Die Form der Mulde, die Lage der Versikkerungsspalte am Rande und die undurchlässige Unterlage aus Wildflysch beweisen, daß es sich um einen Gletscherkolk handelt.

\section{Wildmaadseen}

Auf dem Wildmaad befinden sich eine ganze Anzahl kleinerer Seelein. Es sind alles kleine Wasseransammlungen in den Vertiefungen der glazialen Denudationsfläche. In niederschlagsreichen Jahren sind einige von ihnen durch kleine Wasserläufe verbunden und der unterste Tümpel besitzt dann einen Überlauf in den tiefer gelegenen Kühbodensee. In trockenen Zeiten kann es vorkommen, daß die kleinsten dieser Becken vollkommen austrocknen. Eine kleine Wasseransammlung erfüllt das glazial gebildete Becken zwischen Karrenstock und Gandstock.

\section{Kühbodensee}

Der Kühbodensee befindet sich in einer Wildflyschmulde auf $2040 \mathrm{~m}$ zuoberst in der Kühbodenalp. Das ca. $200 \mathrm{~m}$ lange, sehr flache Becken wird durch ein Nummulitenkalkband abgeriegelt, dessen Scheitel sich um einige Meter über den Seespiegel erhebt. Der Ausfluß des Sees vollzieht sich durch eine Spalte im Nummulitenkalk, wo das Wasser fast $100 \mathrm{~m}$ weit unterirdisch fließt.

BLUMER ${ }^{5}$ zählt den See deshalb zu den Dolinenseen. Die Form der Mulde und die geringe Tiefe lassen jedoch als wahrscheinlich vermuten, da $\beta$ es sich auch bei diesem See um eine glaziale Bildung handelt. Die ganze Uingebung hat typische Karform, und der unterirdische Abfluß ist nicht die Ursache der Beckenbildung, sondern eine nur sekundäre Erscheinung. Auch findet keine Vertiefung mehr statt, sondern der See droht durch eine Schutthalde mehr und mehr ausgefüllt zu werden.

\section{Seelochsee}

Diese auf der Westabdachung des Gipsgrates gelegene Wasseransammlung ist ein Karsee in einer muldenförmigen Vertiefung des alten Karbodens und besitzt einen kleinen Wallmoränenkranz, der vom Ausfluß des Sees durchbrochen wird. Die Verlandung ist infolge der geringen Tiefe schon sehr weit fortgeschritten. Jedenfalls dürfte der See ursprünglich wohl jene Ausdehnung gehabt haben, welche heute von dem ihn umgebenden feuchten Alluvialboden eingenommen wird.

\section{Fässisseen}

Auf dem Karboden von. Fässisalp liegen eine Anzahl kleiner Seen. Die beiden obersten sind in ca. $2200 \mathrm{~m}$ Höhe in eine langgestreckte Mulde gebettet, die sich vom Heustock aus gegen Südosten erstreckt. Die zahlreichen Rundhöcker weisen auf die glaziale Entstehung dieser Seen hin. Möglicherweise hat aber auch die Dolinenbildung Anteil an ihrer Entstehung gehabt; denn die undurchlässigen Quartenschiefer werden am Westufer der beiden Seen vom durchlässigen Rötidolomit begrenzt, der hier in einer Bruchspalte anstößt. 
Rein glazialer Entstehung sind die auf der Westseite des Guntelkamms gelegenen Becken, die in den undurchlässigen Verrucano eingetieft sind.

\section{Fluvialerosion}

Die fluvialen Erosionsformen ältester Zeit sind durch die Wirkungen des Diluviums stark verändert worden. Die Terrassen, Talstufen und Versteilungen zeigen nirgends mehr ihre ursprüngliche Form. Die postglazialen Erosinsformen sind, soweit sie auf die Arbeit des Wassers zurückgeführt werden können, nur spärlich vorhanden. Sie beschränken sich auf Bacheinschnitte, Steilenverlegung und auf Zerstörung der Glazialformen. Von den fluvial angelegten Erosionsformen seien im folgenden Abschnitt die Terrassen, Talstufen und Versteilungen einer eingehenden Besprechung unterzogen, da diese Formen für Talgenese von ausschlaggebender Bedeutung sind. Die Kleinformen haben nur lokale Bedeutung und bedürfen keiner weiteren Betrachtung, da ihre Anlage und Form aus dem Kartenbild hervorgeht.

\section{Die Terrassen}

Die Gehängepartien, die sich aus ihrer Umgebung durch einen etwas kleineren Böschungswinkel herausheben und gemeinhin als Terrassen bezeichnet werden, sind im Sernftal und seinen Nebentälern sehr zahlreich anzutreffen. Nicht alle diese Gehängeverflachungen aber sind von gleicher Bedeutung; und es ist eine wichtige Aufgabe der morphologischen Detailforschung, jene auszuscheiden, die bei der genetischen Deutung für die Rekonstruktion von Talsystemen und Talböden von vorneherein nicht in Frage kommen. Dieses Vorgehen bedingt aber Überlegungen, die nicht mehr rein analytischen, sondern eben teilweise schon synthetischen Charakter aufweisen.

Zur Unterscheidung der für die Talgenese wichtigen Terrassen im Gegensatz zu den übrigen Verflachungen empfiehlt es sich, entsprechende Begriffe zu schaffen. Versuchshalber möchte ich einmal folgende Bezeichnungen anwenden: «Primärterrassen 》 für solche Verebnungen, die für die talgeschichtliche Entwicklung von besonderer Bedeutung sind, oder umgekehrt sogar mit Sicherheit einer ganz bestimmten Phase der Talgeschichte zugeordnet werden können; «Sekundärterrassen 》 sinngemäß für alle übrigen Verebnungen.

Die ursprünglich beabsichtigten Bezeichnungen „Haupt “- und „Nebenterrassen “ mußte ich wieder fallen lassen, da sie zu sehr an Haupt- und Zwischensysteme erinnern; diese Ausdrücke sind aber von $\mathrm{H}$. ANNaHeIM ${ }^{4}$ bereits festgelegt worden und haben sich allgemein eingebürgert. Auch der Ausdruck Erosionsterrasse kann nicht befriedigen, da sozusagen alle Terrassen durch Erosion entstanden sind, wenn es sich nicht gerade um eine Verebnung in einer Akkumulationsform handelt.

Beide Terrassenformen können während ihrer Bildung durch verschiedene Gestaltungsfaktoren begünstigt oder gehemmt worden sein. Als wichtigster Faktor muß neben der Widerstandsfähigkeit des Gesteins die Lagerung der Schichten genannt werden. Diesen Einflüssen kann jedoch bei der Anlage von Primärterrassen meist weniger Bedeutung zugemessen werden als bei den Sekundärterrassen, die ihre Entstehung oft überhaupt nur einem solchen Einfluß verdanken. Gerade deshalb berührt es eigenartig, wenn in der Arbeit Gogartens ${ }^{14}$ über die Terrassen des Linthgebietes die vollständige Unabhängigkeit der Terrassen vom Gestein und dessen Lagerung zu beweisen versucht wird.

$U m$ in der großen $Z$ ahl von Terrassen eine Übersicht zu gewinnen, seien die Primärterrassen tabellarisch zusammengestellt. Damit sind zugleich all jene Formen ausgeschieden, die für die 'Talgenese nicht in Frage kommen. 
2260-2200 Leiterberg ob Wichlenmatt

2240-2180 Wildmaadplateau

Höchgrat a. Heustock $2160-2120$

2200-2150 Berglimatt

2000 Hinter Bischofalp

Bocksmaad $\quad 1980-1930$

Kamm a.Gulderstock $1940-1890$

1930-1910 Obere Kühbodenalp

1930-1870 Oberes Kühtal

Schüpfen

Mittaghorn

$1830-1800$

$1790-1750$

1780-1660 Oberlauelialp

1640-1590 Erbsalp

1600--1580 Oberkreuelalp

1570-1550 Bischofalp

Lauben

1350-1400 Riedboden

1420-1390 Wald

Alp Gheist

1300-1280 Unterkreuelalp

Weißenberge

$1320-1280$

$1280-1350$

\section{Jätztal}

$2520-2360$ südl. Kalkhorn nördl. Rotstock

$2450-2370$
1980 Obererbsalp

\section{Ramintal}

östl. Fährispitz

Kamm südlich

Blattengrat

1950-1900 Geißegg-Herberig südl. Fährispitz

1600-1540 Stäfeli-Sibetsegg

Raminerwald

$2050-2000$

$2010-1930$

1950

$1570-1530$

Krauchtal

Schönbühl-Gulder-

stock

2150 Bützi westl. Foostock

$2240-2200$

1960-1930 westlich

Weißgandstöckli

auf den Saumen

1840 Stuhlegghorn

Obere Hintereggalp $1700-1680$

1370. Trosgialp

Wieleschboden

1300

\section{Miihlebachtal}

Ruchsyten

2230

2200 Auf den Kämmen

1980-2040 Stelliköpfe

Lusermatt-

Glattmatt

$1920-1700$

2040-2010 Oberhalb Jätzalp

Die Höhenzahlen beziehen sich auf den Terrassenrand, da die meisten Verebnungen nur kurz und relativ steil sind.

Gogartin ${ }^{14}$ hat in seiner Zusammenstellung der Terrassen im Sernftal und seinen Nebentälern 131 Gehängeverflachungen herausgegriffen und diese alle als Reste alter Talböden aufgefaßt. Da es sich bei diesen 131 Verebnungen sozusagen überhaupt um alle flacheren Gehängepartien handelt, könnten nach GoGarTeN Sekundärterrassen in unserem Sinne gar nicht existieren. Wenn ich nun einen Großteil der von GoGarten zur Rekonstruktion von alten Talböden benützten Terrassen ausscheide, so sei damit zugleich auch ein Überblick gegeben über die wichtigsten Sekundärterrassen des Sernftales.

Eine große Anzahl der von Gogar'TEN angeführten Talbodenreste sind nicht im anstehenden Fels modelliert, sondern verdanken ihre Entstehung einer jungen Aufschüttung. So ist seine Terrasse von Wartstalden eine gewöhnliche Verflachung in einem Bachschuttkegel. Auf Mittel-Ristenalp sind die Verebnungen auf eine durch einen Bergsturz. veranlaßte Bachaufschüttung zurückzuführen. Als bloße Gehängeschuttanhäufung darf die Terrasse von Käsgaden bei Engi betrachtet werden. - Viele seiner Terrassen liegen auch auf Abhängen mit starker Moränenbedekkung. In einzelnen Fällen mag zwar die Moränenterrasse durch eine unter dem Gletscherschutt liegende Felsterrasse bedingt sein. Da es sich aber meistens um wenig ausgedehnte, flachere Teile einer welligen Moränendecke handelt, sind die Verflachungen oft auf Unebenheiten zurückzuführen, die auf Mächtigkeitsunterschieden oder auf den Untergrundsverhältnissen beruhen. Solche Terrassen wären u. a. Kummerberg bei Engi, Teile auf der Gheist-Alp und Verflachungen oberhalb der Weissenberge. Die Terrasse auf Mittel-Raminalp beruht auf einem Alluvialkegel hinter einer Moräne.

Groß ist aber auch die Zahl der Terrassen, die durch den Wechsel ungleich resistenter Gesteine infolge der Verwitterung entstanden sind, und auch nicht als 
alte Talböden aufgefaßt werden dürfen. Beispiele wären die Terrassen von Brandegg und Hinter-'Trosgialp am Ausgang des Krauchtales. Manchmal handelt es sich auch um Verflachungen, die gar nicht terrassenförmig ausebildet sind, sondern nach oben und nach unten einfach in steilere Teile des Abhanges übergehen. Solche Verflachungen liegen auf Camperdun-Mittelstafel, auf der unteren Embächlialp und in zahlreichen anderen Flyschzonen des Untersuchungsgebietes.

Einige wenige Talbodenreste Gogartens sind gar keine Terrassen, sondern nur flachere Stellen innerhalb eines Grates. Das heißt nicht, daß es sich nicht doch um eine Form handeln könnte, die durch Zerstörung einer Terrasse entstanden wäre; sie aber einfach apriori als alte Talböden zu betrachten ist sicher nicht erlaubt. Als typisches Beispiel sei das Tierbodenhorn genannt.

Wenn aus diesen Gründen fast die Hälfte der von Gogarten angeführten Terrassen als Primärterrassen ausgeschieden werden können, so nähert sich die Zahl schon eher der Menge der von mir beobachteten und als Primärterrassen befundenen Formen. Die zahlreichen Fehlschlüsse Gogartens sind wohl darauf zurückzuführen, daß er seine Terrassen fast nur auf der Karte aufgesucht hat, was für morphologische Studien vollkommen ungenügende Grundlagen gibt. Umso eigenartiger berührt es, wenn A. HeIM im Vorwort zur Arbeit Gogartens diesen als kritischen Beobachter hinstellt.

Ich will in diesem Zusammenhang nicht unerwähnt lassen, daß auch bei der Bildung von Primärterrassen verschiedene Faktoren von maßgebendem Einflul3 gewesen sein müssen. Es ginge nicht an, beispielswveise Härteterrassen allgemein als sekundäre Typen aufzufassen. Oft sind gerade die prachtvoll ausgebildeten Primärterrassen an einen Gesteinswechsel gebunden; besonders auffällig ist diese Tatsache bei den rückläufigen 'Talbodenresten. Wollte man solche rückläufigen Formen nicht einfach ausschließen, so müßten zur Erklärung ihrer Entstehung tektonische Störungen aus jüngster Zeit herangezogen werden. Da aber im ganzen Untersuchungsgebiet keine derartigen Störungen beobachtet werden können, muß die Rückläufigkeit wohl eher mit der Lagerung des Gesteins in Verbindung gebracht werden. Man könnte allerdings noch annehmen, daß es sich um Reste alter Becken handelt ${ }^{32}$, wobei der talauswärts gelegene, höhere Terrassenteil den Abschluß einer solchen Wanne gebildet hätte. Doch fällt auch diese Hypothese dahin, weil die Rückläufigkeit nicht auf beiden Talseiten vorhanden ist, sondern eben nur dort, wo die Gesteine ihren Einfluß auszuüben vermochten. Zahlreiche Terrassen scheinen nur rückläufig, weil die fortgeschrittene Erosion den Rand weiter zurück und dadurch weiter hinauf verlegt hat.

Die Resistenz der Gesteine muß auch bei den Primärterrassen berücksichtigt werden. Gerade in der Flyschzone des oberen Sernftales sind die Terrassen lange nicht so scharf umrissen wie im unteren Talteil. Die geringe Widerstandsfähigkeit des Wildflyschs und der Blattengratschichten haben dafür gesorgt, daß die Ränder der Terrassen schon während der Erosion sehr stark verwischt wurden. Die nachfolgende Verwitterung hat dann mitgeholfen, die Formen noch weiter zu ver. unstalten.

Die geringe Anzahl von Primärterrassen ist wohl darauf zurückzuführen, daß durch die starke Akkumulierung (Schwemmkegel, Bergstürze, Moränen usw.) ein großer Teil gar nicht mehr beobachtet werden kann. Wohl müssen da und dort unter dem Schutt Terrassen vermutet werden. Sie können aber nicht mit Bestimmtheit erkannt werden und dürfen deshalb bei der genetischen Deutung nicht verwendet werden. Im Kartenbild treten sie ebenfalls nicht auf, weil dort nur die beobachtete oder tatsächlich erwiesene Form eingetragen wird. 
Die Arbeit des Wassers bewirkt, daß ein Gefällsknick innerhalb des Längsprofils eines Tales durch die Erosion immer weiter talaufwärts wandert ${ }^{32}$. Die glaziale Überformung durch die Gletscher kann aus solchen Flußsteilen mehr oder minder große Talstufen herausmodellieren. Da auch diese Frage weit mehr dem genetischen Teil der Arbeit angehört, seien hier nur die wichtigsten Versteilungen und Stufungen des Sernftales und seiner Nebentäler beschrieben. Aus dem Längsprofil des Sernfs können drei kleinere Versteilungen herausgelesen werden.

1. Die Mündungssteile. Diese umfaßt den untersten Talabschnitt von Engi bis Schwanden und erstreckt sich über eine Höhendiffierenz von $235 \mathrm{~m}$, bei einer Länge von fast $5 \mathrm{~km}$.

2. Die Steile von Schwendi. Zwischen Matt und Elm liegt eine kleine Stufe von ca. $60 \mathrm{~m}$ Höhe. Die genaue Zahl kann nicht ermittelt werden, da der Sernf nur oberhalb der Steile im Anstehenden flie.st.

3. Die Stufe von Wallenbrugg. An der Vereinigungsstelle des Sernfs (Wichlenbach) mit dem Jätzbach muß eine Stufe angenommen werden. Der Fluß fließt nämlich dort durch mächtige Grundmoränenmassen und besitzt ein außerordentlich starkes Gefälle. Der aus dem Jätztal kommende Bach fließt in seinem eigenen Tal noch kurz oberhalb der Mündung im Anstehenden, mündet dann aber gleichsohlig in den Sernf. Das bedeutet, daß die vorhandene Stufenmündung des Jätzbaches von den mächtigen Moränenmassen bis an ihren oberen Rand aufgefüllt sein muß. Verläßliche Angaben über die Mächtigkeit der Moränendecke können leider nicht gewonnen werden. Immerhin zeigen die folgenden Überlegungen, daß es sich um besonders große Werte handeln muß. $700 \mathrm{~m}$ oberhalb der Vereinigungsstelle fließt der Sernf teilweise noch im anstehenden Fels, wohei die Moränendecke etwa $30 \mathrm{~m}$ tief eingeschnitten werden mußte. Unterhaib Wallenbrugg beträgt die Erosionstiefe des Sernfs in der Moräne stellenweise über $70 \mathrm{~m}$, ohne da $\beta$ das Anstehende aufgeschlossen wäre.

Außer diesen drei Versteilungen passiert der Sernf noch etliche kleinere Gefällsknicke; da jedoch alle durch Akkumulationen verschüttet sind und überdies nur geringe Höhenunterschiede einschließen, dürfen sie für die genetische Deutung nicht in Betracht gezogen werden.

Viel zahlreicher sind die Versteilungen in den Nebentälern. Da in den höheren Regionen die Akkumulationen nur geringe Mächtigkeit haben, und die Flüsse und Bäche daher oft im Anstehenden fließen, sind diese kleinen Versteilungen immer sehr gut erkennbar. So durchfließt der Jätzbach eine ganze Anzahl von teilweise gewaltigen 'Talstufen. Die verschiedenen Stufen des 'Tschingelbaches haben wir schon bei der Besprechung des Martinsmaadkars kennengelernt. Welche dieser Stufen für eine Einordnung in Talbodensysteme in Betracht fielen, soll hier nicht abgeklärt werden.

\section{Die Stufenmündungen der Seitentäler}

\section{Jätzbach}

Die Höhe der Mündungsstufe dieses vom Panixerpaß kommenden Tales kann nicht mit Zahien belegt werden, wie aus den Beobachtungen der Stufe von Wallenbrugg schon hervorgegangen ist. Der relative kleine Querschnitt des Jätztales in seinem untersten Abschnitt beweist aber, daß dieses Tal lange nicht so mächtig ist wie das breite Haupttal an jener Stelle. Wenn auch für die Höhe der Mündungsstufe die Querschnitte von Haupt- und Nebental keinen Maßstab bilden, so darf doch wenigstens ein Bestehen der Stufe daraus abgeleitet werden. 


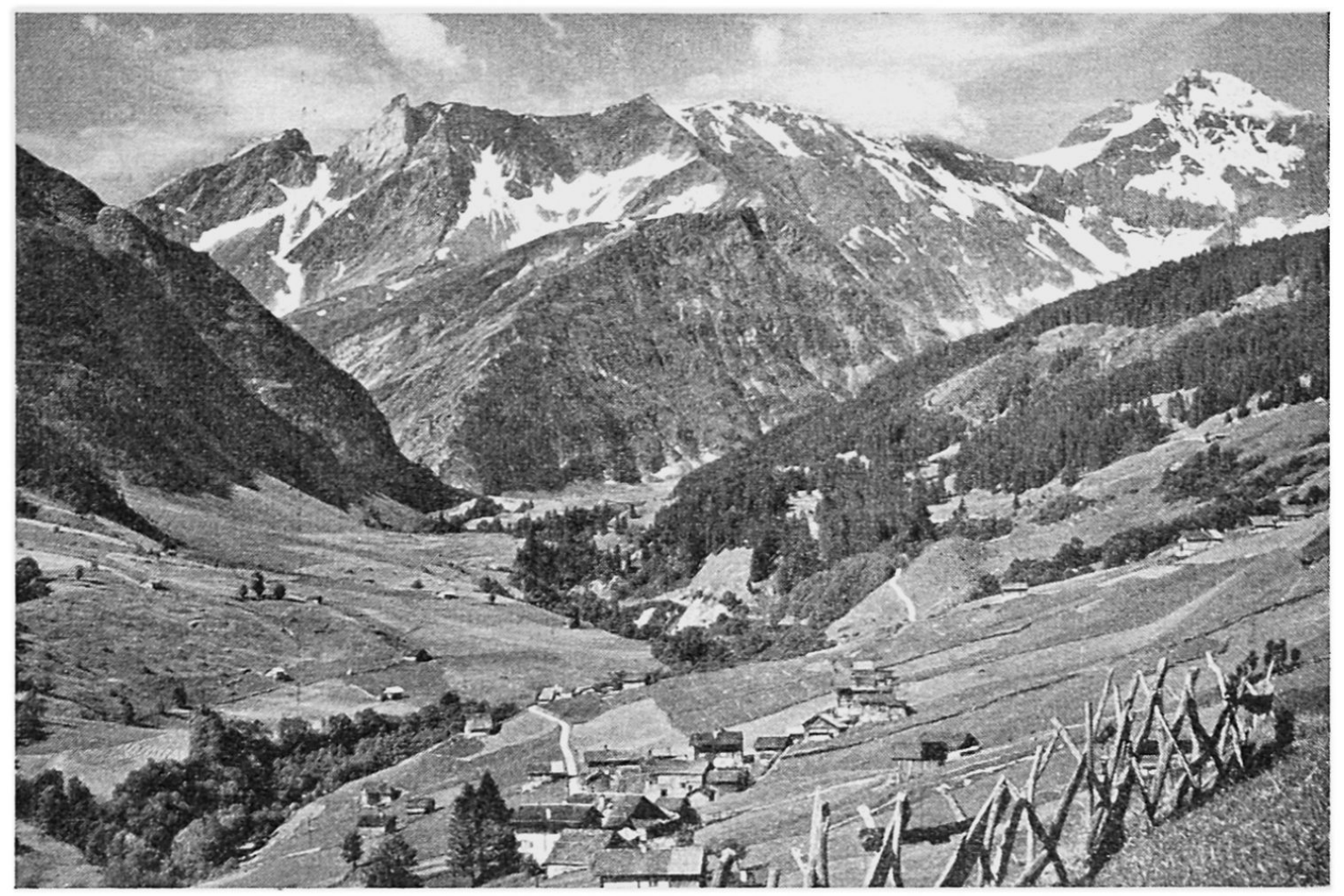

Blick von Hintersteinibach gegen den Talschluß. Links die Mündung des Jätzbaches in den moränenbedeckten Boden von Wallenbrugg; rechts die bewaldete Trogwand unter der Terrasse von Erbsalp. (Photo FreI, EIm)

\section{Tschingelbach}

Der aus dem Martinsmaad kommende 'Tschingelbach durchfließt von der 'Tschingelalp bis Elm eine mächtige Klamm. Die Höhendifferenz, die der Bach in dieser Schlucht überwindet, beträgt rund $300 \mathrm{~m}$; bis zur Vereinigung mit dem Sernf sogar $450 \mathrm{~m}$. Da der Bach die Gesteinsschichten quer zum Streichen durchbricht, muß für diese Mündungsstufe ein hohes Alter angenommen werden. Eigenartigerweise findet man im Bachbett und an den Schluchtwänden keine glazialen Spuren, obwohl am Ausgang der Schlucht eine kleine Wallmoräne liegt, die mit Bestinmtheit dem Tschingelgletscher zugeschrieben werden kann.

\section{Raminbach}

Dieser Nebenfluß des Sernfs hat keine ausgesprochene Mündungsstufe. Das rührt wohl daher, daß vor eine ehemals vorhandene Stufe der Bergsturz von Elm zu liegen kam. Denn kurz oberhalb Düniberg fließt der Raminer-Bach noch im anstehenden Dachschiefer. Dort aber, wo er sein enges Tal verläßt, um ins breite Haupttal zu gelangen, fließt er plötzlich in einem von großen Bergsturzblöcken gesäumten Bett. Wenn auch die Mächtigkeit des Bergsturzschuttes nicht genau festgestellt werden kann, so beträgt sie doch annähernd $100 \mathrm{~m}$. Und es ist nicht unwahrscheinlich, daß ein großer Teil dieser Höhe einer ursprünglichen Mündungsstufe des Raminer-Baches zugeschrieben werden muß.

\section{Krauchbach}

Der Krauchbach gelangt über eine Steilstufe ins Sernftal. Wie alle anderen Nebenflüsse hat auch er die Stufe in einer langen Schlucht durchschnitten. Verlängert man den Talboden vom Eintritt in die Schlucht mit seinem normalen Gefälle bis zum Sernf, so erhält man eine Höhendifferenz von $40 \mathrm{~m}$. Der Moränenschutt 
im obersten Abschnitt der Schlucht beweist, daß diese nicht postglazialer Entstehung sein kann. Wenn nur wenig Moräne vorhanden ist, so ist das darauf zurückzuführen, daß der Bach in der postglazialen Zeit sehr stark ausgeräumt hat. Darauf weisen übrigens auch die Talwände hin, an denen sich nur eine dünne Decke von Gehängeschutt erhalten konnte.

\section{Mühlebach}

Die gleichen Beobachtungen wie bei der Mündungsstufe des Krauchbaches können auch beim Mühlebach gemacht werden, nur daß hier die Höhe der Stufe $220 \mathrm{~m}$ beträgt. Auch ist die Auskleidung mit Moräne weit stärker als beim Krauchbach, was wohl mit der größeren Breite der Mündungsschlucht zusammenhängt. Die Zusammensetzung dieser Moräne liefert übrigens keinen Beweis, daß sie vom Mühlebachgletscher stammt; da sie jedoch in der ganzen Schlucht auftritt, darf sie wohl kaum dem Sernfgletscher zugeschrieben werden.

Außer diesen 5 großen Nebentälern münden aus dem Kärpfgebiet zahlreiche kleine Tälchen ins Haupttal. Da es sich um kleine Wasserläufe handelt, kam es nirgends zu eigentlichen Talbildungen. Die starke glaziale Überarbeitung vermochte aber doch stellenweise eine Stufe zu schaffen, die allerdings später durch starke Zerschneidung wieder aufgelöst wurde. Einzig Bischofbach und Berglibach vermochten etwas breitere Tälchen zu bilden, sodaß es hier auch zu kleinen Stufenmündungen gekommen ist.

Die den Nebenflüssen des Sernf́s zufließenden Gewässer stellen nur kleine Rinnsale dar, die nirgends einzutiefen vermochten. Deshalb fehlen bei ihnen die Mündungsstufen. Meist fallen die Bächlein in einem Wasserfall über die Terrassenränder und zerschneiden diese durch kleine Erosionsrinnen.

Das zur Widersteinerfurggel aufsteigende Seitentälchen des Mühlebachtales ist derart stark von Akkumulationen ausgefüllt, daß keine Stufenmündung beobachtet werden kann.

Bei allen Stufenmündungen des Sernftales zeigt es sich, daß die Anlage sehr alt sein $\mathrm{mu} ß$, da eine starke glaziale Wirkung beobachtet werden kann. Wo die diluvialen Spuren fehlen, kann aus der Größe der Erosion auf ein hohes Alter geschlossen werden.

\section{Karren}

\section{Chemische Erosion}

Im Untersuchungsgebiet treten zwei Karrenfelder auf, die verschiedene Dimensionen aufweisen. Ein größeres bedeckt die oberen Teile der Fässisalp, wo der Rötidolomit die Unterlage bildet. Überall dort, wo die Quartenschiefer anstehen, sind keine Karren zu beobachten. Die Erosionsrinnen sind von verschiedener Größe; ihre Tiefe schwankt zwischen 5 und $30 \mathrm{~cm}$. Die Ränder beweisen, daß sie pustglazialer Entstehung sein müssen, da keine Überarbeitung durch das Eis festgestellt werden kann. Im unteren Teil der Fässisalp verhindert die Vegetationsdecke eine genaue Abgrenzung des Karrenfeldes.

Ein zweites, weitaus kleineres Karrenfeld befindet sich nördlich des Rotstockes am Panixerpaß und bedeckt die Terrasse, soweit der Quintnerkalk anstehend ist. Wie auf der Fässisalp liegen auch diese Karren teilweise auf Rundhöckern; sie müssen aber aus den gleichen Gründen als postglaziale Bildungen betrachtet werden.

Einzelne Karren befinden sich auch an den steilen Malmkalkwänden zu beiden Seiten der Gurgel.

\section{Karrenschlote}

Im kleinen Karrenfeld am Panixerpaß sind ca. 30 Karrenschlote vorhanden. Der Durchmesser beträgt im Mittel $5 \mathrm{~m}$, die 'Tiefe zwischen 3 und $4 \mathrm{~m}$. In nie- 
derschlagsreichen Jahren befindet sich im Schlundloch meistens ein kleiner Schneefleck. Die Schlote sind in drei fast parallelen Reihen angeordnet und liegen auf dem flachsten Teil der Terrasse.

\section{DIE AKKUMULATIONSFORMEN}

\section{Die Moränen}

Neben den Rundhöckern und Karen sind die Moränenbildungen die deutlichsten Zeugen der Glazialzeit. Im Sernftal und seinen Nebentälern treten sie sehr zahlreich auf und sind infolge ihres guten Erhaltungszustandes meist ohne Schwierigkeit zu erkennen. Zur Herkunftsbestimmung können die am Aufbau beteiligten Gesteinsarten benützt werden, was in Untersuchungsgebieten mit einheitlichem Gestein nur beschränkt oder überhaupt nicht möglich ist.

Schwierig gestaltet sich einzig die Bestimmung der Grundmoränendecken. Da schon weit oberhalb Elm der bewachsene Boden einsetzt und nur wenige brauchbare Aufschlüsse vorhanden sind, so ist an vielen Stellen eine genaue Untersuchung und Begrenzung ausgeschlossen. Auch die Mächtigkeit kann oft nur annähernd bestimmt werden, da die Aufschlüsse nicht die ganze Schichtdicke umfassen.

\section{Die Moränen des Hauptgletschers}

Am Talausgang zwischen Wart und Schwanden liegen Ablagerungen des Sernfgletschers; es handelt sich dabei um eine dünne Moränendecke, die nur auf den flachen Gehängepartien zu einer geschlossenen Decke wird. Größere Mächtigkeit erreicht sie nördlich des Sernfs beim Weiler Wart, wo sich auch ein schief über den Abhang herunterlaufender $W$ all abzeichnet. Möglicherweise zeigt er einen längeren Gletscherstillstand an.

Bis oberhalb Elm treten im Talboden keine Moränenbildungen mehr auf. Umso mächtiger werden sie zwischen diesem Dorf und dem Gebiet der Wichlenalp, wo sie den welligen, von zahlreichen Bachschuttkegeln überschütteten Talgrund aufbauen. Den Hauptanteil nehmen die Flyschgesteine ein; daneben finden sich aber auch häufig roter Verrucano und Malmkalk aus dem Vorabgebiet. Daß diese Moränendecke ziemlich mächtig sein muß, zeigt die Eintiefung des Sernfs, welcher stellenweise bis zu $70 \mathrm{~m}$ eingeschnitten hat, ohne das Anstehende aufzuschließen. Endmoränenwälle fehlen vollständig; dagegen treten bei Hintersteinibach auf dem linken Talufer schöne Seitenmoränenwälle auf. Ein etwa $250 \mathrm{~m}$ langer Wall liegt vor der Ausmündung des Bischofbaches, der dadurch aus seiner Richtung abgelenkt wurde. Durch den Straßenbau ist die Morane an mehreren Stellen angeschnitten worden, wo denn auch viele schwach gerundete, dafür gut gekritzte Geschiebe beobachtet werden können. Zwischen Bühlhütte und Wallenbrugg lehnen sich nochmals drei Seitenmoränenwälle an die linke Talseite an. Sie stehen terrassenförmig übereinander und sind talaufwärts gestaffelt.

Wallähnliche Formen beobachtet man auch zwischen Wallenbrugg und Wichlenalp Oberstafel; diese langgezogenen Rücken scheinen aber eher durch Bacherosion entstanden zu sein, so wie die Furche des heutigen Wichlenbaches die Moränenmassen zerschneidet.

Benützt man zur Altersbestimmung dieser dicken und augedehnten Moränendecke die Höhenlage ihres untern Endes bei Elm ${ }^{20}$, so kann man sie zum Gschnitzstadium rechnen. Die Ufermoränen bei Wallenbrugg und am Bischofbach würden als Seitenmoränen ein Rückzugstadium jenes Gletscherstandes anzeigen. Da jedoch Endmoränenwälle vollkommen fehlen, ist eine sichere Altersdatierung ausgeschlossen. 
Mit mächtigen Moränenmassen ist die Terrasse von Alpeli cberhalb Wichlenalp Oberstafel überdeckt. Hangaufwärts stehen sie in direktem Zusammenhang mit den großen rezenten End- und Seitenmoränen des Sernfgletschers. Sie scheinen aber doch bedeutend älter zu sein als diese, da sich die Bäche durch sie hindurch bereits in ihre Flyschunterlage eingeschnitten haben. Ihre mittlere Höhenlage läßt sie dem Daunstadium zugehörig erscheinen.

Prächtige Kränze bilden die rezenten Wallmoränen. Ihre Lage zeigt, daß der Sernfgletscher zur Zeit ihrer Bildung zwei Zungen besessen hat, zwischen denen die Fortsetzung jener vom Wichlengrat heruntersteigenden Felsrippe lag.

Die linke Talseite des Sernftales ist von Elm bis zur Erbsalp weit hangaufwätrs von einer nur selten unterbrochenen Schuttdecke bekleidet. Die darin enthaltenen gekritzten Geschiebe zeigen, daß es sich auch hier um Moränen handelt. Der obere Rand dieser Decke liegt durchschnittlich 3-400 m über der Talsohle, und man könnte deshalb vermuten, daß es sich um Moränen der Seitengletscher aus dem Kärpfgebiet handelt. Da jedoch sehr viele Malmigeschiebe vorkommen, der Verrucano aber stellenweise überhaupt nicht auftritt, ist es wahrscheinlicher, daß auch diese Ablagerungen vom Sernfgletscher stammen. Die Seitenbäche des Sernfs haben stellenweise bis aufs Anstehende erodiert, was aut ein hohes Alter der Moräne schließen läßt. Da sie aber sicher auch älter sein muß als die Ufermoräne von Hintersteinibach, dürfte sie mit großer $W^{\top}$ ahırscheinlichkeit dem Bühlstadium angehören.

\section{Die Moränen in den linken Seitentälern}

Die Ablagerungen in den kurzen, trichterförmigen Seitentälchen, die sich dem Sernftal vom Kärpf her öffnen, beschränken sich meistens auf kleine Moränendekken und Endmoränenwälle in den hochgelegenen, karförmigen Nischen.

Eine dünne Moränendecke liegt im Tälchen, das sich von der Erbsalp zur Kartreppe des Kärpfstockes hinaufzieht.

Ein kleiner Endmoränenbogen in $2150 \mathrm{~m}$ Höhe umsäumt im Hintergrund der Bischofsalp eine Schutthalde. Eine Seitenmoräne leitet zu einem zweiten Endmoränenwall hinunter, der etwa $100 \mathrm{~m}$ tiefer liegt. Etwas deutlicher sind die Endmoränen im oberen Teil der Embächlialp, wo zwei Zungen angedeutet werden, die von den Bleitstöcken herunterkamen. Ein etwa $300 \mathrm{~m}$ langer $W$ all verläuft schräg zum Bach und wird von diesem in der Mitte durchbrochen. Ähnliche Bildungen finden sich auch im Kühbodenalptälchen.

Die auffälligsten sind jedoch die Moränenwälle und Decken der Berglialp. Eine ziemlich mächtige Moränendecke beginnt schon tiet unten im Bachtobel auf $1050 \mathrm{~m}$ und setzt sich durch dans ganze Tal hinauf fort. Bei den Hütten im «Loch» erscheinen zwei parallele, in der Talrichtung verlaufende Seitenmoränen. Zwischen 1600 und $1650 \mathrm{~m}$ liegen zwei Endmoränenwälle, die von einer zwischen Karrenstock und Berglimatt heruntergekommenen Gletscherzunge stammen. Eine zweite Zunge muß vom Wildmaad her durch das Kühtal heruntergeflossen sein, da dort ebenfalls in 1750 und $1900 \mathrm{~m}$ Wallmoränen abgelagert wurden.

Die Moränenwälle, die durchschnittlich auf einer Höhe von $2000 \mathrm{~m}$ liegen, dürfen alle zum Daunstadium gerechnet werden. Älter dagegen sind diejenigen von Berglialp Oberstafel in $1650 \mathrm{~m}$; sie gehören schon ins Gschnitzstadium.

Auf den Terrassen von Riedboden, Wolfental und Kreuelalp liegen ebenfalls Moränendecken, auf denen sich stellenweise Wälle abzeichnen. Ein langer Seitenmoränenwall zieht sich in $1650 \mathrm{~m}$ Höhe von der Berglialp dem Hang entlang bis gegen den Riedboden. Zwei kleine Wälle liegen in $1600 \mathrm{~m}$ bei Wolfental. Drei doppelte Moränenkränze zeigen bei der Hütte von Lauelialp Oberstafel in $1850 \mathrm{~m}$ die Ausdehnungen der Gletscherzungen an, die vom Gandstock herunterflossen. 
Da zur Zeit des Daunstadiums der Gandstock nicht mehr in die Schneeregion geragt hat, muß es sich bei diesen Wällen um Bildungen des Gschnitzstadiums handeln.

\section{Die Moränen in den rechtsseitigen Nebentälern}

\section{Jätztal}

Zwei kleine Endmoränenwälle zieren den Riegel jenes Karbodens, der vom Wichlenberg zum Hexenseeli abfällt. Eigenartigerweise finden sich im hinteren Teil des relativ flachen Bodens keine Moränentrümmer mehr. Das deutet darauf hin, daß die erwähnten Wälle rezenter Entstehung sind oder einen jüngeren Daunstadium angehören.

Eine mächtige, von tiefen Runsen zerschnittene Moränendecke liegt nordwestlich Jätzalp Oberstafel. Sie ist von einer Gletscherzunge abgelagert worden, welche aus der Nische zwischen Kalkhorn und Hagelegg herauskam, und gehört ins Daunstadium. Wenigstens deutet ein Endmoränenwall in $2030 \mathrm{~m}$ darauf hin, wenngleich dieser auch ein Rückzugsstadium dieses Gletscherstandes bezeichnen könnte. Auch die Nische zwischen Kalkhorn und Rinkenkopf hat eine Eiszunge beherbergt, doch sind infolge der mechanischen Verwitterung nur noch am Nordrand einzelne Moränentrümmer zu beobachten. Alles übrige liegt wahrscheinlich unter dem ausgedehnten Gehängeschutt; nur ein stark verbogener Wall hebt sich noch schwach erkennbar aus einem Bachschuttkegel heraus.

\section{Martinsmaad}

Die ehemals vom Segnespaß und vom Vorab herabsteigenden Eismassen haben auf der 'Terrasse von Niederen eine wellige Moränendecke abgelagert, in der vier stark verbogene Wälle erkennbar sind. Sie liegen in $1500 \mathrm{~m}$ und gehören ins Daunstadium. Ein weiterer $W$ all findet sich an der Nordflanke der Tschingelhörner; seine Lage in der Mitte des Kessels rechtfertigt die Annahme, daß es sich um Reste einer Mittelmoräne handelt; auch der unregelmäßige Aufbau deutet darauf hin.

Zwei kleine Wälle liegen auf dem obersten Boden des Martinsmaads. Sie wurden von der Firnzunge abgelagert, die noch vor wenigen Jahren vom Vorabplateau über dic oberste Wandstufe herunterhing.

Ein kleiner Moränenwall liegt am Ausgang der Tschingelschlucht in der Geeren. $\mathrm{Er}$ ist deutlich zu erkennen, läßt sich aber weder dem Tschingelgletscher noch dem Ramingletscher mit Bestimmtheit zuordnen, da er vollkommen bewachsen ist und kein Anriß über seine Zusammensetzung Aufschiuß gibt. Doch dürfte er wohl eher vom Tschingelgletscher abgelagert worden sein, da auch auf dem linken Ufer des Tschingelbaches eine kleine Moränendecke erhalten geblieben ist.

\section{Ramintal}

Der Raningletscher hat sein Hauptsammelbecken in Gebiet des Foopasses gehabt. Er scheint aber mächtigen Zufluß aus dem Sardonamassiv erhalten zu haben, worauf die ausgedehnten Moränenmassen im Ramin- und Camperdunwald hinweisen. Wenngleich eine scharfe Abgrenzung dieser Trümmer zum allseitig verbreiteten Flyschschutt nicht möglich ist, so geben doch zahlreiche Aufschlüsse am Alpweg und an den verschiedenen Bacheinschnitten gebührend Auskunft. Die gekritzten Geschiebe an diesen Fundstellen sind fast ausschließlich Gesteine des Wildflyschs, doch sind auch Verrucanotrümmer vorhanden.

Während der untere Teil des Ramintales nur Grundmoräne aufweist, sind im oberen Teile deutliche Wälle anzutreffen. So erkennt man bei Ramin Mittelstafel in $1750 \mathrm{~m}$ zwei bogenförmige Endmoränenwälle, die einen längeren Gletscherstillstand anzeigen. Sie gehören wohl einem Rückzugsstadium der Gschnitzzeit an; denn zur Zeit der maximalen Ausdehnung des Gschnitzstadiums muß der Gletscher 
weit größer gewesen sein, während im Daunstadium die Schneegrenze schon zu hoch lag ${ }^{20}$, als daß ein so großer Gletscher hätten entstehen können.

Beim weiteren Rückzug des Gletschers sind dann die drei niedrigen Seitenmoränenwälle entstanden, die sich zwischen Mittelramin und Ramin-Matt aufbauen.

Auf $2050 \mathrm{~m}$ liegt ein halbkreisförmiger Wall, der die Endmoräne der zwischen Grünenspitz und Foostöckli gelegenen Gletscherzunge darstellt. Gleichzeitig muß der auf gleicher Höhe am Foopaßweg liegende Wall abgelagert worden sein. Wahrscheinlich stammt er von einer Eiszunge, die von P. 2445 herabhing. Wenigstens deuten die vielen Quarzitblöcke in der Moräne auf diesen Gipfel hin. Da im Daunstadium die Schneegrenze in ca. $2300 \mathrm{~m} \mathrm{lag}$, sind die beiden Moränenwälle in jener Zeit abgelagert worden.

In $2150 \mathrm{~m}$ Höhe liegt am Foostöckli ein weiterer Wall, der ein Rückzugsstadium der Daunzunge anzeigt.

Weitere Ablagerungen liegen auf dem südlichen Teil des Ramintales, auf der Falzüberalp. Die in den Moränen enthaltenen Gesteine beweisen, daß es sich um Ablagerungen der von der Sardona kommenden Hängegletscher handelt. Auf dem Unterstafel liegt eine dichte Moränendecke, die derjenigen im Camperdunwald entspricht und dem Gschnitzstadium angehört.

Die auf Stäfeli $(1670 \mathrm{~m})$ liegenden Endmoränenwälle mögen ebenfalls zum Gschnitzstadium gehören, während die wallartig aufgetürmten Verrucanoschieferblöcke bei Horn (1950 m) sicher dem Daunstadium zuzuschreiben sind.

Auf der Terrasse von Kamm (südlich Blattengrat) liegt ein schwach erkennbarer Wall aus gekritzten Wildflyschtrümmern. Seine Höhenlage entspricht fast genau derjenigen des Walles am Foostöckli. Er gehört somit ebenfalls ins Daunstadium.

\section{Krauchtal}

An den Abhängen des Krauchtales liegen bei Vordereggalp und im Talhintergrund bei Werben ausgedehnte Moränendecken mit stark gewellter Oberfläche. Die Abgrenzung gegen den Gehängeschutt und das Anstehende ist infolge der Vegetationsdecke oft unsicher. Doch geben zahlreiche Fundstellen von gekritzten Trümmern genügend Aufschluß. Die Moränen bestehen größtenteils aus Flyschgesteinen und Verrucano; doch findet man auch Rötidolomit aus dem Gebiet des Spitzmeilens.

Leider ist der ganze hintere Teil des Krauchtales sehr stark ron Gehänge- und Bergsturzschutt überzogen, sodaß keine Moränenwälle mehr anzutreffen sind. Aus diesem Grunde können auch keine Vermutungen über das Alter der Moränendecke angestellt werden.

Am Südabhang des Gulderstockes liegt eine außerordentlich mächtige und umfangreiche Grundmoränendecke. Sie bedeckt die Terrassen von Matt und Fitternstafel und reicht bis auf die Weißenberge hinunter. Sie fällt durch ihre stark gewellte Oberfläche auf; zudem wird sic von mehreren Wällen begleitet. Zwei deutliche Endmoränenbogen und Seitenmoränenwälle in $1500 \mathrm{~m}$ und $1650 \mathrm{~m}$ zeigen die Gletscherstände während des Gschnitzstadiums an. Zwei weitere liegen auf der Terrasse von Kamm in $1950 \mathrm{~m}$ und $2050 \mathrm{~m}$ und gehören ins Daunstadium.

\section{Mühlebachtal}

Die Ablagerungen des Mühlebachgletschers sind ebenfalls beträchtlich. Große Moränendecken liegen auf den Abhängen des Gulderstockes, des Gufelstockes und den 'Terrassen von Lusermatt und Glattmatt, sowie bei Pulstern am Ausgang ins Sernftal. Im hinteren Talteil besteht die Schuttdecke vorwiegend aus Liastrümmern und Verrucano; im vorderen Teil finden sich auch Flyschgesteine. An zahlreicher Stellen lassen sich gekritzte Geschiebe beobachten, besonders am Wege zwischen Engi und Üblital, sowie in kleinen Rutschungen bei Pulstern. 
Moränenwälle sind wie im Krauchtal auch hier nicht zahlreich anzutreffen. Zwei große Wälle ziehen sich über die Gulderblanken nach Gans hinunter. Sie werden von kleineren Seitenwällen begleitet; die Abgrenzung zwischen Endmoränenwall und Seitenmoränenwall ist auf beiden Seiten des Baches sehr schwierig, da sich im unteren 'Teil ein Bergsturz anlehnt und im oberen Teil ein Schwemmkegel über die Moränenmassen ergossen hat.

Die mittlere Höhe der ausgedehnten Wallmoränen liegt auf $1800 \mathrm{~m}$, gleich hoch wie die Wälle im Hintergrund des Mühlebachtales. Sie gehören wie diejenigen auf der Südseite des Gulderstockes ins Gschnitzstadium.

Am Südfuße des Magerrain liegt ein kleiner Moränenwall in $2100 \mathrm{~m}$. Er stellt das Rückzugsstadium einer von diesem Gipfel kommenden Gletscherzunge dar.

Am Südabhang des Gufelstockes liegen Moränen, die von kleinen selbständigen Gletschern stammen. Die Ablagerungen bedecken als wellige Schuttdecke einen großen Teil der Gheist-Alp. Ein deutlicher Wall liegt auf der Ostseite der Stafelruns und stammt von einem Gletscher, der vom Guntelkamm herunterhing. Zwei weitere Wälle bezeichnen das Gschnitzstadium des Fässisalpgletschers, und ein schöner Endmoränenwall in $2200 \mathrm{~m}$ begrenzt die Ausdehnung im Daunstadium.

\section{Diluviale Schotter}

Am Ausgang des Sernftales bei Schwanden findet man geschichtete sandige Kiesmassen von geringer Ausdehnung, die mit Moränen in Verbindung stehen und durch Schmelzwasser abgelagert worden sind. Sie liegen hinter dem Trümmerwall des Bergsturzes von Glärnisch-Guppen, wo Linth und Sernf aufgestaut wurden. F. JENNY ${ }^{21}$ konnte nachweisen, daß die durch den Bergsturz veranlaßte Kiesaufschüttung sich etwa $3 \mathrm{~km}$ ins Sernftal hinein fortsetzte, wobei ihre Oberfläche bis zu den östlichsten Häusern von Wart um etwa $50 \mathrm{~m}$ anstieg. In den Aufschlüssen, die durch eine Wasserkatastrophe im Jahre 1910 bei den Häusern von Wart entstanden waren, beobachtete er unter einer ca. $10 \mathrm{~m}$ mächtigen Grundmoränendecke eine $20-25 \mathrm{~m}$ mächtige Flußablagerung. Diese besteht aus horizontalen Sand- und Kiesmassen, welche bis auf die heutige Talsohle hinunterreichen. OBERHOLZER 29 beobachtete bei den Grabarbeiten für die Druckleitung des Sernf-Niederenwerkes (1930/31) am Fuße der Staukiesmasse eine blaugraue, geschiebefreie Lehmmasse; dies beweist, daß wenigstens in der ersten Zeit nach dem Bergsturz ein Stausee vorhanden gewesen sein muß.

Die auf der Bergsturzmasse und den Staukiesmassen aufgelagerten Moränen beweisen, daß der Bergsturz vor dem Ende der Eiszeit, wahrscheinlich in der Zeit zwvischen Bühl- und Gschnitzstadium, niedergegangen ist. Die Übergletscherung trat jedenfalls erst ein, nachdem die Stauschottermassen und der Bergsturz bereits wieder durchtalt waren. Da die Schotterakkumulation, aber auch die nachfolgende Erosion sehr mächtig war, muß die der Übergletscherung vorausgehende eisfreie Periode entsprechend lange gedauert haben.

Die regelmäßige Bildung der Schotterschichten und das gänzliche Fehlen von gekritzten Geschieben oder eckigen Blöcken beweisen, daß zur Zeit der Ablagerung das Gletscherende nicht in der Nähe lag, sondern sich weit in den Talhintergrund zurückgezogen hatte.

\section{Die Bergstürze}

Das Sernftal ist reich an Bergstürzen verschiedenster Größe. - Während viele Trümmermassen auf den ersten Blick durch ihre morphologischen Verhältnisse sich als Bergsturz zu erkennen geben, bleibt man in manchen Fällen unsicher, ob es sich um einen Bergsturz oder um eine andere Aufschüttungsform handelt. 
Interglaziale Bergstürze können im Sernftal nicht festgestellt werden. Einige wenige mögen ins Ende der Diluvialzeit gehören; die Mehrzahl ist aber postglazialer Entstehung. Einige Bergstürze haben in der neuesten Zeit stattgefunden oder sind durch schriftliche Urkunden bestätigt.

\section{Hausstockgruppe}

Die Moränen von Wichlenalp Oberstafel sind mit Trümmern eines Felssturzes bedeckt, der sich im Winter 1881/82 hoch oben am Leiterberg unter dem P. 2446,6 $\mathrm{m}$ ablöste. Die aus Flyschgesteinen bestehende Felsmasse stürzte zum Bach hinunter, floß durch das Bachbett gegen Osten und strömte dann nordwärts bis zur Einmündung des von Wichlenmatt kommenden Baches. Ein Nachsturz fand im Januar 1942 statt, wobei die Alphütten von Wichlenalp Oberstafel fast vollständig zerstört wurden. Bei beiden Stürzen errreichte die 'Trümmermasse eine außerordentlich große Beweglichkeit, weil sie stark mit Lawinenschnee vermischt war. Der obere Rand des Trümmerfeldes besteht aus Quarzmassen, die die Klüfte im Flyschsandstein ausgefüllt hatten. Überall findet man ganze Blöcke, die aus Bergkristallen zusammengesetzt sind.

Ein kleines Trümmerfeld bedeckt dic Terrasse von Walenboden oberhalb Jätzalp Oberstafel. Die Felsmasse reicht bis an den FußJ des Rinkenkopfs hinauf. Wenngleich die Ausbruchnische nicht erkennbar ist, so muß der Sturz doch von dort erfolgt sein, da die Schuttmasse aus reinen Kalkblöcken besteht.

Ein noch kleinerer Sturz ist vom Kalkhorn nach Süden niedergegangen und hat auf dem alten Karboden einen scharf begrenzten Trümmerkegel aufgeschüttet.

\section{Kärpfgruppe}

Ein kleiner Felssturz hat im 'Tälchen hinter Erbsalp stattgefunden. Die Ausbruchnische liegt in der untersten Wand der vom Kärpf absteigenden Kartreppe. Der Trümmerstrom floß dem Bach entlang und bildet mit seinen groben Blöcken eine lange Schuttzunge.

Auf der Nordseite der Kühbodenruns dehnt sich eine breite Trümmerzone aus, die von der mittleren Kühbodenalp über Bränderberg ins Sernftal hinunterzieht, wo sie sich fächerförmig verbreitert. Oberhalb ihrer gut erkennbaren Abbruchstelle liegt eine weitere kahle Felsfläche, von der sich ein kleinerer Trümmerkegel losgelöst hat. Die Schuttmassen bestehen bei beiden Stürzen aus wirr durcheinandergeworfenen Dachschiefer- und Sandsteinblocken.

Die gleiche Form besitzt der Bergsturz, der sich nördlich der Benzigenruns von der Geißtal-Alp ins Sernftal hinunter erstreckt. Die Ausbruchstelle liegt unterhalb der Gratkante, welche vom Nägelistock den östlichen Ausläufer bildet.

In der Nacht vom 9. auf den 10. September 1926 stürzte aus dem Felsbande, in welchem sich die Stollen des Landesplattenberges bei Engi befinden, eine große Gesteinsmasse ab. Sie überschüttete den Abhang und den schmalen Talboden bis zum Sernf. Da der Abhang schon vorher mit Schieferschutt des Bergwerkes bedeckt war, entstand nur geringer Kulturschaden. Die Rückwand der Abrißnische ist eine glatte, senkrechte Felsfläche von etwa $30 \mathrm{~m}$ Höhe. Nach dem vom Kantonsgeometer erstellten Situationsplan ist die Abrißfläche etwa $120 \mathrm{~m}$ lang. Die größte Breite der Ablagerung beträgt $200 \mathrm{~m}$. Nach den Berechnungen des Herrn WILd (Kantonsgeometer) besitzt die Sturzmasse ein Volumen von $90000 \mathrm{~m}^{3}$. - Ursache des Sturzes war der Bergwerksbetrieb. Das Ausgleiten der unterhöhlten Felsmassen wurde zudem noch durch die geologischen Verhältnisse begünstigt, da die Schieferplatten mit etwa $20^{\circ}$ Neigung gegen das Sernftal abfallen.

Ein weiterer Bergsturz bei Engi erfolgte im Mai 1948. Aus einer Felsnische im Engiwald stürzte eine kleine Schiefermasse gegen die Station Engi-Vorderdorf 
hinunter und überschüttete den Sernf oberhalb des Staubeckens. Brücke und Straße wurden stark beschädigt.

Zwischen der Engiruns und dem Kreuzplattenzug ist die linke Talseite von einer ausgedehnten Schuttmasse bedeckt, die aus großen, mächtigen Blöcken besteht und ganz den Eindruck einer Bergsturzmasse macht. Die riesigen Verrucanotrümmer scheinen aus einer Nische westlich der Hütten von Lauelialp Mittelstafel ausgebrochen zu sein. Der obere Rand dieser Nische liegt in 1960 m Höhe. Die üppige Vegetation läßt leider die Sturzbahn nicht erkennen; es muß sich aber um einen alten Bergsturz handeln, da die Trümmermasse im ưnteren Teil schon von mehreren Bachschuttkegeln überdeckt ist.

Zwei Felssturze liegen in der Nische zwischen Gandstock und Berglimatt. Die Trümmerströme haben sich zu einer langen $Z$ unge vereinigt, welche sich in den oberen Teil der Engiruns ergießt.

Ein kleiner Felssturz erfolgte vom Hohberg gegen Berglialp Oberstafel und hat auf der linken Bachseite die Moränen stellenweise überschüttet.

\section{Vorab-Segnesgruppe}

Ein prachtvoller Bergsturz von ziemlich großer Dimension bedeckt den untersten Teil der Jätzalp. Seine Abbruchnische ist an der hohen Malmwand des Glarner Vorab noch deutlich zu erkennen. Die Trümmermasse stürzte zu den Hütten «Im Loch» hinunter, wo sie sich fächerförmig ausbreitete. Der Jätzbach ist dadurch ganz an die linke Talseite gedrängt worden. Der Schuttstrom ist deutlich gegliedert: in die im Talhintergrund liegende Hauptmasse, welche sich bis an den Talausgang erstreckt, und in die Nachhut, welche oberhalb des heutigen Paßweges liegen geblieben ist. Die beiden Teile sind durch einen schmalen Trümmerkegel miteinander verbunden.

Ein kleiner Bergsturz ging im Jahre 1941 am Segnespaß nieder. Seine Abrißnische liegt genau südlich der $\mathrm{Pa}$ ahöhe, und der Trümmerkegel zieht sich längs des $\mathrm{Paßweges} \mathrm{gegen} \mathrm{Westen.}$

\section{Der Bergsturz von Elm}

Der Bergsturz von Elm ist einer der größten historischen Bergstürze in der Schweiz. Das Ereignis ist von $\mathrm{A}$. $\mathrm{HEIM}^{16}$ eingehend geschildert worden und gab Anlaß zum Studium der Gesetze der Bergsturzbewegung ${ }^{17}$. Es seien deshalb im folgenden lediglich die wichtigsten Tatsachen erwähnt.

Durch einen im Tagbau betriebenen Schieferbruch war der steile Hang des Tschingelberges stark untergraben worden. Dadurch bildete sich im Tschingelwald langsam eine Bruchspalte, die im Jahre 1881 rasch an Länge und Tiefe zunahm. Nach einer längeren Schlechtwetterperiode stürzte die gelöste Felsmasse am Sonntag, den 11. September ab. Der Hauptsturz erfolgte abends um 17.36 Uhr, nachdem schon im Laufe des Nachmittages zwei kleinere Vorstürze stattgefunden hatten. Eine riesige Felsmasse von ca. 10 Mill. $\mathrm{m}^{3}$ Inhalt stürzte fast senkrecht einige hundert Meter auf eine Terrasse nieder, von wo aus sie in einem Sprung durch die Luft ins Untertal fiel. Als breiter Trümmerstrom fuhr sie daraufhin dem Boden entlang, brandete etwa $100 \mathrm{~m}$ hoch am gegenüberliegenden Abhang hinauf, wurde dort um etwa $50^{\circ}$ nach links abgelenkt, um auf dem breiten Talboden als riesiger Schuttstrom noch etwa $1 \frac{1}{2} \mathrm{~km}$ talauswärts zu fließen.

Das Abrißgebiet ist ca. $250 \mathrm{~m}$ hoch, $450-500 \mathrm{~m}$ breit und fast $100 \mathrm{~m}$ tief. Es stellt eine unregelmäßige, flachmuschlige Nische dar, deren obere Kante $600 \mathrm{~m}$ über dem Talboden liegt. Die Schuttmasse besteht aus Dachschiefern, Blattengratschichten und Nummulitenkalk. Der Trümmerstrom war ringsum scharf begrenzt und bedeckte ein Areal von 58 ha. Durch den Bergsturz wurden 115 Menschen verschüttet und 83 Gebäude zerstört.

Das Trümmerfeld wurde nördlich vom Untertal bald nach dem Bergsturz urbarisiert; eine zweite Partie im Untertal selbst erst im Jahre 1912. Nur im östlichen Teil des Untertales und am Düniberg liegen heute noch unveränderte Reste des Trümmerfeldes. Ein gewaltiger Schieferblock von $15 \mathrm{~m}$ Länge, $10 \mathrm{~m}$ Höhe und ebenso großer Breite wurde inmitten fruchtbarer Wiesen und Äcker als Denkmal stehen gelassen.

Foostock-Spitzmeilenkette

Unklar ist die Entstehung des Trümmerfeldes von Camperdun Unterstafel im Ramintal. Mächtige, wirr durcheinandergeworfene Nummulitenblöcke bedecken 
den unteren Teil dieser Alp und reichen fast bis an den oberen Rand der Brandungswelle des Elmer Bergsturzes hinunter. Der westliche Teil dieser Trümmer stammt wohl aus einer Nische in $1670 \mathrm{~m}$ beim Kalberboden; der östliche Teil dagegen scheint eher eine Rutschung zu sein, welche gleichzeitig mit dem Bergsturz niedergegangen ist. Die Blattengratschieferpakete, mit denen der Wald- und Weideboden bei Ramin Unterstafel bedeckt ist, sehen wenigstens ganz so aus, als ob sie von einem Felsrutsch stammten.

Die Abgrenzung der Trümermasse und die Trennung zwischen Bergsturz und Rutschung ist sehr schwierig, weil eine dichte Vegetationsdecke vorhanden ist.

Im Krauchtal liegt ein kleiner Felssturz am Eingang in die Risetenalp. Die Abrißnische ist an der Schieferwand unter der Terrasse "In der Schnur» deutlich sichtbar. Die Trümmermasse besteht aus Schiefer und Nummulitenkalk. Der Schuttstrom hat sich bis in die Talsohle ergossen, wo der Bach auf die rechte Talseite gedrängt wird.

Nördlich eines Bachschuttkegels, der das genannte kleine Trümmerfeld im Norden begrenzt, liegt die ausgedehnte Trümmermasse eines riesigen Bergsturzes. Von Westen her bietet er den Anblick eines großen Schuttkegels, der sich an die Gipfelwand der Risetenhörner anlehnt und bis zum Krauchbach hinunterreicht. Die Schuttmasse ist am Fuße fächerförmig verbreitert, doch hat sich kein eigentlicher Trümmerstrom entwickelt. Die Oberfläche des $1,5 \mathrm{~km}$ langen und an der Basis $1 \mathrm{~km}$ breiten Schuttkegels besitzt die charakteristischen wellenförmigen Unebenheiten. Auffällig ist die im mittleren Teil gelegene, flache Terrasse von Risetenalp Mittelstafel. Da das Trümmerfeld vorwiegend aus Verrucanoschiefern und Wildflysch besteht, ist die Oberfläche arm an großen Blöcken. - Die Abrißfläche ist die etwa $200 \mathrm{~m}$ hohe Gipfelwand der Risetenhörner. Doch gehört die Nische, in welcher der Risetenpaß den Grat überschreitet, offenbar nicht mehr zum Abrißgebiet, sondern war schon vorher vorhanden. - Die ziemlich starken Veränderungen, die der Rand des Trümmerfeldes durch neue Schuttbildungen erfahren hat, beweisen, daß es sich um einen alten Bergsturz handeln muß; mangels aller Gletscherwirkungen auf seiner Oberfläche muß er jedoch postglazialer Entstehung sein.

Ein ausgedehntes Trümmerfeld lehnt sich im Westen an den Faulenstock an. Die Schuttmasse hat wohl ebenfalls bis zum Krauchbach gereicht, ist aber heute von drei Bachschuttkegeln bedeckt. Die Abrißnische wird an ihrem oberen Ende von einer etwa $350 \mathrm{~m}$ langen Bergkante begleitet, die an zwei Stellen kurz unterbrochen ist. Über die Mitte des Trümmerfeldes hat sich der Schwemmkegel der Stafelruns gelegt, und auch der nördliche und südliche Rand der Bergsturzmasse sind von Schuttkegeln überdeckt. Es dürfte sich wohl auch bei diesem Bergsturz um ein praehistorisches Ereignis handeln.

Von der steilen Südwand des Schönbühls hat sich ein Bergsturz gelöst, dessen Trümmerfeld bis nach Werben hinunterreicht. Die Abrißnische liegt noch unterhalb der ausgedehnten Terrasse, die sich zwischen Spitzmeilen und Gipsgrat erstreckt.

Auf der Westseite des Gipsgrates liegt unterhalb der Stelliköpfe ein Trümmerfeld, das von einem Bergsturz herrührt, welcher aus der Terrasse «Auf den Kämmen》 ausgebrochen ist. Der Terrassenrand ist auf einer Strecke von etwa $120 \mathrm{~m}$ abgebrochen, und der Schutt hat eine wellige Zunge aufgebaut, die sich bis an den Mühlebach hinunterzieht. Der südliche Rand des Trümmerfeldes liegt auf Grundmoräne auf; der Sturz ist somit postglazial.

Ein kleiner Felssturz ist an der Südwand des Magerrains niedergegangen. Die Liastrümmer bedecken die dünne Moränendecke auf dem Karboden von Mühlebachalp. Die Abrißnische wird von einem kleinen Felswändchen gebildet, welches sich durch die Wand des Magerrains durchzieht. 
Der westliche 'Teil der Gulderblanken am Nordabhang des Gulderstocks wird von $1950 \mathrm{~m}$ bis an den Mühlebach hinunter von einem Schuttmantel bedeckt, der von einem alten Bergsturz am Guiderstock herrührt. Der Schuttstrom scheint am Abhang des Übeliserwaldes emporgebrandet zu sein und ist dann noch etwa $300 \mathrm{~m}$ talauswärts geflossen. Die Ausbruchnische ist identisch mit dem Kessel auf der Nordseite des Gulderstockgipfels. Da jedoch nach dem Bergsturz die Nische nochmals von einem Gletscher ausgefüllt war, sind die ursprünglichen Formen glazial rerwischt worden. Ein sicherer Beweis für die diluviale Entstehung des Bergsturzes ist die Tatsache, daß die Gschnitzmoränen in clen Gulderblanken auf dem Bergsturzschutt aufliegen. Der Sturz dürfte wohl gegen das Ende der Eiszeit erfolgt sein; wahrscheinlich zwischen Bühl- und Gschnitzstadium.

Ein weiterer Bergsturz ist westlich P. 1926,5 der Wieleschegg niedergegangen. Die Abbruchstelle liegt unterhalb eines Felsbandes; der Trümmerstrom hat sich bis zum Bach hinunter fächerartig ausgebreitet. Zwischen dem untersten Rand des Schuttstromes und dem Bach liegt noch ein schmaler Saum Moräne. Leider kann man nicht feststellen, ob die Moräne auf dem Bergsturzschutt oder darunter liegt, da die Grenze infolge Überwachsung nur ungenau bestimmt werden kann. Da jedoch der rechte Rand des Trümmerfeldes bei Üblital auf Grundmoränen aufliegt, darf der Sturz wohl eher in die Postglazialzeit versetzt werden.

Ein mächtiger Bergsturz ist von der Kühfitternalp gegen Engi niedergegangen. Das Fehlen größerer Blöcke und die schwache Wellung der Oberfäche lassen zwar Grundmoräne vermuten. Doch ist das Gesteinsmaterial für Moräne zu einförmig; der Schutt besteht ausschließlich aus Gesteinen, die in der Nische unter Kühfittern Oberstafel anstehend sind, wobei der Verrucanoschiefer am stärksten vertreten ist. Im obersten Teil des Trümmerstromes ist eine Verrucanoschiefermasse mit erhaltengebliebener Schichtung abgerutscht. - Im mittleren Teil des Trümmerfeldes hat die Kühfitternruns in einer schwachen Erosionsrinne den Dachschiefer schon wieder bloßgelegt; ein Zeichen, daß die Trümermasse nicht so mächtig ist, wie man bei oberflächlicher Betrachtung annehmen könnte. Die unscharfen Formen der Abrißstelle und die fortgeschrittene Verwitterung der Schuttmasse deuten auf ein hohes Alter.

Auf der Alp Gheist liegt ein Bergsturz mit Blöcken aus rotem Verrucanokonglomerat, der von der Felswand westlich des Guntelkamms abgebrochen ist. Der scharf begrenzte Schuttstrom ist noch eine Strecke weit durch den Alpbachgraben hinausgeflossen.

Am Südabhang des Gufelstocks liegt cin ausgedehntes, fächerförmiges Trümmerfeld, das von einem Bergsturz unterhalb P. $2157 \mathrm{~m}$ herrührt. Die Schuttmasse reicht bis nach Engi hinunter, kann aber gegen den ebenfalls aus Verrucano bestehenden Moränenschutt nicht genau abgegrenzt werden.

Außer diesen größeren Bergstürzen haben sich im Untersuchungsgebiet noch eine ganze Anzahl kleinerer Felsstürze creignet, die auf der morphologischen Karte alle eingetragen sind, aber keiner weiteren Besprechung bedürfen.

\section{Rutschungen und Sackungen}

Außer den eigentlichen Bergstürzen, bei denen die Gesteinsmassen in freiem Fall zur Tiefe stürzten, findet man auch Rutschungen oder Sackungen, bei denen die Gesteine ihren Standort durch langsames Gleiten gewechselt haben.

Die Felsrutschung auf Camperdun Unterstafel ist schon im Zusammenhang mit dem nebenanliegenden Bergsturz genannt worden (Seite 119).

Ein weiterer Felsrutsch hat sich im Ramintal südlich vom Fährispitz ereignet. Durch die starke Erosion des vom Blattengrat kommenden Baches sind die von Nummulitenkalk durchzogenen Mergelschichten unterspühlt worden, sodaß die 
herausgearbeiteten Nummulitenkalkbänke auf den weichen Blattengratschichten in Bewegung gerieten. Die geologische Karte gibt zwar an jener Stelle nur Gehängeschutt an; der am unteren Ende der Schuttmasse schwach ausgebildete Stauwall zeigt aber deutlich, daß es sich um einen Rutsch handelt. Die Gesteinsmassen sind nicht vollkommen kompakt geblieben, haben sich aber auch nicht vollständig in Blockschutt aufgelöst.

$Z_{w}$ ei Sackungen liegen nebeneinander im oberen Krauchtal. Unterhalb der 'Terrasse «Auf den Saumen 》 ist der Wildflysch um einige Meter abgerutscht, ohne sich auch nur ein bißchen in Trümmer aufzulösen. Die Abbruchstellen sind infolge der starken Gehängeschuttbildung nur schwach zu erkennen. Ursache ist die starke Verwitterung der Hangfläche gewesen, und das östliche Einfallen der Gesteinsschichten hat das Absacken noch begünstigt.

Blickt man von Elm aus gegen das hintere Sernftal, so macht die Terrasse von Erbsalp ganz den Eindruck einer Sackung. Wie ein mächtiger Wall stößt die Terrasse weit ins Tal hinaus vor und verursacht eine Krümmung im Talverlauf, die zu den parallel und geradlinig verlaufenden Talwänden in scharfen Gegensatz steht. Da jedoch die Moränen nicht nur den Fuß und die Steilwand, sondern auch die Terrassenfläche bedecken, müßte es sich um eine interglaziale, wenn nicht praeglaziale Sackung handeln. Da ich trotz eifrigem Suchen keine weiteren Anhaltspunkte gefunden habe, bleibt es fraglich, ob es sich tatsächlich um eine Sackung handeit. Der in der Terrassenwand anstehende 'Taveyannazsandstein korrespondiert in seiner Lage genau mit demjenigen des Leiterberges. Auch wenn die Ausbruchnische glazial vollkommen umgestaltet worden wäre, müßte sie trotzdem irgendwie erkennbar sein, da die fehlenden Gesteinsmassen mehrere Millionen Kubikmeter betragen würden. Sehr wahrscheinlich hat der am Aufbau der Terrasse beteiligte Taveyannazsandstein als Härtling gewirkt und als mächtige Bastion eine Krümmung in Talverlauf verursacht.

\section{Gehängeschutt}

Die im Sernftal auftretenden Gesteine sind der Bildung von Gehängeschutt fast alle in gleichem Grade günstig. Einzig die Größe der Schuttkörner hängt stark vom beteiligten Gestein ab. So sind die Schutthalden im Verrucanogebiet fast immer durch gröbere Blöcke gekennzeichnet, daß man oft an Felsstürze glauben könnte, während die Schuttbildungen im Flysch meist eine feinere Struktur aufweisen.

Die riesige Anzahl von Schutthalden im Untersuchungsgebiet verunmöglicht zum vorneherein eine Einzelbesprechung; überdies handelt es sich ja um leicht verständliche Erscheinungen.

Schutthalden entstehen infolge der allmählichen Abwitterung und häufen sich vorwiegend am $\mathrm{Fu} ß$ steiler Abhänge an. Mit den Bachschuttkegeln gehören sie zu den jüngsten Ablagerungen des Gebirges und ihre Bildung nimmt heute noch ithren Fortgang. Diejenigen aus der Diluvialzeit sind durch die Gletscher vollständig weggeräumt worden.

Obwohl die Schuttbildungen auf der morphologischen Karte einen breiten Raum einnehmen, haben sie kein sehr großes Volumen. Sie bilden meist nur eine dünne Decke über dem anstehenden Gestein. In Gebieten mit geschlossener Vegetationsdecke ist es oft schwierig, Gehängeschutt und Moränen gegeneinander abzugrenzen. Vereinzelte Aufschlüsse bei Straßen und Wegen zeigen deutlich, daß die dünnen Schuttdecken auf den bewaldeten Steilabhängen weit öfters aus Gletscherschutt bestehen als aus lokalen Schuttbildungen. Auch in den Sammelbecken der diluvialen und rezenten Gletscher kann oft keine scharfe Grenze zwischen echtem Gehängeschutt und dem vom Eis transportierten Schutte gezogen werden. 
Wo die Trümmer durch Steinschlagrinnen oder Lawinenzüge fallen, erzeugen sie sehr oft trockene Schuttkegel. In der Karte sind sic meist an ihrer dreieckigen Form erkennbar, ohne daß dafür eine spezielle Signatur gewählt worden wäre. In der Natur falien sie durch ihre regelmäßige Böschung auf, die zwisçhen 30 und $40^{\circ}$ beträgt.

Sehr oft liegen eine ganze Anzahl solcher Kegel nebeneinander und bilden eine lange Schutthalde. Man erkennt dann den Aufbau daran, da $\beta$ im obersten Teil die Seitenränder der einzelnen Kegel divergieren und die Ansatzstellen der Schutthalden sichtbar werden.

\section{Bachschuttkegel}

Ähnliche Kegelformen wie bei den Schutthalden entstehen auch durch fliel3ende Gewässer, sobald ihre Kraft zum Weitertransport der Gesteine nicht mehr ausreicht. Die Schuttkegel der Bäche liegen deshalb meistens dort, wo der Bach auf die Talsohle eines größeren Gewässers aufstößt.

Die diluvialen Bachschuttkegel sind durch die Gletscher wohl vollständig zerstört worden; die heutigen Bachablagerungen dürfen deshalb als postglaziale Bildungen betrachtet werden. Zusammen mit den Gehängeschuttbildungen liefern sie einen Maßstab für die postglaziale Abwitterung des Gebirges. Die Gesteinsmassen der Schwemmkegel entsprechen aber nicht ganz dem fehlenden Gestein in den Bacheinschnitten, weil ein großer Teil des Geschiebes vom Hauptfluß fortlaufend weiterverfrachtet wird. Zudem sind große Teile des fehlenden Materials schon im Diluvium ausgeräumt worden.

Das Material der Bachschuttkegel wird nur in den wenigsten Fällen dem anstehenden Fels entnommen, da die Erosionswirkung der Bäche im Fels nur gering ist. Meist stammen die Bachgeschiebe aus alten Gehängeschuttbildungen und Moränenmassen, die in das Einzugsgebiet des Baches hineinreichen. Die Größe der Erosionswirkung im anstehenden Fels hängt sehr stark vom Gestein ab. Relativ wenig erodieren die Bäche im Verrucano und im Kalk; bedeutend größer und stärker ist die Erosionswirkung in den weichen Gesteinen der Flyschzone.

Es würde zu weit führen, sämtliche Bachschuttkegel im Sernftal einer eingehenden Betrachtung zu unterziehen. Zudem haben sie alle die gleiche Form und sind von ähnlicher Entstehung. Auf der morphologischen Karte sind sie fast ausnahmslos eingezeichnet.

Kurz erwähnt seien die Schuttkegel des Mühlebaches und des Krauchbaches, welche an ihrer Basis ein mehrere Meter hohes Steilbord besitzen, das von den Einkerbungen alter Bachrinnen durchschnitten ist. Aus diesen Rinnen strahlen kleinere sekundäre Bachschuttkegel aus. Es stellt sich nun die Frage, ob dieses Steilbord durch die Tieferlegung des Sernfbettes entstanden ist, oder ob es bloß eine Folge der Seitencrosion ist. Da der Sernf vor seiner Korrektion durch Dämme stark mäandriert hat, dürften diese Steilborde wohl eher auf seine Seitenerosion zurückzuführen sein.

Von ähnlicher Entstehung wie die Bachschuttkegel sind zahlreiche Alluvialböden auf den Terrassen und Abhängen des Gebirges. Die Bachaufschüttung endet entweder am oder über dem eigentlichen Geschiebeboden. Die Stauung erfolgt vielmals durch Moränenwälle oder durch Felsriegel.

Der ausgedehnteste Schwemmkegel im Sernftal liegt auf der Wichlenmatt, wo der Bach durch einen Riegel aufgestaut wurde. Über den Geschiebeboden, der auch lakustriner Entstehung sein kann ${ }^{21}$, hat der zwischen Kalkstöckli und Hahnenstock herunterkommende Bach einen mächtigen Schwemmkegel aufgescliüttet.

Ähnliche Formen weisen die Schwemmkegel auf der Terrasse von Glattmatt im Mühlebachtal auf, nur daß dort die Bäche durch Moränen gestaut worden sind. 
Das Sernftal ist arm an Torfmooren von größerer Ausdehnung. Die wenigen kleinen Moorbildungen liegen meistens in kleinen Vertiefungen auf Terrassen oder Abhängen. Diese Wannen sind nicht selten mit Moränenschutt ausgekleidet.

Durch den Geschiebeboden und die Moränendecke, die vom Bach und vom Gletscher des Jätztales stammen, ist das kleine Flachmoor entstanden, das südlich der Hütten von Wichlenalp Unterstafel ausgestaut ist. Nach persönlichen Mitteilungen von Frau Dr. HofmanN aus Ennenda, die dort eine Bohrung vorgenommen hat, steht folgendes fest:

An der einzigen Bohrstelle wurden 5,4 m Torf gemessen. Die Pollenuntersuchungen ergaben, da $\beta$ die älteste Ablagerung aus der Eichenmischwaldzeit stammt, also etwa 5-6000 Jahre zurückliegt. Die Pinuszeit, die älteste, ist hier nicht aufgeschlossen, obwohl sie sonst im ganzen Sernftal, auch auf größeren Höhen, auftritt. Es ist aber leicht möglich, daß diese Schicht unter altem Schutt begraben liegt. Dadurch erhält die Wahrscheinlichkeit einer Stauung duch die Seitenmoräne geringere Bedeutung. Wohl eher ist anzunehmen, daß jeweilige Hochwasser des Jätzbaches die Tümpelbildung verursacht haben. So wäre dann auch erklärt, weshalb die einzelnen Schichten durch starke Schuttbildungen voneinander getrennt sind.

Kleinere Moore liegen auf der Wichlenmatt. Auch dort hat Frau Dr. Hofmann Bohrungen vorgenommen und aus den Pollenuntersuchungen ersehen können, da $\beta$ diese Moore schon zur Pinuszeit bestanden haben müssen.

Weitere Moorbildungen finden sich auf der Terrasse von Lusermatt im Mühlebachtal. Ein wenig größer sind diejenigen in hinteren Krauchtal, die durch Stauung infolge Bergstürzen entstanden sind.

Ein erloschenes Torfmoor befindet sich am Südrand des Dorfes Elm. Bei Drainagearbeiten im Jahre 1910 wurden zum ersten Mal unter der Humusschicht etwa $2 \mathrm{~m}$ dicke Torfschichten festgestellt, in denen Reste von Baumstämmen gefunden wurden. Durch die Tieferlegung des Straßenfundamentes im Jahre 1948 wurden diese Schichten nochmals bloßgelegt. Als Unterlage kamen Trümmer von Verrucano, Flyschsandstein und Malmkalk zum Vorschein.

Die geringe Ausdehnung dieser Moore ist wohl der Grund, daß im ganzen Sernftal nirgends mit der Ausbeute begonnen wurde.

Die Moorkarte von $F_{R U ̈ H}{ }^{12}$ enthält nur die wenigsten Moorbildungen des Sernftales.

\section{DIE GEWÄSSER}

Vorkommen, Anlage und Ausbildung der Gewässer im Sernftal gehen mit Deutlichkeit aus der morphologischen Karte hervor und bedürfen deshalb keiner Einzelbesprechung. Es seien im folgenden nur einige Bemerkungen allgemeiner $\mathrm{Na}$ tur angeführt.

Die im Untersuchungsgebiet auftretenden Quellen sind entweder Schichtquellen oder solche, die aus Schuttbildungen ausfließen. Viele dieser letzten haben ihr Sammelgebiet tatsächlich im Schutte selbst. Andere aber kommen aus dem anstehenden Fels und fließen zuerst eine kurze Strecke durch Akkumulationen, ehe sie zutage treten. Die Unterscheidung wird deshalb sehr oft erschwert. - Von den reinen Schuttquellen sind die aus den Moränendecken stammenden die größten. Das rührt wohl daher, daß der Moränenschutt meist aus grobem Felsschutt besteht und deshalb eine große Menge Wasser aufzunehmen imstande ist.

Speziell erwähnt seien zwei Mineralquellen des Sernftales. Eine befindet sich am Südrand des Dorfes Elm und wird von einer Mineralwasserfabrik genützt. Eine zweite Quelle, die Schwefelwasser lieferte, ist eingegangen. Sie befand sich 
auf einer Terrasse südlich der Hütten von Wichlenalp Unterstafel und vurde bis zum Jahre 1762 benutzt ${ }^{13}$. Am 29. Juni jenes Jahres wurde sie durch eine Rüfe verschüttet und zwei Jahre später wurde auch das Badgebäude abgebrochen. 1887 hat A. Herm ${ }^{19}$ eine Abhandlung über die Wiedergewinnung der Wichlenbadquelle verfaßt.

Die fießßenden Gewässer des Untersuchungsgebietes haben sehr oft durch Verheerungen dem Kulturland großen Schaden zugefügt. Aus diesem Grunde sind nicht nur am Sernf, sondern auch an zahlreichen Nebenbächen große Korrektionen durchgeführt worden. - Außer den unterirdischen Abflüssen des Hexenseelis und des Kühlbodensees (S. 105) sind keine Spezialformen zu erwähnen.

Die stehenden Gewässer sind im ganzen Untersuchungsgebiet glazial gebildete Formen und wurden im Abschnitt der Erosionsformen eingehend besprochen.

\section{ANTHROPOGENE FORMEN}

Die anthropogenen Formen sind, soweit sie mit der Morphologie in Zusammenhang stehen, im Untersuchungsgebiet nur spärlich anzutreffen. Sie beschränken sich auf Kiesgruben, Steinbrüche und Verbauungen gegen die Kraft der Lawinen oder der Wildwasser. Die durch Ausbeutungsstellen geschaffenen Anrisse sind für die Geologie von weit größerer Bedeutung als für die Morphologie.

Immerhin vermochten die Schieferbrüche von Engi und Elm ihren Einfluß auf die Oberfläche der Umgebung in nur zu starkem Maße auszuüben. Denn durch den Tagbau am Plattenberg ob Elm ist der mächtige Bergsturz ausgelöst worden. Und auch der Sturz am Landesiattenberg bei Lingi ist auf den Bergwerksbetrieb zurückzuführen. Im Umfang des Elmer Bergsturzes ist wohl kein anderes Naturereignis $\mathrm{zu}$ finden, welches seine Entstehung der Menschenhand verdankt.

Von besonderem Gepräge sind die gcwaltigen Lawinenverbauungen. Die größten befinden sich am Ausläufer des Schafgrindspitzes östlich vom P. 1722,2 m. Diese ausgedehnten Sicherungsmaßnahmen haben die Aufgabe, den hochgelegenen Jungwald vor der Zerstörung durch abgleitende Schneemassen zu schützen. Nördlich P. 1722,2 $\mathrm{m}$ liegt in den schroffen Hängen der Benzigenruns das Nährgebiet der Meißenbodenlaui. Gegen diesen Lawinenzug sind bis jetzt noch keine Verbauungen erstellt worden, sodaß die Lawine jeden Winter ein- bis zweimal niedergeht und den Verkehr im Talboden nicht selten für Tage zu unterbrechen vermag.

Weitere Lawinenverbauungen befinden sich ain Stuhlegghorn ob Matt, südlich von P. $1838,1 \mathrm{~m}$ der Vorderegg (Kühfitternalp) sowie an anderen Stellen des Tales. Daneben sind zahlreiche Alphütten durch Lawinenkeile oder Mauern geschützt.

Die Kraft des Wildbaches wurde an vielen Stellen durch Schwellenverbauungen gebrochen, und die Überschwemmungsgefahr durch Hochwasser ist an größeren Bächen und vorwiegend am Sernf durch Dammbauten gebannt worden.

Im Ganzen gesehen vermögen diese wenigen, von Menschen geschaffenen Formen dem Landschaftsbild nur lokal ein anderes Aussehen zu geben; sie sind deshalb nur der Vollständigkeit halber erwähnt.

\section{Zur Morphogenese des Sernftales}

\section{EINLEITUNG}

Wenn auch in der Darstellung der morphologischen Verhältnisse des Sernftales, die als Erläuterung zur morphologischen Grundkarte gedacht ist, die meisten Formen eine genetische Deutung erfahren haben, so handelte es sich dabei nur um 
die Individualgenese einzelner teliebiger Formen oder Formgruppen. Der Charakter dieser morphologischen Untersuchungen ist jedoch derart analytisch, daß er $\mathrm{zu}$ einer Synthese zwingt, die als Morphogenese über die Entwicklungsgeschichte des gesamten Untersuchungsgebietes Auskunft geben muß. Einem solchen Unterfangen stellen sich aber eine Menge Schwierigkeiten gegenüber, die zum vorneherein erkannt werden müssen, wenn eine objektive Darstellung verbürgt werden soll.

Die Hauptschwierigkeiten einer genetischen Untersuchung liegen in folgenden Tatsachen begründet: Das Sernftal ist kein selbständiges Tal, sondern nur ein Nebental des weitaus größeren Linthtales. Obwohl es mit seinen $210 \mathrm{~km}^{2}$ einerseits für morphologische Detailuntersuchungen ein enorm großes Gebiet darstellt, ist es anderseits für morphogenetische Studien doch zu klein, als daß aus den Beobachtungen im Tale allein genügend Anhaltspunkte gefunden werden könnten, die zur Lösung der zahlreichen Fragenkomplexe notwendig sind.

Es wird sich somit nicht vermeiden lassen, bei bestimmten Fragen auch die Verhältnisse der angrenzenden Gebiete, insbesondere jene des Haupttales, näher zu beleuchten. Für ganz spezielle Fragen, wie beispielsweise für das Alter der Eintiefungssysteme, wird man sogar die Verhältnisse am Alpenrand in die Untersuchungen einbeziehen müssen. -- Da aber eine genaue Erforschung der umliegenden Gebiete den Rahmen der vorliegenden Arbeit weit überschreiten würde, kann es sich höchstens darum handeln, auf Grund der vorhandenen Literatur Anknüpfungspunkte zu finden und Parallelen zu ziehen. Leider stößt auch dieses Unternehmen auf große Schwierigkeiten, weil in den erwähnten Gebieten noch keine eingehenden Studien gemacht wurden. Die wenigen Arbeiten, deren Ergebnisse zur Verfügung stehen, sind meist älteren Datums; die Auffassungen der verschiedenen Autoren divergieren zudem so stark, daß ihre Ergebnisse nur unter Vorbehalt in die Untersuchungen einbezogen werden dürfen.

$\mathrm{Da}$ die zahlreichen Probleme innerhalb des morphologischen Teiles der Arbeit nach einer Gesamtgenese drängen, sei der Versuch gewagt, auch wenn dem zweiten Teil der Arbeit in manchen Punkten der Vorwurf, Hy'pothese zu sein, nicht erspart werden kann.

\section{SCHWIERIGKEITEN IN DER REKONSTRUKTION VON TALBÖDEN}

Wie aus dem Abschnitt über die T'errassen des Sernftales hervorgeht, sind die zahlreichen Verflachungen im Untersuchungsgebiet nicht alle von derselben. Bedeutung für die Morphogenese. Eine ganze Anzahl dieser Verebnungen darf. für die Rekonstruktion von alten Talböden gar nicht herangezogen werden, weil es sich bei ihnen nicht um Erosionsterrassen, sondern nur um flache Partien innerhalb von Akkumulationen usw. handelt. Da nun aber gerade die Genese der jungtertiären Formen eine genaue Kenntnis der alten Talböden verlangt, wird diese Frage umso schwieriger, wenn man bedenkt, daß im ganzen Untersuchungsgebiet nur ungefähr hundert Restformen vorbehaltlos der Rekonstruktion dienen können. Da sich diese Terrassen auf ein relativ großes Gebiet verteilen, sind sie miteinander nur schwer in Beziehung zu bringen. Der stetige Gesteinswechsel verursacht zudem Komplikationen, weil durch ihn die Gefällsverhältnisse an verschiedenen Stellen scheinbar aus dem Gleichgewicht gebracht worden sind.

Aus diesen Gründen befinden sich zwischen den einzelnen Terrassen gleichen Niveaus oft große Lücken, sodaß die Koordination außerordentlich erschwert wird. Allein durch die Mündungen der Seitentäler, sowohl der großen als auch der kleinen, werden die Lücken zwischen den Verflachungen oft derart groß, daß schon ein Aneinanderreihen in der Längsichtung des Tales problematisch werden kann. 
Noch komplizierter ist die Parallelisierung der links- und rechtsseitigen Talbodenreste. Der stetige Gesteinswechsel und die schiefe Lage der Schichten verursachen auf den beiden Talseiten verschiedene Terrassengefälle, soda $\beta$ man über die Zugehörigkeit links- und rechtsseitiger Verebnungen oft im Zweifel sein kann. Mancherorts gibt aber ein Querprofil doch die Möglichkeit, solche Terrassen zu verbinden, auch wenn die Feldbeobachtung an Ort und Stelle keinen Zusammenhang vermuten läßt.

Wo eine Parallelisierung der Terrassen möglich ist, sollte eigentlich auch die Höhe des ehenaligen Talbodens bestimnt werden können. Da nun aber schon die Verbindung der Terrassen ein schwieriges Problem bildet, so ist die Bestimmung der ursprünglichen 'Talbodenhöhe noch weit fragwürdiger. Wohl finden sich auch im Sernftal Orte, an denen die Terrassen auf beiden Talseiten gleiches Gefälle, gleiche Ausdehnung und gleiche Lage aufweisen, und somit eine Rekonstruktion des ehemaligen Talbodens mit großer Genauigkeit gewährleistet ist. Leider sind diese Fälle aber selten, da die Terrassen gegen die Talmitte meist verschiedenes Gefälle besitzen, sodaß in diesen Fällen nur cine ungefähre Profillinie rekonstruiert werden kann.

Die gleichen Schwierigkeiten stellen sich auch ein, wenn die ehemaligen Talböden der Seitentäler bis zum Haupttal verlängert werden sollten.

Wenn auch für das Sernftal die Rekonstruktion von Talböden im Einzelfall auf Schwierigkeiten stößt, so lassen sich im Gesamten doch genügend Anhaltspunkte für die elemaligen Eintiefungseinheiten finden.

\section{DIE EINTIEFUNGSSYSTEME}

Von den zahlreichen Arbeiten über die Terrassen und Talstufen im Alpengebiet seien hier kurz jene erwähnt, wclche über die Verhältnisse im Sernftal und seinen Nebentälern Auskunft geben, oder mit ihnen in enger Verbindung stehen.

Schon A. HEIM ${ }^{18}$ hat im Linthtal vier übereinanderliegende Talbodensysteme rekonstruiert. A. BoDmer ${ }^{6}$ schloß sich in ganzen der Darstellung Heims an, schaltete jedoch noch neue Talböden ein und gruppierte die Terrassen des Linthtales und seiner Ncbentäler zu sieben verschiedenen 'Talböden. A. Aeppli ${ }^{1}$ fand von Glarus weg talauswärts zehn verschiedene Systeme zwischen $1140 \mathrm{~m}$ und $420 \mathrm{~m}$ Höhe, die er bis weit ins Mittelland hinaus verfolgte, von denen aber nur wenige mit den Talböden Bodmers übereinstimmen. E. BRÜCKNER 8 dagegen stellt im Linthtal nur zwei Systeme fest, wobei er das höhere ins Praeglazial, das tiefere in die Mindel-Riß-Interglazialzeit einordnet. Schließlich hat sich auch Gogarten ${ }^{14}$ mit den Terrassen des Linthtales und seiner Nebentäler befaßt. Er fand im ganzen Gebiet 411 Talbodenreste, aus denen er 17 übereinanderliegende Talsysteme rekonstruiert, wobei er sich im allgemeinen den Ansichten von HeIM und BoDMER anschließt und der Glazialerosion jeglichen Einfluf $j$ auf die Talgestaltung abspricht.

Diese außerordentlich starke Divergenz in den Ansichten der genannten Autoren rührt daher, da $\beta$ die meisten der angeführten Talbodenreste keine in der Natur begründeten, objektiven Erscheinungen sind, sondern mehr oder weniger willkürliche, subjektive Rekonstruktionen darstellen.

Ohne die Arbeit der genannten Verfasser verurteilen $\mathrm{zu}$ wollen, darf doch gesagt werden, daß eben nur eine intensive morphologische Durchforschung der Alpentäler eine genaue Beantwortung der jungtertiären und pleistozänen Talgenese ermöglichen wird. - Aus diesem Grunde wird auch nur eine objektive Formanalyse, unter Ausschließung jeglicher Willkür in der Koordination, genaue und verwertbare Ergebnisse zeitigen. 
Im Sernftal sind drei ausgeprägte Terrassensysteme zu beobachten, welche teilweise auch in den Nebentälern feststellbar sind und dem Tal ein deutliches Schachtelrelief geben. Es sind dies von oben nach unten das Wildmaadsystem, das Wichiensystem und das Waldsystem.

Die Namen stammen von Lokalitäten im obersten Talteil. Außer der Tatsache, daß an den genannten Orten die Systeme am schönsten ausgebildet vorkommen, sind keine anderen Gründe für diese Namengebung maßgebend gewesen.

Im Gegensatz zu großräumigeren Gebieten treten im Sernftal die Systeme in einer relativ regelmäßigen Verbreitungsdichte auf. Aus diesem Gunde sind selbst talauswärts noch zahlreiche Formenreste des höchsten Systems vorhanden, und die Formen des tiefsten Systems vermögen keine beherrschende Stellung einzunehmen.

\section{Das Wildmaad-System}

Die Verflachungen dieses höchsten Systems sind nur in den Gipfelregionen der umrahmenden Gebirgskette erhalten geblieben, lassen sich dort aber im ganzen Untersuchungsgebiet beinahe lückenlos verfolgen. Besonders in der Kärpfgruppe und in der Spitzmeilenkette beherrscht das Wildmaadsystem durch seine ausgedehnten Flachformen die Landschaft und verleiht den aufgesetzten Gipfelpartien den Charakter eines Mittelgebirges. Erst die Tiefenerosion vermochte diesem ursprünglichen Mittelgebirge den Hochgebirgscharakter aufzuzwingen. Wohl hat im Kärpfgebiet die Härtezone des Lochseitenkalkes zur weiträumigen und auffälligen Ausbildung dieses Systems wesentlich beigetragen, doch wird gerade dadurch die einheitliche Entstehung nur umso eindrücklicher, da die gleichartigen Verflachungen auch in den Trias-Schichten der Spitzmeilenkette verbreitet sind. Ein prinzipieller Unterschied zwischen den Verebnungen im Kärpfgebiet und den parallelen Verflachungen in der östlichen Talumrahmung besteht darin, daß in der Kärpfgruppe Kare eingetieft sind, die vom Wildmaadsystem überhöht sind, während in den anderen Gebirgsketten unter dem höchsten System keine Karbildung mehr vorkommt. Diese Tatsache rührt daher, daß die zahlreichen kleinen Nebentälchen, welche zwischen Kärpf und Gandstock gegen das Sernftal absteigen, in ihrem obersten Teil karartig umgestaltet wurden, wobei die Flyschunterlage die Ausbildung begünstigte. Demgegenüber handelt es sich bei den östlichen Zufüßen um eigentliche Täler, bei deren Ausgestaltung der Gesteinswechsel nicht maßgeblich beteiligt sein konnte, da keine weichen Schichten aufgeschlossen werden.

Verfolgt man die Terrassen des Wildmaadsystems und die Karböden nach ihrer Höhenlage, so kann man folgendes feststellen:

Am Kärpfstock liegen die höchsten Terrassenreste in einer Höhe von $2470-2390 \mathrm{~m}$. Es sind die relativ flachen, von Rundhöckern bedeckten oberen Karböden, die sich wie ein Kranz um den Gipfel legen und deren Karzwischenwände fast vollständig abgetragen sind. Von gleicher Ausbilduug ist die glazial überformte Felsfläche zwischen dem Schwarztschingel und den Bleitstöcken, welche allerdings fast $100 \mathrm{~m}$ tiefer liegt. Sie findet ihre Fortsetzung in der anschließenden glazialen Denudationsfläche des Wildmaads, dessen Rand fast exakt mit der $2200 \mathrm{~m}$-Isohypse übereinstimmt.

Die weiter nördlich am Berglihorn und Karrenstock liegenden Verflachungen weisen die gleiche Höhenlage auf, sind jedoch nur schwach ausgebildet. Erst auf der Berglimatt und am Gandstock werden die entsprechenden Verflachungen wieder weiträumiger, woran die dort auftretenden basischen Eruptiva nicht unwesentlich beteiligt sind.

$\mathrm{Da}$ die östliche Talflanke durch die großen Nebentäler unterbrochen ist, können die parallelen Verflachungen auf dieser Talseite erst in den Talschlüssen dieser Nebentäler gesucht werden. Es ist deshalb klar, daß eine direkte Koordination zwischen links- und rechtsseitigen Terrassenresten nur bedingt möglich ist, weil die Entfernungen von der heutigen Talmitte ungleich groß sind. Immerhin kann diesem Umstand nicht allzu große Bedeutung beigemessen werden, da diese Erscheinung überall auftritt, wo Seitentäler vorhanden sind.

Im Gebiet des Panixerpasses lehnt sich nördlich des Rotstocks eine Terrasse an, die fast genau gleich hoch liegt wie der untere Rand jenes Karbodens, der vom Hexenseeli gegen Norden ansteigt. Die mittlere Höhe von $2400 \mathrm{~m}$ stimmt genau überein mit den Karböden am Kärpfstock. Leider finden diese Verflachungen in der Vorabgruppe kein Aequivalent.

Die mächtige Vorabhochfläche liegt bedeutend höher als die höchsten Gipfel des übrigen Sernftales mit Ausnahme des Hausstocks. Nur die Hochfläche der Sardona korrespondiert mit der Vorabfläche in der Höhe. Eine Einordnung dieser beiden Verflachungen in ein System kann nur erfolgen, wenn die morphologischen Verhältnisse auf der Bündnerseite einer eingehenden Betrachtung unterzogen würden, da die Formen gesamthaft gesehen viel stärker gegen das Rheintal weisen. Die wenigen Spuren, die vom Bündnerbergfirn gegen das Sernftal deuten, sind nur von lokaler Bedeutung. - Einzig der Karboden I des Martinsmaads könnte unter Umständen mit dem Wildmaadsystem koordiniert werden. Sein unterer Rand liegt in $2200 \mathrm{~m}$ Höhe, fällt aber gerade mit 
einer von einem Nummulitenkalkband gekrönten Härtezone zusammen, sodaß einè Einordnung dieses Bodens allzu problematisch wird.

Vón geradezu prachtvoller Ausbildung sind dagegen die Karböden und Terrassen in der Foostock-Spitzmeilenkette, wo trotz dem Absinken der Mürtschendecke gegen Westen die Niveaus fast durchwegs gleiche Höhe aufweisen.

Sowohl die Karnische Bützi am Foostock, wie auch diejenige auf der Westseite des Weißgandstöcklis liegen in $2200 \mathrm{~m}$ Höhe und dürfen mit Sicherheit gleiches Alter besitzen wie die Verebnungen in der Kärpfgruppe.

Überraschend ähnlich wie das Wildmaad ist die Nische von Schönbühl am Spitzmeilen ausgebildet. Dieses mächtige Kar besitzt einen unregelmäßigen Boden in $2250 \mathrm{~m}$, der gegen den Gulderstock hin in Form einer Terrasse eine Verlängerung besitzt, die in $2200 \mathrm{~m}$ bis zu diesem Gipfel verläuft, wo sie in einen anderen Karboden überleitet. Dieser lehnt sich im Osten an den Gulderstock an und ist durch die Rinne von Fukenthal in zwei Teile zerschnitten.

Auf der Westseite des Gipsgrates liegt eine aequivalente Verebnung zur Nische von Schönbühl. Der untere Rand dieses glazial stark überarbeiteten Bodens liegt in $2230 \mathrm{~m}$. Gleiche Höhe weist auch der Karboden östlich des Bützistockes auf.

Von gewaltiger Ausdehnung ist die Karrenfläche im Karboden der oberen Fässisalp. Zusammen mit den kleinen Verebnungen von Ober-Gufelialp läßt sie sich bei einer mittleren Höhe von 2270$2160 \mathrm{~m}$ gut dem Wildmaadsystem einordnen.

Betrachtet man die Gesamtheit all dieser Verflachungen, so kann man feststellen, daß sozusagen sämtliche Teile gleichartig ausgebildet sind. Meist handelt es sich um Karböden, die stark von Rundhöckern bedeckt sind, oder welche eine dünne Moränendecke tragen. Die Ausgeglichenheit in der Ausbildung, sowie die Regelmäßigkeit in bezug auf die Höhenlage rechtfertigen einen Zusammenschluß dieser Verebnungen zu einem System.

\section{Das Wichlen-System}

Von ungleich anderer Art sind die Terrassen des Wichlensystems. Wohl handelt es sich auch hier teilweise um Karböden. Im Vergleich zu jenen des Wildmaadsystems liegen sie aber wesentlich tiefer. Die Mehrzahl der Verflachungen dagegen ist von terrassenförmiger Art und nicht mehr auf Nischen und abseits gelegene Hohlformen beschränkt. In ihrer Anlage sind sie allerdings meist schmal und relativ steil.

In den linksseitigen Nebentälchen gehen sie in die unter dem Wildmaadsystem gelegenen Karböden über, ohne eigentliche Flachstreckenfolgen zu bilden. Dies rührt daher, daß es sich bei diesen Nebentälchen weit mehr um trichterförmige Ausweitungen als um eigentliche Täler handelt.

In den größeren Nebentälern, wie im Krauchtal und im Mühlebachtal, ist das Wichlensystem nur lückenhaft vorhanden und beschränkt sich meistens auf Verflachungen im Talhintergrund. In den nordwärts exponierten Talwänden des Krauchtales steht es oft in Verbindung mit Schichtrippen, da die Gesteine hier nach Süden einfallen. Die größere Widerstandsfähigkeit dieser Schichtkopfreihen gegenüber dem Gestein mit streichender Lagerung hat die Terrassenbildung verhindert, sodaß an Stelle von Verebnungen nur Kanten vorhanden sind.

Im Ramintal ist das Wichlensystem derart stark von Runsen und kleinen Tälchen zerschnitten, daß von den ehemaligen Verflachungen nur noch Kammformen übrig geblieben sind.

Eine Verfolgung des Wichlensystems vom Talschluß talauswärts ergibt folgendes Bild:

Im Wichlenmattkar und auf der Terrasse des Erbserstockes beträgt die durchschnittliche Höhe der Verebnungen $2100 \mathrm{~m}$. Über der Erbsalp liegt eine 'Terrasse, welche durch einen Bachanschnitt aufgelöst ist; ihr unterer Rand kann mit $1980 \mathrm{~m}$ bestimmt werden. Bleiben wir auf der linken Talseite des Sernftales, so konstatieren wir, daß über eine weite Strecke an den Gehängen des Haupttales keine Verflachungen mehr auftreten. Erst oberhalb des Riedbodens und der Kreuelalp erscheinen wieder Terrassen in einer Höhe von $1730-1620 \mathrm{~m}$. Diese Lücke in der Terrassenfolge rührt wieder von den kleinen Seitentälchen her. Dafür lassen sich die Verebnungen innerhalb dieser kleinen Nebentälchen verfolgen, wo sie allerdings eine größere Höhe einnehmen als im Haupttal. - So liegen die entsprechenden Verflachungen im Tälchen der Bischofalp auf rund $1930 \mathrm{~m}$, in jenem der Embächlialp gar auf $2060 \mathrm{~m}$, im Kühbodenalptälchen auf $1910 \mathrm{~m}$ und im Kühtal auf $1860 \mathrm{~m}$. Daß es sich um die gleichen Verflachungen handelt wie im Haupttal, geht daraus hervor, daß die kleinen Terrassenreste der Nebentälchen sehr oft in die entsprechenden Systemreste des Haupttales übergehen.

Ähnlich wie das Wildmaadsystem verhält sich auch das Wichlensystem auf der rechten Talseite. Die großen Nebentäler verursachen starke Lücken in der Terrassenfolge. Im Hausstockkar zieht sich im Hintergrund eine vom harten Taveyannazsandstein bedingte Verflachung durch, deren unterer Rand in $2200 \mathrm{~m}$ liegt. Im Jätztal weicht das Wichlensystem bis an die Stufe der Gurgel zurück, wo der untere Rand $2040 \mathrm{~m}$ hoch liegt. Gleich alt dürften die Verflachungen im Kar nördlich des Kalkhorns sein. Auf der rechten Seite des Jätztales läßt sich die Terrasse ein Stück weit talauswärts verfolgen. Von $2040 \mathrm{~m}$ oberhalb des Walenbodens sinkt sie bis in die Gegend über dem „Loch“ auf $1890 \mathrm{~m}$ hinunter. 
An der Nordabdachung der Vorabgı uppe liegt der Karboden des Bocksmaads mit dem unteren Rand in $1960 \mathrm{~m}$. Unterhalb der Schafblanken zieht sich das Wichlensystem auf einer Höhe von $1840-1780 \mathrm{~m}$ dem Gehänge entlang bis zum Plattenberg.

Im Nebental des Tschingelbaches steigt es im Martinsmaad wieder leicht an und ist im Karboden II in $2010 \mathrm{~m}$ Höhe zu finden. Gleiche Höhe weist auch die stark zerschnittene Verflachung im Segneskar auf.

Im Ramintal liegen die Reste des Wichlensystems auf gleicher Höhe wie im Haupttal. Sie fallen von $2060 \mathrm{~m}$ am Foostöckli und am Blattengrat langsam abvïrts. Auf Ramin Mittelstafel liegt der untere Terrassenrand noch $1900 \mathrm{~m}$ hoch. Die mächtige Terrasse von Matt auf der Falzüberalp hat eine mittlere Höhe von $1960 \mathrm{~m}$, der untere Rand liegt auf $1910 \mathrm{~m}$. Genau gleich hoch liegt die Terrasse der Geißegg östlich von Matt.

Im Krauchtal läßt sich des Wichlensystem eine kurze Strecke weit roon Talhintergrund aus verfolgen. Aus einer Höhe von $2000 \mathrm{~m}$ weisen die Terrassen ein leichtes Gefille as bis auf $1940 \mathrm{~m}$ hinunter. Obwohl die Verebnungen auf der rechten Talseite an eine Härtekr.nte gebunden sind, liegen sie korrespondierend zu den linksseitigen Verflachungen. Weiter talauswärts liegt die Terrasse „In der Schnur" nur noch in $1830 \mathrm{~m}$.

Am Südwestabhang des Gulderstockes liegen weitere Reste des Wichlensystems. Die Terrasse von Sandigen und Ochsenbühl in $1560 \mathrm{~m}$ gehören schon wieder zu den Haupttalleisten. Auf der unteren Ochsenfitternalp scheint eine weitere Terrasse durchzuziehen, doch läßt sich infolge der starken Moränenbedeckung keine genaue Abgrenzung ermöglichen.

Im Mühlebachtal ist das Wichlensystem nur spärlich ausgebildet. Einzig die untere Terrasse „Auf den Kämmen“ darf mit Sicherheit zu diesem System gerechnet werden. Die gewaltige Ausdehnung hängt mit einer Härtezone zusammen, welche sich in den Stelliköpfen durchzieht. Die übrigen etwaigen Terrassenreste liegen wahrscheinlich unter den ausgedehnten Akkumulationen, welche teilweise von den höchsten Erhebungen bis auf die Talsohle hinunterreichen.

Die starke glaziale Überarbeitung des Wichlensystems hat teilweise mächtige Niveauunterschiede geschaffen. Der ebenfalls enorme postglaziale Abtrag hat weiter mitgeholfen, die ehemaligen Talformen zu zerstören und dem ganzen System den Stempel der Unregelmäßigkeit aufzudrücken. Aus diesem Grunde sind die Reste in den Nebentälern weit mehr verwischt worden, sodaß eine geschlossene Systemform nur noch im Haupttal beobachtet werden kann. Trotz all diesen Erscheinungen bildet auch das Wichlensystem eine für das ganze Untersuchungsgebiet charakteristische Einheit, und die zahlreichen lokalen Unterschiede in der Ausbildung vermögen den Gesamteindruck nur wenig abzuschwächen.

\section{Das Wald-System}

Die steilen Wände unter dem tiefstgelegenen Waldsystem kennzeichnen es als Trogschulterphase. Im Gegensatz zu den beiden höher gelegenen Systemen läßt sich diese Eintiefungsphase fast lückenlos durch das ganze Sernftal und teilweise auch durch die Nebentäler verfolgen. Die Ausbildung und der Erhaltungszustand sind aber keineswegs durchgehend gleichmäßig. Besonders an der nördlichen Talseite des oberen Sernftales ist der Trogrand lange nicht so eindrücklich vorhanden wie man erwarten könnte. Die weichen Flyschschichten haben wohl ursprünglich zur ausgesprochenen Trogbildung beigetragen; anderseits haben sie aber auch durch ihre geringe Widerstandsfähigkeit der Erhaltung entgegengewirkt. Weit klarer tritt der Trog im mittleren Talteil hervor, wo der Sernf in ein Quertal übergeht.

Vom Talschluß aus, wo die Verebnungen des Trogschlusses in einer Höhe von $1840 \mathrm{~m}$ liegen, fallen die Terrassen talauswärts gleichmäßig ab. Auf der Terrasse von Erbsalp hat die Verflachung dieses Niveaus noch $1670 \mathrm{~m}$ Höhe, während der Trogrand auf $1620 \mathrm{~m}$ verläuft. Bis Elm senken sich die Trogränder auf beiden Talufern bis auf $1410 \mathrm{~m}$ hinunter. Einzig am Plattenberg in der Umgebung des Bergsturzes von Elm ist auf der rechten Talseite ein kleines Ansteigen des Terrassenrandes auf $1510 \mathrm{~m} \mathrm{zu}$ beobachten, was durch eine Härtezone im Wildflysch und durch das Zurückschneiden des Terrassenrandes verursacht wird. Auf der Terrasse von Wald über Elm scheint eine starke Erniedrigung der Terrassenfläche stattgefunden zu haben. Jedenfalls hat sich dort die Konfluenz mit dem Ramintal bemerkbar gemacht. Zwischen Elm und Matt sind die Reste des Systems nur noch als Kanten vorhanden, da das steile Einfallen, der Schichten eine Terrassierung verunmöglichte.

Prachtvoll ausgebildet ist die Trogschulter wieder von Matt an auswärts. Auf der linken Talseite läßt sich die Terrasse sozusagen lückenlos verfolgen, wobei sie vom Riedboden aus $1450 \mathrm{~m}$ bis auf $1340 \mathrm{~m}$ absinkt, bis sie auf der Kreuelalp ausklingt. Auf der rechten Seite verläuft sie in der Terrasse der Weißenberge talauswärts leicht ansteigend, was durch einen Gesteinswechsel, aber auch durch das starke Zurückschneiden bedingt ist.

Sowohl die Mündungen der Seitentäler auf der linken Talseite, als auch die Mündungen der großen Nebentäler auf dem rechten Ufer haben an den Konfluenzstellen jeweilen ausgeprägte Erniedrigungen der Terrassen zur Folge gehabt.

Im Gebiet der Mündungsschlucht erscheinen einzig noch auf der Nordseite des Sernf einige flache Gehängepartien. Ihre Lage läßt vermuten, daß es sich ebenfalls um Verflachungen des Wald- 
systems handelt, obgleich an einigen Stellen nicht zuletzt auch Härtezonen Veranlassung zu Verebnungen gegeben haben.

In den Nebentälern läßt sich das Waldsystem ebenfalls sehr gut verfolgen, obwohl es nicht immer eine ausgesprochene Trogform aufweist. *

Im Vergleich zum Haupttal liegen die Verebnungen des Waldsystems in den Nebentälern entsprechend höher.

So gehört die Stufe von Jätzalp Oberstafel im Jätztal zum Waldsystem. Die mittlere Höhe beträtg $1660 \mathrm{~m}$. Der untere Rand ist an eine Härtezone gebunden, die durch die Schichten der Panärafalte verursacht wird. Die starke Akkumulierung des Talbodens durch den Bergsturz im "Loch“ hat die Formen sehr stark verwischt.

Im Martinsmaad liegt die entsprechende Verflachung des Waldsystems auf dem Karboden IV in 1700-1640 m. Sie umschließt den mit Moränen bedeckten Boden von Niederen auf der Tschinglenalp und geht über in die Verebnungen über den Rändern der Mündungsschlucht.

Von ähnlicher Ausbildung 'sind die Terrassen und Verflachungen im Ramintal. Obwohl keine ausgesprochene Trogform vorhanden ist, lassen sich diese flachen Gehängepartien eindeutig dem Waldsystem zuordnen. Auf der linken Talseite liegt der Boden von Stäfeli in $1650 \mathrm{~m}$ Höhe und findet auf dem rechten Ufer sein Korrelat in zwei ausgedehnten Verebnungen zwischen 1560 und $1610 \mathrm{~m}$. Der Trogschluß des Ramintales ist von allen Nebentälern am schlechtesten erhalten, da der Talhintergrund außerordentlich stark durch Runsen und die dadurch bedingte Zerschneidung aufgelöst ist. Er dürfte wohl kurz unterhalb von Ramin Mittelstafel gelegen haben. Die starke Moränenbedeckung an jener Stelle und die Konfluenz vom Raminerbach mit dem vom Foostöckli kommenden Bächlein haben eine große Lücke in dieser Systemform geschaffen.

Viel eindrücklicher sind die Trogformen im Krauchtal und im Mühlebachtal ausgebildet und erhalten geblieben. Obschon der Trogschluß des Krauchtales bei Werben durch eine mächtige Bergsturzmasse verschüttet ist, läßt sich das System vom Talhintergrund bis nach Matt verfolgen, wo es in die gleichaltrigen Verebnungen des Sernftales übergeht. Vom Talschluß bis zur Mündungsstelle senkt sich das Trogschultersystem im Krauchtal von $1800 \mathrm{~m}$ bis auf $1390 \mathrm{~m}$, ehe es in die Terrassen der Weißenberge überleitet. Infolge der Härtezone in der Terrasse „Auf den Saumen “ verläuft es im Talhintergrund eine Strecke weit rückläufig, analog der Rückläufigkeit der oberen Systeme an jener Stelle.

Auch im Mühlebachtal läßt sich das Waldsystem über große Strecken verfolgen. Eine geradezu einmalig große Verebnung bildet die Terrasse von Glattmatt und Lusermatt, welche ohne Unterbrechung in den Trogschluß von Mühlebachalp in $1930 \mathrm{~m}$ überleitet. Auf der linken Talseite des Mühlebachtales sind leider keine Verflachungen im Anstehenden festzustellen, da sich vom Gulderstock über Gulderblanken bis zur Talsohle eine riesige Akkumulationsfläche von Moränen-, Bergsturz- und Gehängeschutt ausdehnt.

Der schmale Graben, der vom Ueblital zur Widersteinerfurggel hinaufzieht, besitzt stellenweise auf beiden Ufern kleine und steile Verebnungen, die ebenfalls auf Grund ihrer trogschulterartigen Ausbildung dem Waldsystem angehören müssen.

\section{Die Frage der Zwischensysteme}

Außer den Haupteintiefungssystemen treten im Sernftal eine Anzahl Terrassen auf, die weder dem einen noch dem anderen System angehören. Meist handelt es sich um wenig ausgedehnte Verflachungen, die noch steiler und kürzer sind als jene der Hauptsysteme. Ihre von den Hauptterrassen verschiedenartige Ausbildung und Anlage läßt vermuten, daß es sich um Verebnungen weiterer Eintiefungssysteme handelt. Anderseits kommen sie aber nur ganz vereinzelt vor, sodaß man wiederum im Z weifel sein kann, ob es sich nicht einfach um lokale Erscheinungen handelt.

Die schwierige Frage der Einordnung in ein bestimmtes Eintiefungssystem könnte sich erst lösen lassen, wenn man die gleichen Beobachtungen auch in den umliegenden Gebieten machen köunte.

$\mathrm{Da}$ die wenigen Verflachungen nicht zu geschlossenen $Z$ wischensystemen verbunden werden können, wäre es verfehlt, wenn auf Grund der wenigen Beobachtungen hypothetische Eintiefungsphasen konstruiert würden. Sollte aber später einmal auf Grund weiträumiger Untersuchungen doch noch eines oder mehrere Zwischensysteme gefunden werden, so könnten die im Sernftal auftretenden Verebnungen als weitere Beweismittel herangezogen werden.

In Frage kämen die Verebnung des Walenbodens im Jätztal $(1940 \mathrm{~m})$, der dritte Boden des Martinsmaads $(1780 \mathrm{~m})$, die kleinen Verflachungen in den tiefgelegenen Karen der Hausstockgruppe, sowie die durch Unterschneidung bedingten Kanten in der Mündungsschlucht $(1500 \mathrm{~m})$.

Viele kleine Terrassierungen sind jedoch an Härtezonen gebunden und fallen als Systemreste von vornherein weg. - Die Rekonstruktion von $Z$ wischensystemen würde im Sernftal reiner Willkür entsprechen.

* Auf der morphologischen Grundkarte wurde das Trogschulterzeichen nur dort angewendet, wo sich unterhalb des Terrassenrandes ein typischer Trog befindet. Für alle übrigen, zum Waldsystem gehörenden Terrassen wurde nur das Systemterrassenzeichen benützt. 


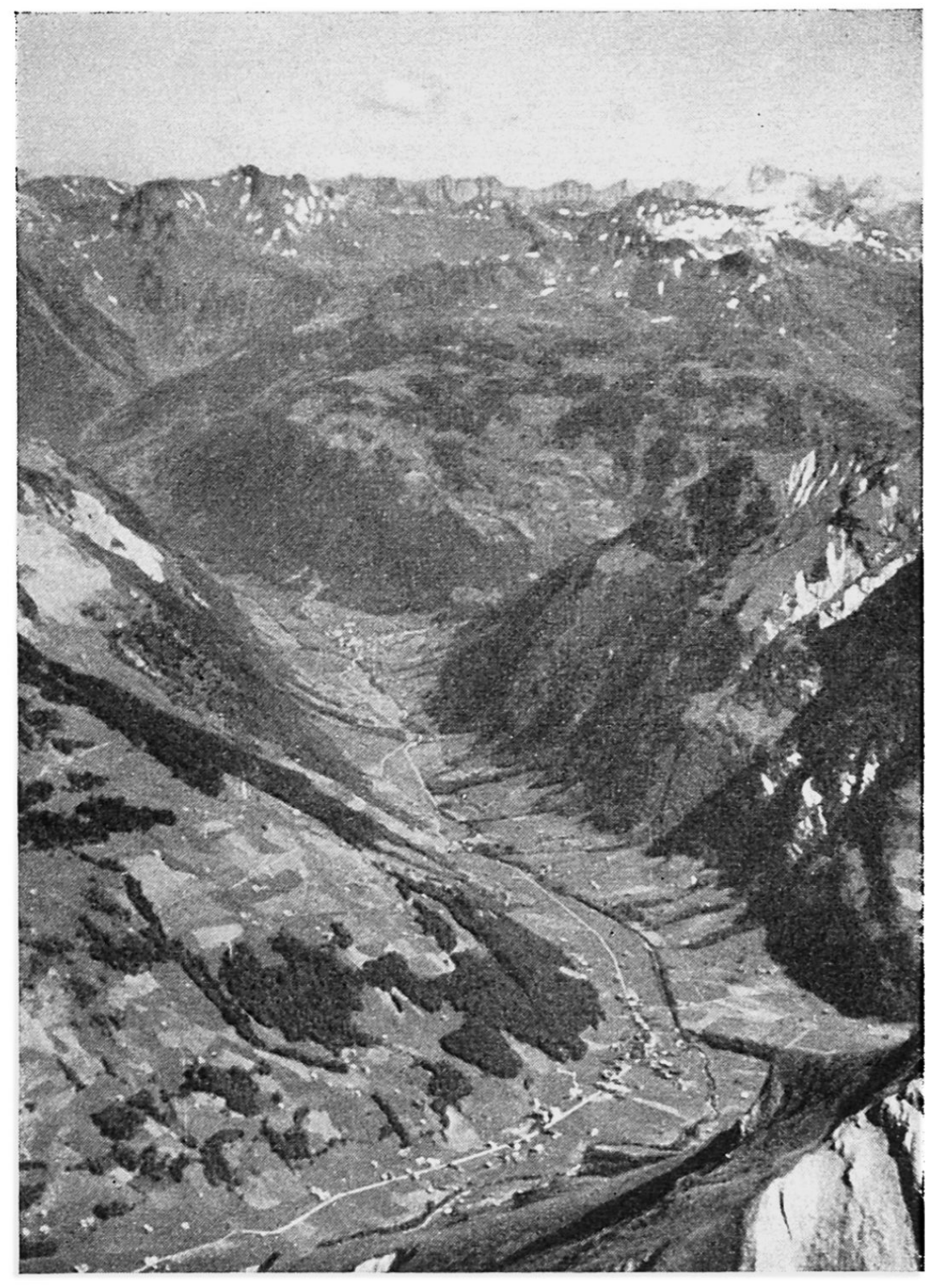

Blick von den Zwölfihörnern ins mittlere Sernftal. Über den bewaldeten Trogwänden erscheinen die präglazialen Terrassen des Waldsystems. Am Gulderstock (Bildmitte) erkennt man die spätaltpliozänen Verebnungen des höher liegenden Wichlen-Niveaus.

(Photo Helbling)

DAS PROBLEM DER ALTERSDATIERUNG

In einem Untersuchungsgebiet wie dem Sernftal dürfte es wohl von vorneherein unmöglich sein, auf Grund morphologischer Indizien allein eine Altersdatierung der verschiedenen Eintiefungssysteme geben zu wollen. Selbst bei weit ausgedehnteren Gebieten dürfte ein solches Unterfangen noch zahlreichen Schwierigkeiten begegnen. Die einzige Möglichkeit, die sichere Ergebnisse zeitigen kann, ist die stratigraphische Methode, wo die Systeme mit den Ablagerungen des Vorlandes verknüpft werden. Benützt man hingegen nur den morphologischen Tatsachenschatz zur Altersbestimmung eines Systems, so wird man sich bei allen weitergehenden Folgerungen der Gefahr des Zirkelschlusses aussetzen.

Da das Sernftal nur ein Nebental des Linthtales ist und dadurch nicht bis zum Alpenrand reicht, fehlt auch die direkte Verbindungsmöglichkeit mit den Vorlandablagerungen. Diese Schwierigkeit wird bei der Untersuchung sämtlicher inneralpiner Täler auftreten; sie ist ein weiterer Hinweis, daß erst eine genaue morphologische Detailforschung über große Räume die jungtertiäre Morphogenese zu enthüllen vermag.

Um für das vorliegende Untersuchungsgebiet trotzdem eine Altersbestimmung der Eintiefungsphasen geben zu können, verfolgen wir die Terrassensysteme des 


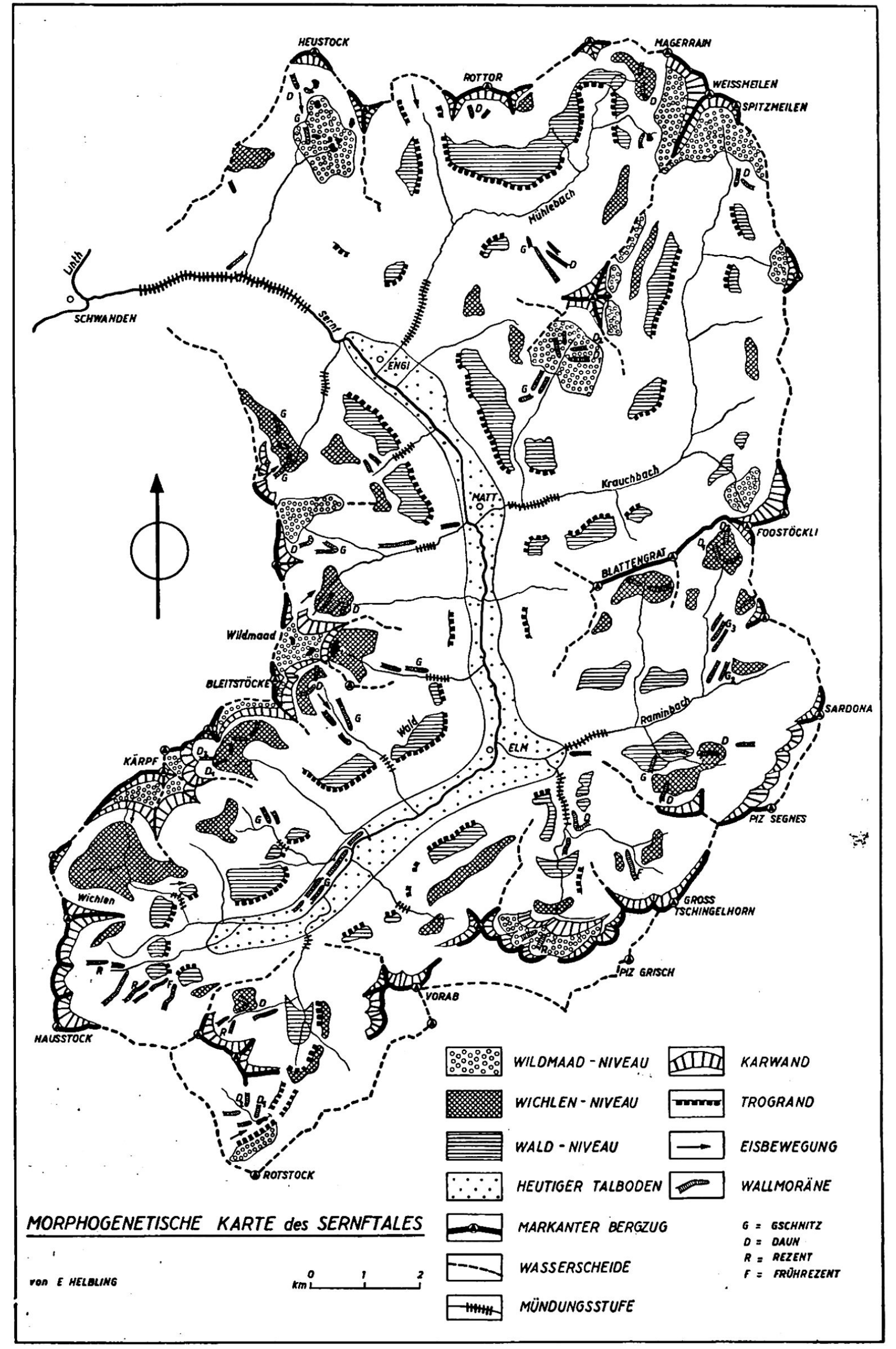


Sernftales auf behelfsmäßige Art im Haupttal weiter. Die Querprofile im Linthtal zeigen, wie die entsprechenden Eintiefungsphasen am Alpenrand liegen. Wenn auch ein solches Vorgehen mit einer Detailuntersuchung keineswegs Schritt zu halten vermag, so kann es doch annähernd über die Verhältnisse Auskunft geben.

Da das Sernftal bei Schwanden an der Vereinigungsstelle mit dem Großtal ungefähr gleiche Größe aufweist, wird im vorliegenden Fall das Unternehmen eher von Erfolg gekrönt sein, als bei anderen Nebentälern, die im Vergleich zum Haupttal nur geringe Dimensionen aufweisen. Auch ist der Alpenrand (Entfernung $20 \mathrm{~km}$ ) relativ nahe gelegen, was allzu große Fehler bis zu einem gewissen Grade ausschließt.

Immerhin bleibt das Sernftal doch ein Seitental, und die Mündungsschlucht zeigt mit ihrer Stufe deutlich, daß im Linthtal weitaus größere morphodynamische Kräfte am Werk gewesen sind.

\section{Die Fortsetzung der Systeme im Linthtal}

Die Terrassen des tiefsten Systems im Linthtal, die in ihrer Anlage und Ausbildung mit den Verflachungen des Waldsystems unseres Untersuchungsgebietes gut übereinstimmen, liegen zwischen Schwanden und Ziegelbrücke wesentlich tiefer als im Sernftal. Während die mittlere Höhe dieser Verflachungen bei Schwanden noch zwischen 1100 und $1150 \mathrm{~m}$ beträgt, fallen die Terrassen bis Ziegelbrücke auf durchschnittlich $1000 \mathrm{~m}$ hinunter. Sie umfassen dort die wenig ausgedehnten Verflachungen des Brunnerberges $(1000 \mathrm{~m})$ bei Mollis und von Platten $(1020 \mathrm{~m})$ bei Oberurnen. Die Terrassen von Kännelalp und Mullernberge liegen in 1070-1090 m Höhe. Das Gefälle dieser Verebnungen ist fast genau gleich groß wie das Gefälle des rezenten Talbodens auf dieser Strecke.

Auch im südlich von Schwanden liegenden Abschnitt des Linthtales können die Verebnungen gut verfolgt werden. Die große Steilheit bewirkt jedoch ein rasches Ansteigen, sodaß schon in der Umgebung von Linthtal (Braunwaldterrasse) die gleiche Höhe erreicht wird, wie sie das Waldsystem im unteren Sernftal aufweist.

Auch für das Wichlensystem findet sich im Haupttal ein Korrelat. Die Terrassen von Achseli $(1460 \mathrm{~m}), \ddot{A} u g s t e n(1510 \mathrm{~m})$, Heubodenalp $(1470 \mathrm{~m})$ und obere Neuenalp $(1530 \mathrm{~m})$ liegen zwar alle auf der rechten Talseite; leider fehlen am linken Talufer die entsprechenden Verebnungen. Die zahlreichen, durch Schichtfolgen bedingten Terrassen in der Wiggisgruppe könnten erst auf Grund genauer morphologischer Untersuchungen mit Systemen in Einklang gebracht werden.

Viele andere Verflachungen dürfen bei unserer oberflächlichen Betrachtung nicht als Erosionsterrassen in die Untersuchung einbezogen werden, da sie durch Akkumulationen bedingt sind. Die Vielzahl der Aufschüttungsformen geht aus der geologischen Karte des Glarnerlandes deutlich hervor.

$\mathrm{Da}$ für das tiefgelegene Waldsystem, welches genetisch zugleich das jüngste ist, eine Altersdatierung am ehesten möglich sein wird, seien die Beobachtungen kurz mit konstruierten Terrassenhöhen verglichen. Die nachstehende Übersicht zeigt die mit Hilfe des Flachstreckenreliefs berechnete Systemhöhe :

\begin{tabular}{|c|c|c|c|c|}
\hline Ortschaft : & Entfernung & $\begin{array}{l}\text { Gefälle der } \\
\text { Flachstrecke }\end{array}$ & $\begin{array}{l}\text { Absolutes } \\
\text { Gefälle }\end{array}$ & $\begin{array}{l}\text { Berechnete } \\
\text { Systemhöhe }\end{array}$ \\
\hline Elm & $14 \mathrm{~km}$ & $16 \%$ & $220 \mathrm{~m}$ & 0 \\
\hline Schwanden & $15 \mathrm{~km}$ & $10 \%$ & $150 \mathrm{~m}$ & \\
\hline
\end{tabular}

Die berechnete Systemhöhe $(1030 \mathrm{~m})$ bei Ziegelbrücke stimmt fast genau mit der Höhe der beobachteten Terrassen $(1000-1020 \mathrm{~m})$ überein. Diese Übereinstimmung zeigt deutlich, daß es sich bei den Verflachungen des Haupttales um die gleichen handelt wie bei denjenigen des Waldsystems im Sernftal, trotzdem in der $5 \mathrm{~km}$ langen Mündungsschlucht des Sernfs die Beobachtungsreihe eine relativ große Lücke aufiveist.

\section{Das Alter des Waldsystems}

Wenn es nun gelingt, mit Hilfe der stratigraphischen Metlode für das Trogsystem des Linthtales ein bestimmtes Alter zu eruieren, so ist damit zugleich die Altersbestimmung für das Waldsystem unseres Untersuchungsgebietes gegeben. Es sei deshalb im folgenden versucht, das Trogsystem mit den Vorlandablagerungen zu verknüpfen.

Das Waldsystem hätte eindeutig präglaziales Alter, wenn es sich mit der Basis des älteren Deckenschotters im Vorland verbinden ließe. Eine solche Koordinierung ist aber nicht ohne weiteres 
möglich. Im Gebiet des Albis liegt der ältere Deckenschotter am Uetliberg in $840 \mathrm{~m}$ Höhe, was für den präglazialen Boden nur ein Gefälle von etwas mehr als $3 \%$ ergäbe. Auch wenn man berücksichtigt, daß sich die voreiszeitliche Oberfläche nur noch im Mittelland als solche zu erkennen gibt, da in den Alpen die „präglaziale Oberfläche “ heute tiefer liegt als ihr ursprüngliches Niveau, ist ein Gefälle von nur 3\% viel zu klein. - Bis in die Gegend des oberen Glatt- und Tößtales, wo WEBER ${ }^{37}$ die Deckenschottersohle untersucht hat, würde das Gefälle mit $6 \%$ schon eher der erwarteten Größe entsprechen. Tatsächlich ist ja das präglaziale Flußsystem nicht eindeutig bekannt, und es wird auch angenommen, daß die Linth erst viel später ihren Weg durch das heutige Zürichseebecken eingeschlagen hat. Anderseits hält WEBER an der Theorie des Rücksinkens der Alpen fest, sodaß die Verhältnisse dadurch nochmals verwickelter werden. Da die von HeIM und AEPPLI ${ }^{1}$ geschaffene Theorie über das Einsinken der Alpen nach der Zeit der Deckenschotterbildung jeder Grundlage entbehrt, darf sie füglich auch bei den vorliegenden Untersuchungen außer acht gelasssen werden.

BRÜCKNER ${ }^{8}$ bestimmte die Verflachungen der Mullernberge, die unserem Trogsystem entsprechen, als mindel-riß-interglaziale Formen, wodurch der präglaziale Talboden an dieser Stelle mit dem nächsthöheren Niveau (ca. $1550 \mathrm{~m}$ ) zu identifizieren wäre. Das ergäbe nun in Verbindung mit der Deckenschottersohle bis zum Uetliberg ein Gefälle von $15 \%$, bis zum Tößtal gar ein solches von über $20 \%$. Diese Werte sind aber wiederum zu groß, selbst wenn man die Versteilung des Gefälles durch Höherschaltung des Gebirgskörpers berücksichtigt, die nach ANNAHEIm ${ }^{4}$ etıva $8 \%$ beträgt.

$\mathrm{Da}$ nun das Trogsystem aus diesen Gründen einerseits nicht M-R-interglaziales Alter haben kann, anderseits aber auch das präglaziale Alter nicht mit vollkommener Sicherheit bewiesen werden kann, wäre die Frage zu prüfen, ob der Trog nicht eine günzglaziale Bildung ${ }^{*}$ darstellt. Die Verebnungen über dem Trogrand wären dann nicht präglazial, sondern hätten vielleicht G-M-interglaziales Alter. Für eine solche Annahme müßten aber im Linthtal eingehende Forschungen gemacht werden, da für diese Theorie bis jetzt keine Anhaltspunkte gefunden werden konnten.

Wenn ich der Trogschulterphase unseres Untersuchungsgebietes trotz dieser fragwürdigen Verhältnisse präglaziales Alter zuschreibe, so gcschieht es, weil Vergleiche mit anderen Alpentälern ebenfalls zu diesem Resultat führen.

Die relativ niedrige Höhenlage dieses präglazialen Systems am Alpenrand ist sicher 2 . $T$. auf den eiszeitlichen Abtrag zurückzuführen; zudem haben wohl an der Konfluenzstelle von Linthtal und Rhein-Wallensee-Furche zahlreiche Kräfte gewirkt, die bei unserer oberflächlichen Betrachtung nicht berücksichtigt werden können. Solange nicht genaue morphologische Analysen am Alpenrand und im Vorland grundsätzlich andere Aspekte bringen, würden andere hypothetischen Darstellungen jeglicher Grundlage entbehren.

\section{Das Wichlensystem}

\section{Das Alter der höheren Systeme}

Die Verflachungen des Wichlensystems erstrecken sich vom Wichlenmattkar $(2050 \mathrm{~m})$ über Ober-Erbsalp $(1980 \mathrm{~m})$, Kreuelalp $(\mathrm{ca} .1700 \mathrm{~m})$ und Ochsenfitternalp $(1650 \mathrm{~m})$ bis zu den Terrassen von Mittel-Fronalp $(1590 \mathrm{~m})$ und Ober-Neuenalp $(1580 \mathrm{~m})$ im unteren Linthtal.

Während das durchschnittliche Gefälle des Trogniveaus aus dem Talhintergrund bis zur Linthebene etwa $20 \%$ beträgt, ergibt sich für das Wichlensystem nur ein Gefälle von $10 \%$. Dadurch nimmt die Höhendifferenz der beiden Systeme von $300 \mathrm{~m}$ im Talhintergrund auf $500 \mathrm{~m}$ am Alpenrand zu. Da für dieses System stratigraphische Korrelate fehlen, ist eine sichere Altersdatierung ausgeschlossen. Erst die Vergleiche mit anderen Alpentälern können über das Alter des Wichlensystems hypothetisch Auskunft geben.

\section{Das Wildmaadsystem}

Genau die gleichen Schwierigkeiten treten uns auch bei der Datierung des höchsten Systems des Sernftales entgegen. Wohl können auch hier parallele Verebnungen im Linthtal konstatiert werden, und wir sehen, daß im alpenrandnahen Gebiet gleichartige Verflachungen auf der oberen Heubodenalp $(1850 \mathrm{~m})$ und auf der oberen Fronalp $(1840 \mathrm{~m}) \mathrm{zu}$ finden sind. Verfolgt man dieses Niveau vom Talschluß aus, so ergibt sich für sein Gefälle eine durchschnittliche Neigung von ungefähr $8 \%$. Die Höhendifferenz zum tiefer gelegenen Wichlensystem beträgt also fast durchgehend $250 \mathrm{~m}$.

$\mathrm{Da}$ für diese beiden letzten Systeme im Alpenvorland korrelate Sedimente fehlen und eine lückenlose Beobachtungsreihe bis zum Alpenrand ausgeschlossen ist, können diese beiden Niveaus nicht aus dem nördlichen Alpenvorland heraus datiert werden. $\mathrm{Zu}$ einer angenäherten Altersbestimmung müssen Vergleiche mit anderen Alpenlandschaften herangezogen werden.

Das morphologische Aussehen des Wichlensystems, sowie seine absolute und relative Höhenlage lassen mit Erfolg einen Vergleich mit den Verhältnissen im Wallis ${ }^{35}$, im Berner Oberland ${ }^{28}$ und zum Teil auch mit dem oberen Tessingebiet ${ }^{4} \mathrm{zu}$. Sie stimmen aufs beste überein mit den Beobachtungen von Merian ${ }^{26}$ im Engelbergertal. Leider mußte auch er sich auf eine Altersbestimmung durch Vergleiche beschränken, soda $\beta$ seine Ergebnisse mit den Resultaten in unserem Untersuchungsgebiet nur bedingt verknüpft werden dürfen. Da jedoch eine große Anzahl Erscheinungen 
in anderen Alpentälern Parallelen aufweisen, dürfte auch einer rein vergleichsmäßigen Datierung ein gewisser Erfolg beschieden sein.

Ein Vergleich mit anderen Alpentälern zeigt deutlich, daß das Wichlensystem unseres Untersuchungsgebietes sehr gut mit den spät-altpliozänen Talformen übereinstimmt, wie sie im Wallis, im Berner Oberland und im Obertessin gefunden worden sind. Aus den gleichen Erwägungen heraus muß für das höher gelegene Wildmaad-Niveau früh-altpliozänes Alter angenommen werden. - Wenn nun früher dem Wichlen-Niveau präglaziales Alter zugeschrieben wurde, so kann nach meinen Beobachtungen erst das tiefer liegende Wald-Niveau ins Präglazial gestellt werden. Damit erfolgt aber eine Tieferlegung des Präglazials um $300 \mathrm{~m}$ im Alpeninnern und um $500 \mathrm{~m}$ am Alpenrand, wie das auch in den oben genannten Gebieten der Fall war*.

VERGLEICHENDE ÜBERSICHT

Tabellarische Zusammenstellung der Talniveaus

\begin{tabular}{|c|c|c|c|c|c|c|}
\hline Niveau & $\begin{array}{r}\text { Absolu } \\
\text { Talschluß m }\end{array}$ & $\begin{array}{l}\text { e Höhe } \\
\text { Alpenrand m }\end{array}$ & $\begin{array}{r}A b \\
\text { alschluß } \mathbf{m}\end{array}$ & $\begin{array}{l}\text { tand } \\
\text { Alpenrand } \mathrm{m}\end{array}$ & $\begin{array}{c}\text { Neigung } \\
\text { durchschn. } \%\end{array}$ & Alter \\
\hline Wald & 1800 & 1000 & & & 28 & präglazial \\
\hline Wichlen & 2100 & 1400 & 300 & 400 & 10 & spät-altpliozän \\
\hline Wildmaad & d 2300 & 1600 & 200 & 200 & 8 & früh -altpliozän \\
\hline
\end{tabular}

Aus dieser Zusammenstellung geht hervor, daß die Niveaus mit zunehmendem Alter eine Gefrillsabnahme aufweisen. Und es wäre eigentlich zu erwarten, daß auch die Reliefenergie im Innern des Tales entsprechend abgenommen hätte. Im Gegensatz zu anderen inneralpinen Tälern ist dies aber im Sernftal nicht der Fall, da noch im Talschluß ganz beträchtliche Höhenunterschiede auftreten. Dies beruht nicht nur darauf, da $\beta$ die Massenerhebung im Talschlu $\beta$ größer ist als am Alpenrand, sondern auch darauf, daß das Sernftal keine groß angelegte Taltreppenlandschaft darstellt, weil die Hauptsysteme bis in den Talschluß reichen. Schon bei der Beschreibung der Talversteilungen (siehe Seite 109) wurde darauf hingewiesen, daß wohl kaum alle Gefällsknicke für die genetische Deutung in Frage kommen dürften. $\mathrm{Da}$ die Hauptsysteme des Sernftales erst im Talschlu $\beta$ in Versteilungen übergehen (siehe Profil S. 136), macht sich die Stufung erst im hinteren Talabschnitt bemerkbar. Augenfälliger ist die Stufung in den kleinen Nebentälern. Die erosionsschwachen Täler des Jätzbaches und des Tschingelbaches haben am Panixerpaß und im Martinsmaad eng gestufte Taltreppen bewirkt; die größeren Nebentäler. des Krauchund Mühlebaches schließen sich in ihrer Anlage dagegen mehr dem Sernftal an. Die vielen linksseitigen Nebentälchen haben keine eigentlichen Talwegformen zu schaffen vermocht, und ihre Flachstrecken leiten mit großer Genauigkeit auf die Haupttalleisten über.

Da die Systemsteilen des Sernftales im Talhintergrund liegen und dort beinahe zu Akkumulationssteilen zusammengewachsen sind, darf mit Sicherheit behauptet werden, daß die Durchtalung für das Präglazial bei einem ausgeglichenen Längsprofil stattgefunden hat. Die kleinen, heute vorhandenen Versteilungen des Sernftales sind wohl alles kleine Resistenzsteilen im rezenten Talboden.

Die Anlage und der Verlauf der verschiedenen Niveaureste, sowie ihre absolute und relative Höhenlage lassen vermuten, da $\beta$ das Längsprofil des Sernftales vor jeder Hebungsphase ausgeglichen gewesen sein muß. Einzig in den Nebentälern hat die Erosion jeweilen nicht bis in den Talschluß vorzudringen vermocht.

Falls eingehende Untersuchungen im Linthtal diese Vermutung bestätigen sollten, ergäbe sich eine Möglichkeit zur Altersdatierung der Mündungsstufe des Sernftales. Auf Grund der Beobachtungen im Tale allein ist eine genaue Altersbestimmung jedoch nicht möglich, wenngleich fesgestellt werden kann, daß die

* Die Ergebnisse sind in der morphogenetischen Karte des Sernftales zusammengestellt. Die wenigen Beobachtungen im Linthtal lassen keine genetische Karte des ganzen Glarnerlandes zu. 


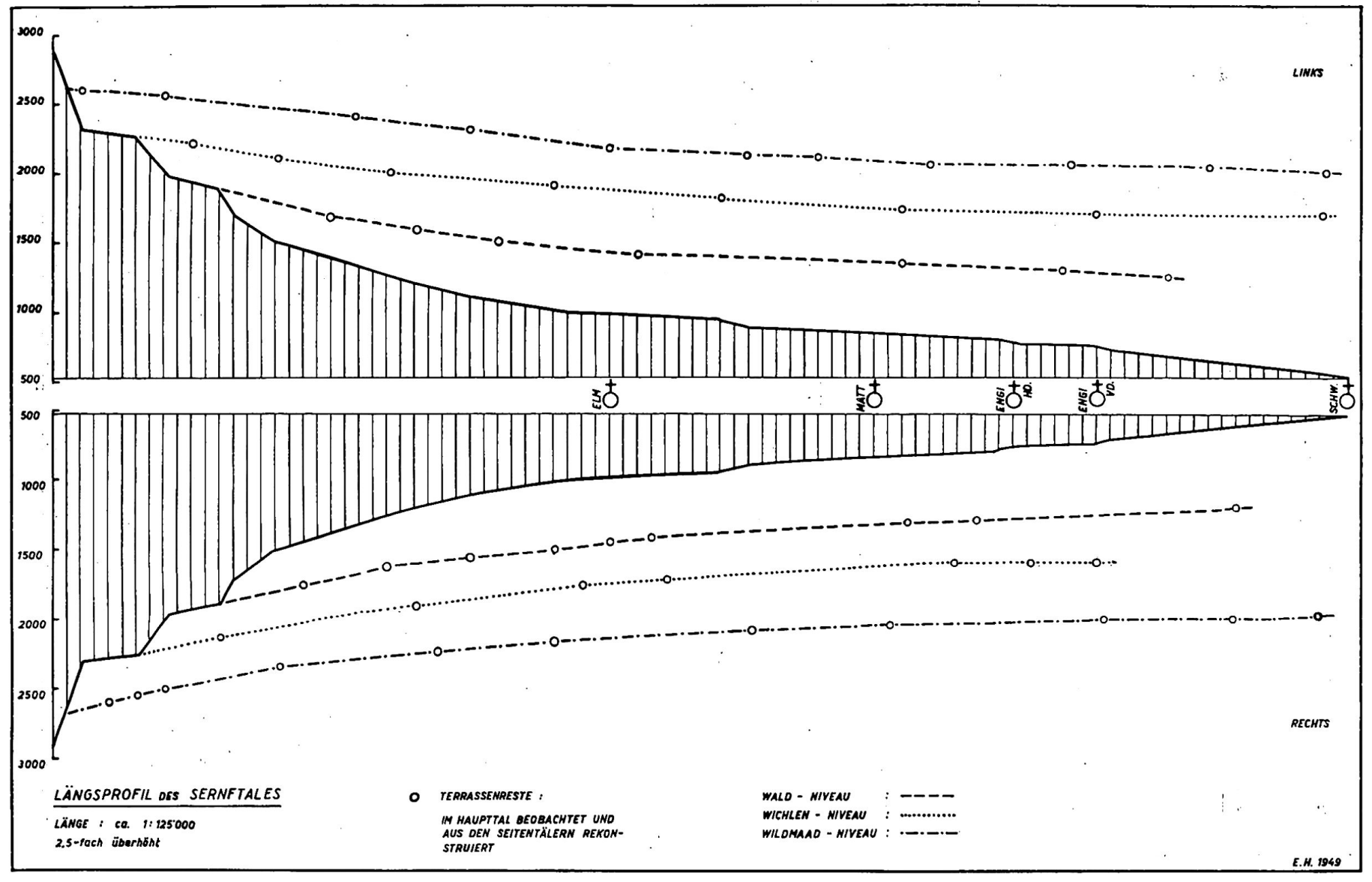


Stufenmündung sehr frühzeitig angelegt worden sein muß und wohl schon im Präglazial eine der heutigen ähnliche Form aufgewiesen hat.

Die Stufenmündungen der Seitentäler des Sernftales haben im Präglazial noch nicht ihre heutigen Ausmaße gehabt. Die Terrassenreste des Präglazials in den Seitentälern leiten fast gleichsohlig in die entsprechenden Verflachungen des Sernftales aus. Es darf deshalb angenommen werden, daß ein beträchtlicher Teil an der Höhe all dieser Stufen auf die glaziale Übertiefung des Sernftales zurückzuführen ist. Immerhin scheint aber doch eine kleine Stufe schon vordem vorhanden gewesen zu sein, worauf vor allem die tiefen, fluviatil angelegten Erosionsfurchen hinweisen, die ihrer Größe und Ausbildung nach ein beträchtliches Alter haben müssen.

Im weiteren gibt der Zusammenhang der verschiedenen Talniveaus auch ein Maß für die Größe der Erosion, resp. für die Hebung. Für das Sernftal ergibt sich aus der relativen Höhendifferenz zwischen dem früh-altpliozänen Wildmaadsystem und dem präglazialen Waldsystem eine pliozäne Eintiefung von 5-600 m, was mit den Beobachtungen in anderen Tälern der Nordalpen gut übereinstimmt ". Die pleistozäne Eintiefung umfaßt im Sernftal rund $450 \mathrm{~m}$, nimmt aber gegen das Vorland hin beträchtlich zu. Schon an Alpenrand beträgt sie zwischen 600 und $650 \mathrm{~m}$, und im Vorland steigt sie gar auf rund $750 \mathrm{~m}$ (tiefster Punkt des Zürichsees $263 \mathrm{~m}$ ). Diese Angaben seien lediglich zur Ergänzung gedacht; eine weitergehende Auswertung würde den Rahmen der vorliegenden Arbeit überschreiten.

\section{PLEISTOZÄNE G:E.NESE}

Die pleistozäne Talentwicklung erfolgte durch die abwechselnde Wirkung von Fluß- und Eisarbeit und ist gekennzeichnet durch die trogförmige Talvertiefung unter den Wald-Niveau. Die Eintiefung beträgt im Sernftal zwischen 350 und $450 \mathrm{~m}$, während sie in den Nebentälern nur zwischen 200 und $300 \mathrm{~m}$ schwankt, was wohl auf die Größe und die damit verbundene Kraft der Gletscherströme zurückzuführen ist. Im weiteren äußert sich die pleistozäne Entwicklung auch in einer Stufung des Längsprofils. Wie jedoch schon weiter oben angeführt wurde, erreichen die Talwegstufen unter dem Wald-Niveau nur geringe Ausmaße und es dürfte schwierig sein, auf Grund der wenigen Formen und Formenreste eine genetische Deutung und Klassifizierung zu finden. Sicher steht nur fest, daß sie auf keinen Fall mit pleistozänen Eintiefungsphasen koordiniert werden können, weil unter dem Wald-Niveau keine Systemreste zu finden sind.

Umso eindrücklicher erscheint dagegen die Arbeit der Flüsse und der Gletscher an den Mündungsstufen der Seitentäler. Meist liegen die Mündungen der Nebentäler unseres Untersuchungsgebietes unter dem Niveau des präglazialen Talbodens des Haupttales; und nur die erosionsschwachen, kaum talförmig ausgestalteten Tälchen leiten direkt ins Präglazial des Haupttales über.

\section{Höhe der Stufenmündungen}

$\begin{array}{ll}\text { Jätztal . . ca. } 250 \mathrm{~m} \\ \text { Martinsmaad . } & \text {. } 460 \mathrm{~m} \\ \text { Ramintal . } & \text { ca. } 230 \mathrm{~m} \\ \text { Krauchtal. } & \text {. } 240 \mathrm{~m} \\ \text { Mühlebachtal } & \text {. } 220 \mathrm{~m}\end{array}$

Die Angaben beruhen auf einer Berechnung der Höhenspannung zwischen dem bis zur Haupttalmitte verlängerten Längsprofil und dem heutigen Talboden. Die starke Schuttbedeckung des Haupttalbodens schließt aber eine exakte Angabe an manchen Stellen aus.

$\mathrm{Da}$ auch in den Nebentälern unter dem präglazialen Niveau eine starke Eintiefung stattgefunden hat, muß sowohl die glaziale als auch die interglaziale-fluviale Erosion sehr beträchtlich gewesen sein. Bei allen Mündungsstufen sind deshalb tiefe Erosionsrinnen anzutreffen, die schon frühzeitig entstanden sein mußten, da sie vielfach Moränenschutt aufweisen. Zahlreiche andere Faktoren weisen ebenfalls auf ein hohes Alter unserer Stufenmündungen hin. 
Von allen Nebentälern des Sernftales weisen nur die beiden untersten, rechtsseitigen Zuflüsse, nämlich das Krauch- und das Mühlebachtal gleichartig ausgebildete Mündungsstufen auf. Beide Täler zeigen eine starke Eintiefung unter das Präglazial, die im Durchschnitt $250 \mathrm{~m}$, an einzelnen Stellen über $300 \mathrm{~m}$ beträgt. Bei beiden Tälern ist die Stufe durch eine starke Durchtalung zerschnitten. Die entstandenen Mündungsschluchten erstrecken sich über eine Länge von $2-3 \mathrm{~km}$ und sind nach oben stark V-förmig erweitert. Aus diesem Grunde fehlt der jähe Abfall zum Haupttal, was darauf schließen läßt, daß auch der Seitenabtrag beträchtlich gewesen sein muß. Möglicherweise ist bei diesen beiden Tälern das voreiszeitliche Relief von großem Einfluß auf die pleistozäne Ausoildung gewesen.

Die auffälligste Mündungsstufe besitzt der T'schingelbach. Vom untersten Boden des Martinsmaads hat sich dieser Fluß eine enge Klamm geschaffen, in der er über $400 \mathrm{~m}$ Höhe überwindet, ehe er in den Boden des Haupttales gelangt. Obwohl keine diluvialen Spuren zu finden sind, muß die ganze Anlage dieser Mündungsstufe doch voreiszeitlich geschaffen worden sein, da eine solch mächtige, postglaziale Eintiefung wohl einzig dastehen würde. Sehr wahrscheinlich ist der Maadgletscher, der ja vom Überlauf des Bündnerbergfirns gespeist wurde, an der Vereingungsstelle mit dem Sernfgletscher von diesem gestaut worden und vermochte deshalb nicht stark zu erodieren. In den Interglazialzeiten mußte der Fluß dann seine Arbeit wieder an der gleichen Stelle aufnehmen. Diese Annahme erklärt auch die relativ hohe Lage des präglazialen Karbodens in dieser eng gestuften Taltreppe.

Eine ähnliche Entwicklung scheint auch die Mündungsstufe des Jätzbaches durchgemacht zu haben. Die Mündungsschlucht ist jedoch zu einer breiten Mulde ausgeräumt worden, deren Sohle gleich hoch liegt wie die Oberfläche des Moränenschuttes im Haupttal. Wie schon früher gezeigt wurde (siehe S. 109), muß sich am untersten Ende der Stufe nochmals ein kleiner Abfall befinden, der allerdings durch die Akkumulation im Haupttal verdeckt wird. Die starke glaziale Überarbeitung der eigentlichen Mündungsstufe im Loch beweist, da $\beta$ auch diese Stufe sehr alt sein muß.

Die Stufe des Raminerbaches ist diejenige Form, die am besten den komplexen Charakter dieser Erscheinung verdeutlicht. Flußj- und Gletscherwirkung vermochten hier den Talboden so stark zu erodieren, daß er von weit hinten im Tale bis zum Haupttal ein gleichmäßiges Gefälle aufweist und nur in geringer Höhe über dem Haupttal ausmündet. Da jedoch der Raningletscher an der Vereinigungsstelle frontal auf den Sernfgletscher auftraf, ist es vollkommen unwahrscheinlich, da/3 die Tiefenwirkung glazialen Ursprungs ist. Es scheint vielmehr, daß es sich um eine sehr alte Anlage handelt, wobei angenommen werden darf, daß schon vor dem Eintritt der Vereisung eine starke Erosion stattgefunden hat. Die beträchtliche prädiluviale Eintiefung wäre dann auf die weichen Flyschgesteine zurückzuführen, die der Erosion keinen Widerstand entgegenzusetzen vermochten.

Wenn auch über den glazialen Abtrag keine bestimmten Angaben gemacht werden können, so scheint er doch sehr gewaltig gewesen zu sein; denn wenn die Haupterosion jeweilen in den Interglazialzeiten erfolgt wäre, so müßten zumindest Anhaltspunkte gefunden werden, die auf pleistozäne Talwegstufen hinweisen. Über die Größe und Ausdehnung der Gletscher zur Zeit der Höchststände könnte nur die Schliffgrenze Auskunft geben, die im Sernftal leider nicht genau bestimnt werden kann. Umso besser lassen sich die verschiedenen Rückzugsstadien bestimmen, wie das schon bei der Beschreibung der Moränen (S. $112 \mathrm{ff}$.) gemacht wurde.

Die nacheiszeitliche Talgestaltung hat keine großen Veränderungen mehr gebracht, wenn man von der flächenhaften Überdeckung durch die verschiedenen postglazialen Akkumulationen absieht. 


\section{Zusammenfassung}

Die vorliegende Arbeit ist das Ergebnis einer genauen morphologischen Detailuntersuchung im Gelände. Als Hauptergebnis darf die morphologische Spezialkarte des Untersuchungsgebietes betrachtet werden, die einen kleinen Beitrag zur Morphologie der Schweizer Alpen bildet.

Mit besonderer Eindrücklichkeit ist im Sernftal die Abhängigkeit der Kleinformen vom geologischen Bau klar geworden, und es wäre interessant, zu erfahren, ob nicht auch in anderen Flyschgebieten die gleichen Erfahrungen gemacht werden müßten. Die isolierte Lage des Untersuchungsgebietes in bezug auf morphologisch erforschte größere Räume erschwert dagegen das Erkennen der großen Zusammenhänge ganz beträchtlich. Wenn auch die Analyse hin und wieder kleinere genetische Probleme zu erklären vermag, so fehlen für eine gesamtgenetische Darstellung doch noch zahlreiche Grundlagen.

Immerhin lassen sich im Sernftal, wie in anderen Alpentälern auch, drei ausgeprägte Terrassensysteme beobachten. Auf Grund von Vergleichen mit anderen Gebieten würde die Anlage des höchsten Systems ins frühe Altpliozän fallen, während sich das mittlere Niveau ins späte Altpliozän einordnen läßt. Die prachtvoll ausgebildete Trogschulterphase muß auf Grund morphologischer Überlegungen und durch Verknüpfung mit dem Deckenschotter im Vorland als präglaziale Talbildung aufgefaßt werden.

Die alpenrandnahe Lage des Sernftales und seine Stellung als Nebental zum Linthtal bewirken in der morphogenetischen Untersuchung komplizierte Verhältnisse, soda $\beta$ den Ergebnissen nur hypothetischer Charakter zukonimt. Obwohl die genetischen Betrachtungen auch auf morphologisch noch nicht untersuchte Gebiete ausgedehnt werden mußten, ergibt sich doch eine relativ große Übereinstimmung mit anderen nordalpinen Tälern.

Es zeigt sich somit deutlich, daß die geomorphologisch orientierte Hochgebirgsforschung noch zahlreicher Beiträge bedarf. Erst auf diese Weise könnte die Gesamtgenese des Alpenlandes nüher abgeklärt werden, und auch der Zusammenhang mit der Morphogenese des Molasselandes würde sicher leichter zu erfassen sein.

Meine Untersuchungen seien ein Steinchen in diesem noch zu schaffenden Mosaik.

\section{LITERATURVER ZEICHN IS}

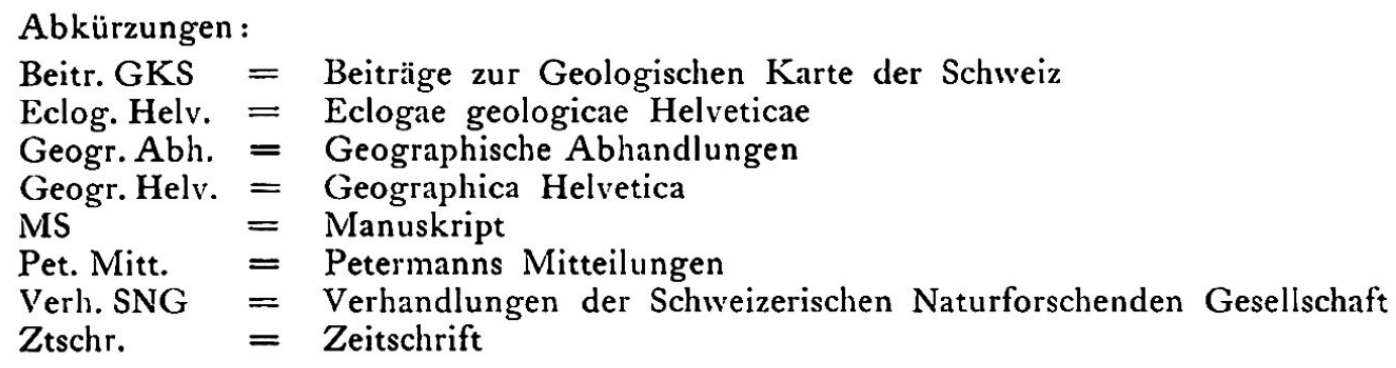

1. AEppl, A.: Erosionsterrassen und Glazialschotter in ihrer Beziehung zur Entstehung des Zürichsees. Beitr. GKS, N. F., 4. Lief. 1894.

2. Annaheim, H.: Die Landschaftsformen des Luganerseegebietes. In Geogr. Abh., 3. Reihe, Heft 8, Stuttgart 1936.

3. Annahelm, H.: Begleitwort zur Legende der morphologischen Grundkarte der Schweizeralpen. MS 1944, Basel.

4. Axwanem, H.: Studien zur Geomorphogenese der Südalpen zwischen St. Gotthard und Alpenrand. Geogr. Helv. I, 1946.

5. Blumer, S.: Zur Entstehung der glarnerischen Alpenseen. Eclog. Helv. Bd. VII, 1902.

6. Bodmer, A.: Terrassen und Talstufen der Schweiz. Ein Beitrag zur Erklärung der Talbildung. In Vierteljahrsschrift der Naturf. Ges. Zürich, 25. Jahrg., 1880.

7. Bascu, H.: Morphologische Karten. Schweizer Geograph 1945, Heft 3/4. 
8. Brúckner, E. \& Penck, A.: Die Alpen im Eiszeitalter. Bd. II, Leipzig 1909.

9. Clubführer durch die Glarneralpen. Herausgeg. vom Schweiz. Alpen-Club. 5. Aufl., Zürich 1932.

10. Davis, M. V.: Die erklärende Beschreibung der Landformen. Verlag Teubner. Leipzig und Berlin, 1912.

11. FRÜH, J.: Geographie der Schweiz. 3 Bände. St. Gallen 1939 ff.

12. FRÜH, J.: Moorkarte der Schweiz. 1903.

13. Glarner Nachrichten vom 23. und 24. Februar 1886.

14. Gogartex, E.: Über alpine Randseen und Erosionsterrassen. Pet. Mitt. Ergänzungsheft Nr. 165, 1910.

15. Herm, A.: Zur Frage der Glarner Doppelfalte. Verh. d. k.k. geolog. Reichsanstalt, Nr. 3, 1885.

16. Heim, A.: Der Bergsturz von Elm am 11. Sept. 1881. Denkschrift, Zürich 1881.

17. HeIM, A.: Über Bergstürze. Neujahrsblatt der Naturf. Gesellschaft Zürich, 1882.

18. Heim, A.: Über Terrassen und Talstufen in den Alpen. Verh. SNG, Bern 1878.

19. HeIM, A.: Über die Wiedergewinnung der Wichlenbadquelle bei Elm. MS, Zürich 1887.

20. Jegerlehner, J.: Die Schneegrenze in den Gletschergebieten der Schweiz. Gerland's Beitr. z. Geophysik, Bd. V, 1902.

21. Jenny, F.: Diluviale Schotter mit Moränenbedeckung am Eingang ins Sernftal. Eclog. Helv., Bd. XIV, 1918.

22. Lautensach, A.: Die Übertiefung des Tessingebietes. Geogr. Abh. Leipzig und Berlin, 1912.

23. MachatcheK, F.: Die Depression der eiszeitlichen Schneegrenze. Ztschr. f. Gletscherkunde, Bd. VIII, 1913.

24. Маснатснек, F.: Zur Morphologie der Schweizeralpen. Ztschr. f. Erdkunde, Sonderband, Berlin 1928.

25. Maull, O.: Geomorphologie. In Enzyklopädie der Erdkunde, 1938.

26. Merian, R.: Eine neue geomorphologische Untersuchungs- und Darstellungsmethode am Beispiel des oberen Engelbergertales. Dissertation, Zürich 1946.

27. Neuenschwander, G.: Morphometrische Begriffe. Dissertation, Zürich 1944.

28. Nussbaum F.: Zur Frage der präglazialen Talböden im Berner Oberland, Schweizer Geograph 1945.

29. Oberholzer, J.: Geologie der Glarneralpen. Beitr. GKS. N.F., 28. Lief., Bern 1933.

30. PENCK, A.: Morphologie der Erdoberfläche, 2 Bde. Stuttgart 1894.

31. Richthofen v., F.: Führer für Forschungsreisende. Hannover 1901.

32. SöLch, J.: Fluß- und Eiswerk in den Alpen zwischen Ötztal und St. Gotthard. Pet. Mitt. Ergänzungsheft Nr. 219, 1935.

33. Staub, R.: Grundzüge und Probleme alpiner Morphologie. Denkschrift der SNG, Bd. 69, Zürich 1934.

34. Síaub, R.: Der Bau der Alpen. Beitr. GKS, N. F. 52. Lief., Bern 1924.

35. Staub, R.: Alte Talböden bei Visp im Mittelwallis und im Reußtal zwischen Flüelen und Amsteg. Schweizer Geograph 1945.

36. Wasserverhältnisse der Schweiz. Herausgeg. von d. Abteilung f. Landeshydrographie, Bern 1905.

37. WeBER, A.: Die Glazialgeologie des Tößtales und ihre Beziehungen zur Diluvialgeschichte der Nordostschweiz. Dissertation, Zürich 1928.

Karten :

Geologische Karte des Kantons Glarus, 1:50 000, von J. OBERHolzer. Herausgeg. von der Geolog. Kommission, 1942.

Moorkarte der Schweiz, 1:530 000. In FrūH \& Schröter: Die Moore der Schweiz. Beitr. z. Geologie der Schweiz, geotechn. Serie.

Photogrammetrischer Übersichtsplan, 1:10 000. Eidg. Landestopographie, Bern. Herausg. zum persönlichen Gebrauch. Auswertungen 1944.

Topographischer Atlas der Schweiz, 1:50000. Nachgeführt bis 1944; Zusammensetzung Foopaß.

\section{DE LA MORPHOLOGIE DU SERNFTAL}

Le présent travail expose les recherches minutieuses que j'ai faites sur la morphologie de la plus grande vallée latérale de la Linth. Le résultat principal en est la carte spéciale du territoire de $210 \mathrm{~km}^{2}$ qui a été l'objet de mon étude. C'est une contribution à la connaissance de la morphologie des Alpes à laquelle s'applique la Société Suisse de Géomorphologie.

Dans le Sernftal, la dépendance des petites formes de la grande formation géologique ressort avec clarté. Cependant, la situation isolée de ce territoire, par rapport à de plus grands espaces déjà explorés morphologiquement, a rendu très difficile une vue d'ensemble sur la continuité des formes. Les quelques petits problèmes génétiques que l'analyse a permis de résoudre ne permettent pas une description entière de la genèse. Pour cela les bases devraient être élargies.

Toutefois - comme pour d'autres vallées des Alpes - on peut distinguer nettement trois systèmes de terrasses. La comparaison avec d'autres territoires permet de placer les formations du 
plus haut système au commencement et celles du niveau moyen à la fin du Pliocène inférieur. Les épaulements de l'auge glaciaire, extrêmement bien formés, seraient alors une formation de vallée préglaciaire; la méthode morphologique et la continuité avec les cailloutis des plateaux du Mittelland justifient cette conception.

La proximité du bord des Alpes et la position du Sernftal par rapport au Linthtal créent des situations très difficiles pour les recherches morphogénétiques. Quelques résultats ne pourront donc avoir qu'un caractère hypothétique. - Une fois de plus, on reconnait que les recherches géomorphologiques alpestres offrent encore un vaste champ d'activité.

\section{SULLA MORFOLOGIA DELLA VALLE DEL SERNF}

Il presente lavoro sulla più grande valle laterale della vallata della Linth si fonda sull'analisi morfologica dettagliata. Il suo risultato più importante è la carta morfologica della zona esaminata, di $210 \mathrm{~km}^{2}$, che rappresenta un contributo agli studi d'alta montagna, d'orientamento geomorfologico, a cui aspira la Società Svizzera di Geomorfologia.

Con particolare evidenza è stato chiarito il rapporto di dipendenza, nella zona di «flysch o della valle del Sernf, delle forme particolareggiate dalla struttura geologica. La posizione isolata del territorio esaminato rispetto a zone più vaste già analizzate morfologicamente, aumenta invece le difficoltà nello individuare $\mathrm{i}$ tratti generali. Sebbene l'analisi sia in grado di chiarire alcuni problemi genetici minori, mancano tuttavia ancora numerosi dati che permettano di tracciare un quadro genetico d'insieme.

Nella valle del Sernf si notano, come in altre valli alpine, tre marcati sistemi di terrazzi. Secondo i confronti fatti con altre zone, l'origine del sistema più alto risalirebbe al periodo pliocenico antico, mentre il piano medio rientrerebbe nel periodo pliocenico recente. $\mathrm{La}$ fase delle spalle vallive, di notevole evidenza, va considerata, per ragioni morfologiche e per la relazione che esiste con le coperture ciottolose della zona preposta, una formazione valliva preglaciale.

La posizione della valle del Sernf sul limite delle Alpi e il suo rapporto colla valle della Linth creano una situazione complicata per l'analisi morfogenetica, cosicchè $i$ risultati spesso non hanno che un valore d'ipotesi. Anche in questo caso risulta che l'esplorazione geomorfologica delle Alpi necessita ancora di molti contributi. La presente analisi vorrebbe essere una pietra nel mosaico da compiersi.

\section{DE LA SCIENCE GÉOGRAPHIQUE YOUGOSLAVE}

\section{B. Z. Milojević}

Comme chez les autres peuples, de même en Yougoslavie, la science géographique est cultivée dans les universités et dans les sociétés de géographie. Après la libération qui a suivi la seconde guerre mondiaie, on a commencé à la cultiver également dans les instituts particuliers des académies des sciences.

La science géographique dans les universités. - La science géographique telle qu'elle est conçue à notre époque est apparue chez les Yougoslaves en premier lieu chez les Croates. Les premières contributions importantes dans ce sens ont été fournies par Petar MatKović (1830-1898), professeur à l'université de Zagreb. Elève de Kari. Ritter, Matković a travaiilé principalement dans le domaine de la géographie historique. Les délégations de l'empereur d'Allemagne et du roi de Hongrie qui, au XVIème siècle, se rendaient à Constantinople, empruntaient les routes longitudinales balkaniques allant du nord vers le sud. Dans ces délégations se trouvaient toujours des personnes instruites qui observaient les lieux et les régions et notaient leurs observations dans leurs carnets de route. Il en était de même pour les envoy'és qui, partant de Venise, également pour Constantinople, suivaient de la côte adriatique les routes balkaniques transversales, allant de l'ouest vers l'est. MatKović étudiait et publiait des examens critiques de ces descriptions de voyage et il a contribué de cette façon à renouveler et accroître nos connaissances sur les aspects antérieurs et sur la vie des lieux et régions balkaniques.

Artur Gavazzi (1861-19+4), élève de Matković, également professeur à l'université de Zagreb, incité par l'enseignement qu'il avait reçu à Vienne, à l'école d'Albrechit Penck, s'occupa de géographie physique - surtout d'hydrographie 


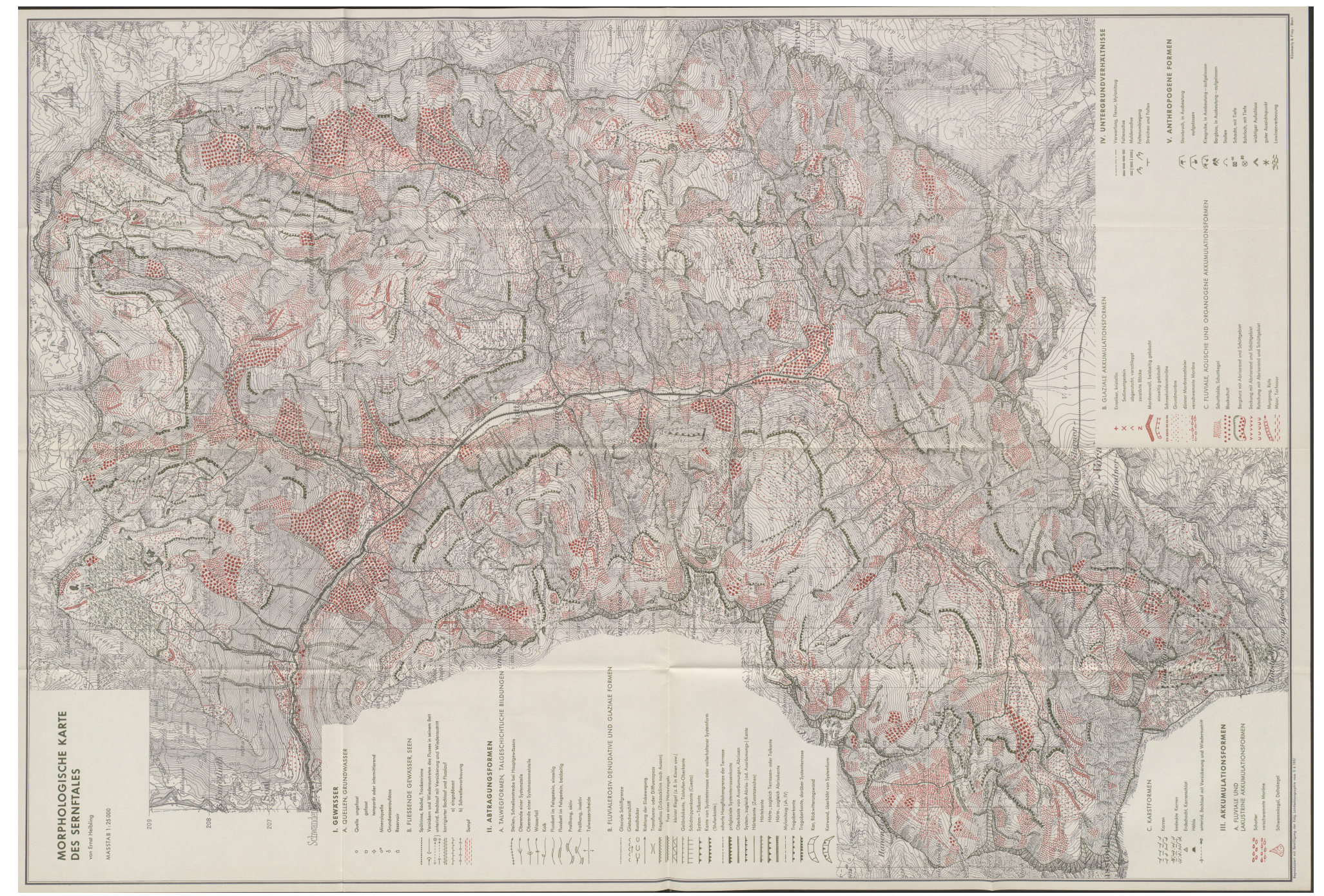

